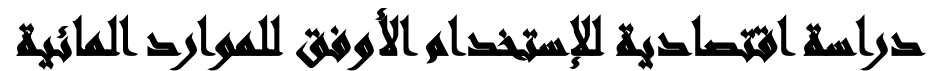

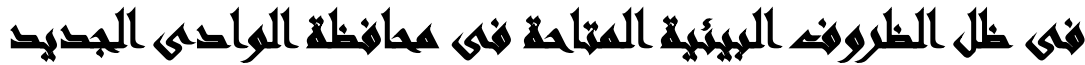

[०]

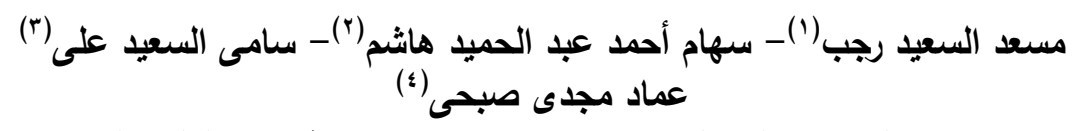

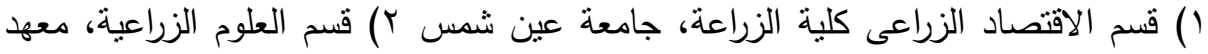

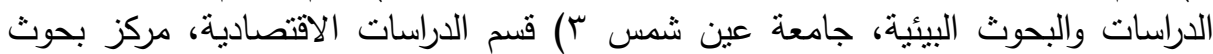
الصحراء ع) قسم الدراسات الاقتصادية، مركز بحوث الصعة الصحراء

\section{المستخلي لإن}

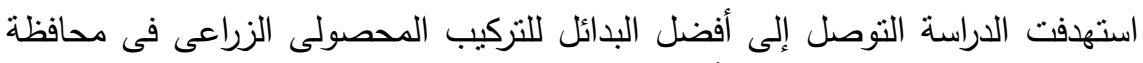

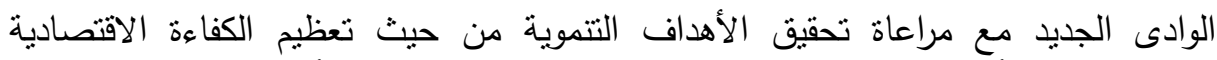

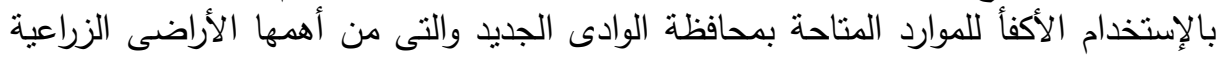

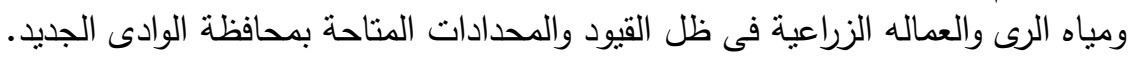

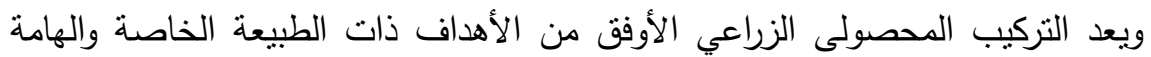

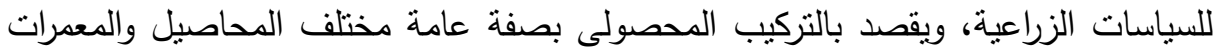

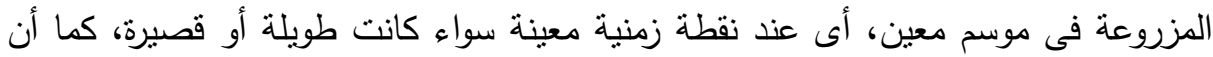

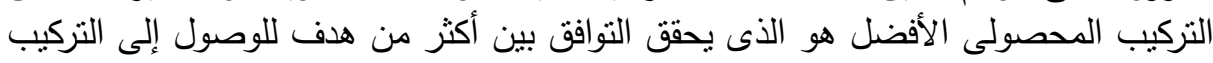

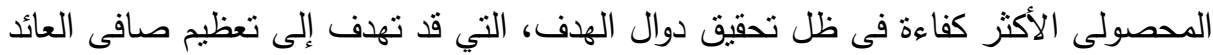

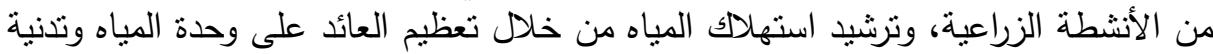

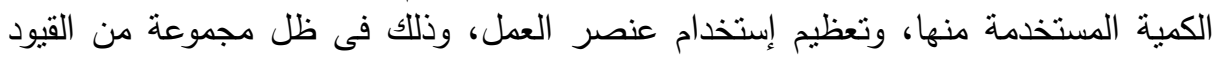
والمحددات الإنتاجية

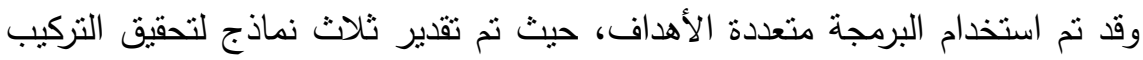

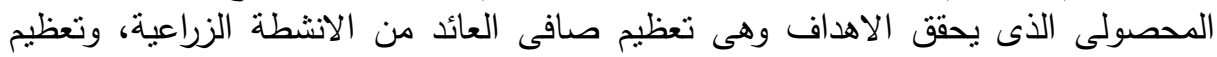

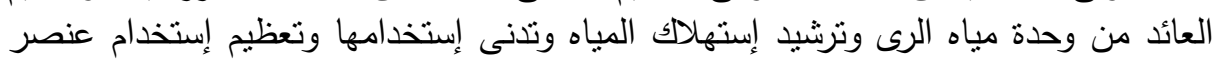

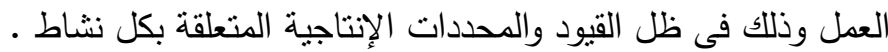
الكلمات المفتاحية: التركيب المحصولى، الموارد المائية، محافظة الوادى الجديد، البرمجة

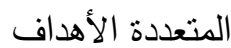




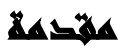

إن من أحد الأهداف الرئيسية للسياسية الزراعية المصرية هو الاستغلال الاقتصادى

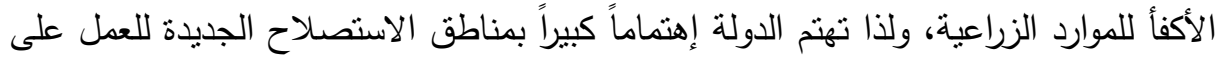
زيادة الانتاجية بها، فاتجهت الابصار إلى محافظة الوادى الجديد، حيث تحتل مكاناً متميزاً

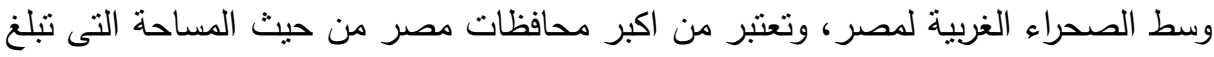

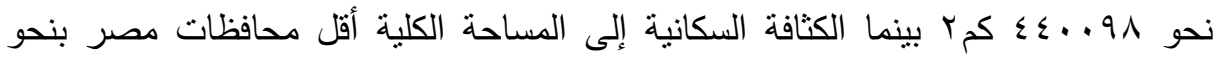

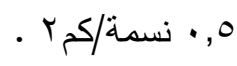

وبدراسة الموارد الاقتصادية بمحافظة الوادى الجديد يتضح ان المساحة الكلية للمحافظة

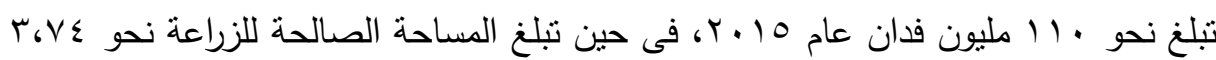

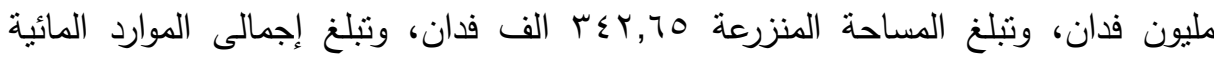

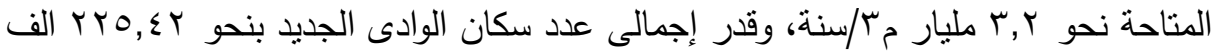

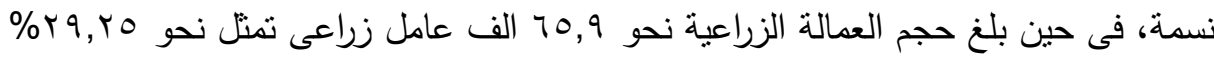
من إجمالى عدد سكان المحافظة. ويعتبر التركيب المحصولى الأوفق مفهوماً نسبياً نظراً لعدم سهولة معرفة ما هو الأوفق

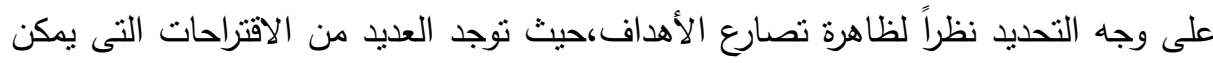

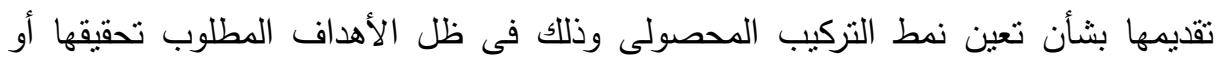

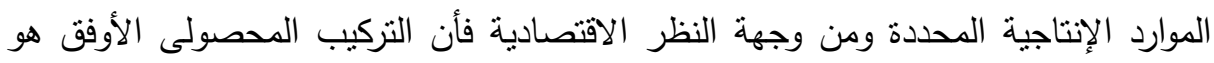
الذى من شأنه تعظيم العائد الاقتصادى فى ظل الإمكانيات الفنية والمحددات الاخرى.

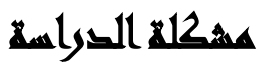

تتعرض محافظة الوادى الجديد لمشكلة فى المياه نتيجة الحفر غير المخطط والسحب الجائر لمياه الثرب والزراعة من الآبار العميقة التى تم حفرها مما ترتب علية لاستنزاف النطاقات الإنتاجية الحاملة للمياه فى الوقت الذى زاد فيه الطلب على المياه الجوفية وهذا 
يتطلب مراجعة دقيقة للتركيب المحصولى والمقننات المائية المطلوبة لمواجهة العجز فى الطلب على الموارد المائيه.

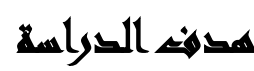

تستهدف الدراسة الإستخدام الأكفأ للموارد المائية فى ظل الظروف البيئية المتاحة فى البى محافظة الوادى الجديد للتوصل إلى التزكيب المحصولى الأوفق بما يحقق الإستخدام

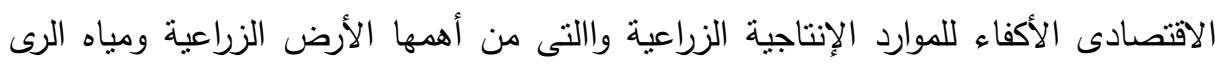
والعمالة الزراعية.

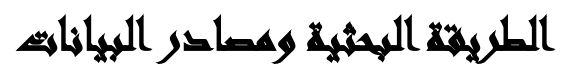

الاسلوب البحثيى المستخدم إعتمد على البرمجة الرياضية متعددة الأهداف Multi) لتحقيق التركيب المحصولى الذى يعظم صافى العائد من Objective Programming) الأنشطة الزراعية والذى يرشيد استهلاك مياه الرى والذى يعظم إستخدام عنصر العمل، وذلك فى ظل القيود والمحددات الإنتاجية المتعلقة بكل نثاط. وقد اعتمدت الدراسة على البيانات الإحصائية الثانوية المنشورة وغير المنشورة التي لئيأي

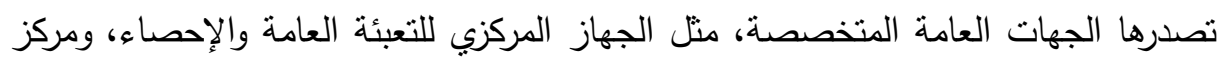

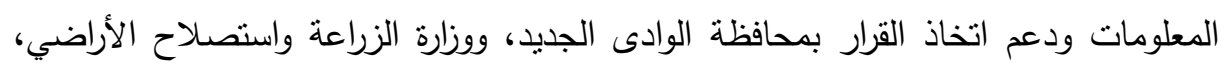

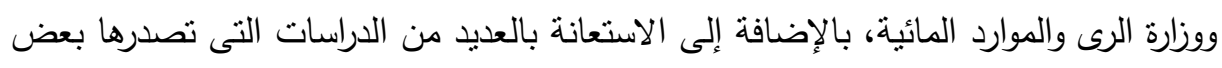

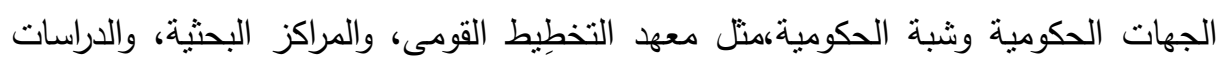
السابقة ذات العلاقة بموضوع الدراسة. أولاً: الموارد الاقتصادية بمحافظة الوادى الجديد

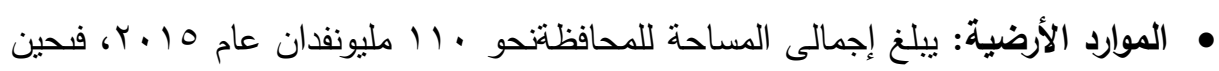

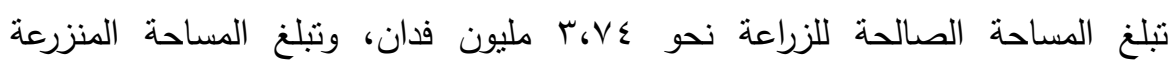

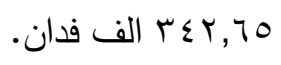

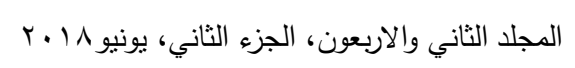


• الموارد المائية: تتحصر مصادر المياه فى الوادى الجديد فى المياه الجوفية، ويبلغ إجمالى

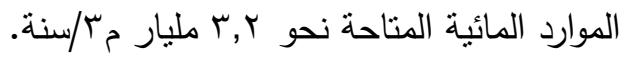

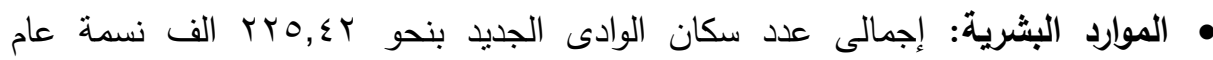

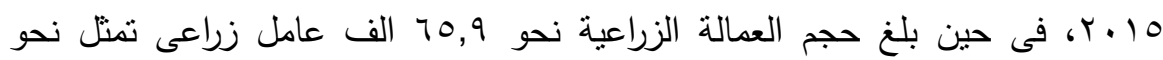

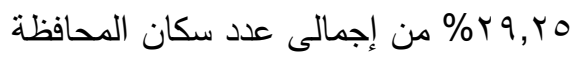

\section{ثانياً: الإطار النظرى للبرمجة متعددة الأهداف فى إقتراح التراكيب الممكنة فى} محافظة الوادى الجديل: نم وضع نماذج للتراكيب المحصولية بالمحافظة وذلك بإستخدام البرمجة متعددة الأهداف لتحقيق التركيب المحصولى الذى يحقق الاهداف وهى تعظيم صافى

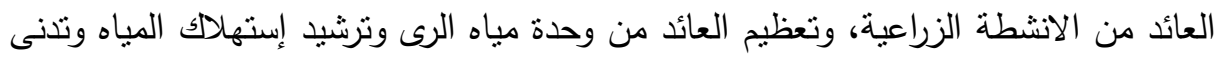
إستخدامها وتعظيم إستخدام عنصر العمل وذلك فى ظل القيود والمحددات الإنتاجية المتعلقة بكل نشاط للوصول إلى التركيب المحصولى الأكثر كفاءة فى تحقيق دالة الهدف وفى ظل الموارد المتاحة بمحافظة الوادى الجديد.

1) الانشطة الزراعية: ويتضح من الجدول رقم(1) أن نموذج تحليل البرمجة المتعددة

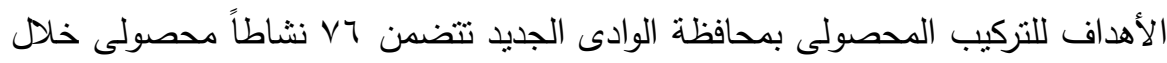

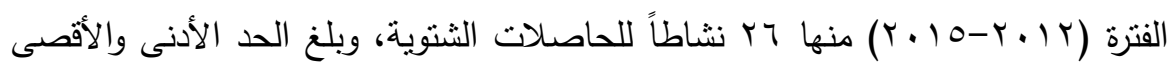

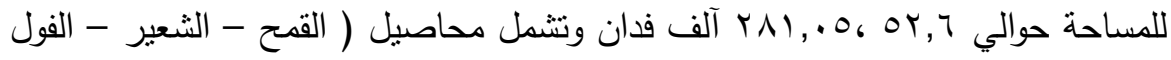
البلاي - الترمس - الحلبة الجافة- بنجر السكر - البرسيم المستديم - البصل - الثوم -

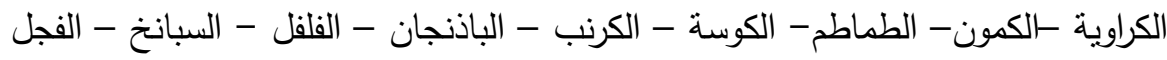

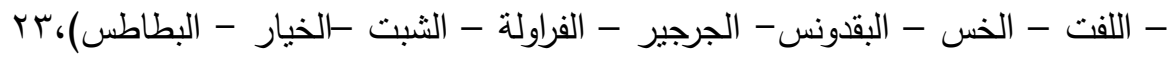

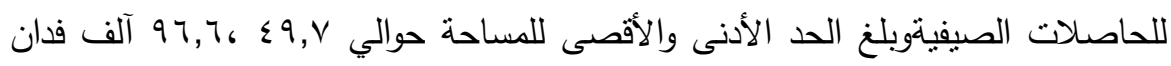
وتشمل محاصيل ( الارز - الذرة الثامية البيضاء - الذرة الثامية الصفراء- الذرة الرفيعة

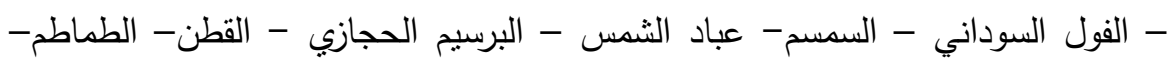
الفلفل - الباذنجان - الكوسة - بامية- ملوخية - جرجير - الفجل - الثمام - الكنتالوب الفئمبن - الخيار - قتاء - بطيخ لب-البطاطس)، باء اللحاصلات النيليةوبلغ الحد الأدنى مليه 


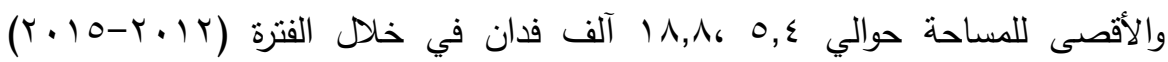
وتتمل محاصيل ( الذرة السكرية- لوبيا العلف - الذرة الثامية علف - الذرة الرفيعة

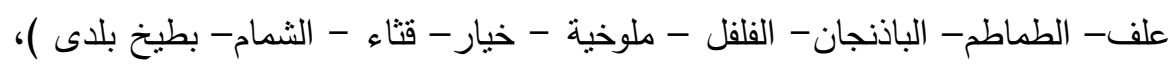

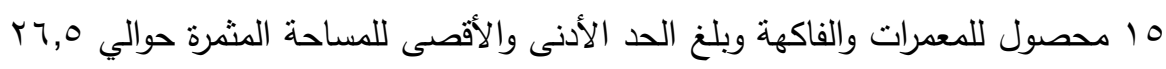

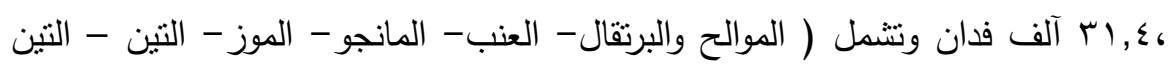
الثوكي - الجوافة- الرمان - المشمش - الكثري- التفاح - الخوخ- البرقوق - الزيتون

جدول رقم(1): الحد الأدنى والحد الأقصى للمساحة وصافى العائد للفدان والمقننات المائية وإحتياج

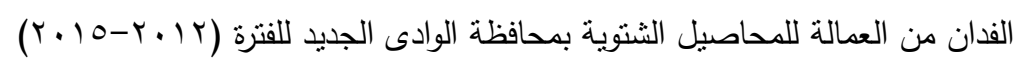

\begin{tabular}{|c|c|c|c|c|c|c|c|c|c|c|}
\hline \multicolumn{2}{|c|}{ عائد الوحدة المائية } & \multicolumn{2}{|c|}{ العتياج الفدان } & \multicolumn{2}{|c|}{ المقنتات المائية } & \multicolumn{2}{|c|}{ صافى العائد للفدان } & \multicolumn{2}{|c|}{ المساحة (فدان) } & \multirow{2}{*}{ المحصو } \\
\hline أقصى حد & أدنى حد & أقصى حد & أدنى & أقصى حد & أدنى حـ & أقصى حد & أدنى حـ & أقصى حد & أدنى حد & \\
\hline $1, r q$ & $1, \cdot r$ & $0 \leqslant$ & $\sum V$ & YษA & rTos & TVt & T & $197 \cdot \leq 9$ & 1.741 & القمح \\
\hline., 97 & $\cdot, 91$ & or & $\leq 0$ & 1918 & 10T5 & 1910 & 1149 & $r \leqslant \vee v q$ & $10 \wedge \varepsilon$. & الشعير \\
\hline I, Yr & $1, r V$ & 00 & $\leq 9$ & $r \leq r r$ & 1人TE & r9OV & rTVt & rVI $\leq$ & Y19. & البلدى الفول \\
\hline $1, r V$ & 1,11 & 91 & $\wedge \wedge$ & 191. & Iror & Yo.A & $1 \% \wedge 9$ & rv & r) & الترمس \\
\hline$\cdot, \wedge 0$ & $\cdot, \vee_{0}$ & $9 \vee$ & AV & Tr人T & $1 \wedge T \varepsilon$ & 1901 & $1 T 9 V$ & $0 \leqslant 7$ & rVo & الجلبة \\
\hline 1, & $1, \leqslant 9$ & ro & rq & $r \leq V T$ & YVA & $07 \leqslant 0$ & $\leq 1 \leq r$ & $1 \ldots$ & $r$. & السكر \\
\hline$r, q 1$ & $r, \cdot V$ & TV & $\Delta \wedge$ & rqтo & TIr. & $11 \leqslant v$. & $7 \leq 01$ & $|7 \leqslant Y|$ & |ודזו| & المستريم \\
\hline$r, \wedge r$ & 1,94 & $\vee \wedge$ & Vr & ro91 & 519. & 9911 & ETrO & $r .11$ & $|\pi| \varepsilon$ & البصل \\
\hline $0, \pi 4$ & $r, 90$ & $\vee \wedge$ & VY & rrq. & $11 \leq 0$ & $|r \wedge|$. & $0 \leqslant$ Tा & $r \leq 0$ & IVT & الثوم \\
\hline $1, Y Y$ & $1,1 \mathrm{~V}$ & $1 \Lambda$ & $\Lambda \varepsilon$ & Trוo & $197 V$ & rq10 & KYqS & A. & IT & كراوية \\
\hline $1, v_{1}$ & 1,71 & 19 & $\wedge \mathrm{T}$ & rזוr & 1914 & דrYT & Miso & vi & 17 & كمون \\
\hline E,r & r,A. & 9. & 10 & r৭AV & $r r \leq r$ & $1 Y 900$ & 19.0 & NTr & 190 & طماطم \\
\hline r,rq & $1, r$. & 94 & AV & rTs. & $r .91$ & 00Y1 & rVTo & 17 & $\varepsilon$ & كوسة \\
\hline 0,09 & $r, \cdot V$ & 9. & 10 & rצT & $r 191$ & $1 \leq V \mid V$ & $\leqslant 007,0$ & $\leqslant r$ & $1 T$ & كرنب \\
\hline$r, r v$ & $1, r \wedge$ & 91 & $\Lambda_{7}$ & $r 1 \ldots$ & $17 V A$ & 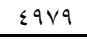 & THYT & $r \leq$ & Ir & باذنجان \\
\hline$r, . \varepsilon$ & $1, \leqslant 9$ & 9. & $\Lambda \varepsilon$ & rVot & $r \leqslant T V$ & ᄉrq. & rד. & ד4 & $\wedge$ & فلفل \\
\hline r, 70 & $1,1 \mathrm{r}$ & 19 & Ar & Y.0T & 1199 & $0 \leqslant \leqslant 0$ & 1119 & $V V$ & r & سبانخ \\
\hline$\cdot, r q$ & r & AV & vo & $r \cdot \Lambda V$ & ivor & 110 & rYA & 00 & rA & فجل \\
\hline
\end{tabular}


تابع جدول رقم(1): الحد الأدنى والحد الأقصى للمساحة وصافى العائد للفدان والمقننات

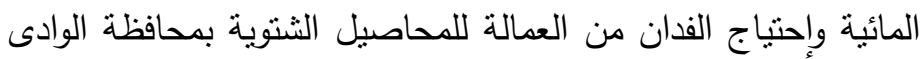

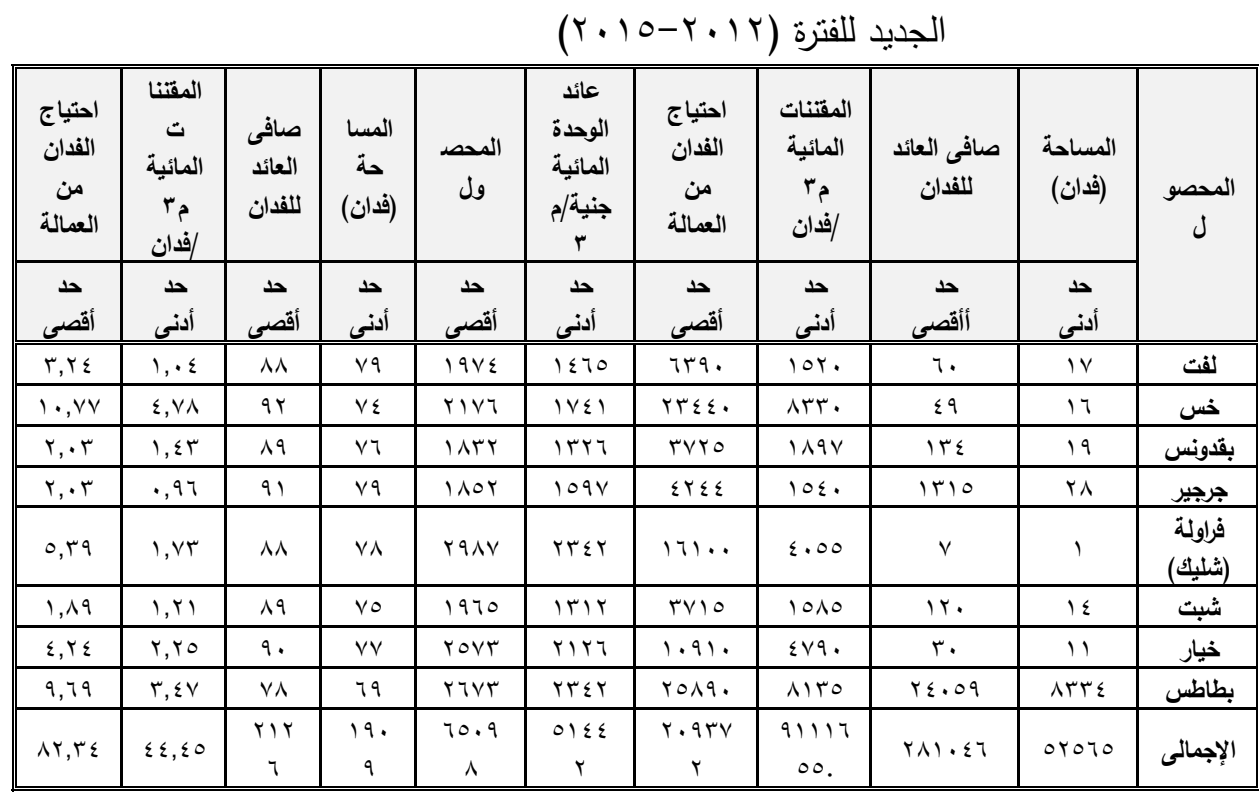

المصدر: وزارة الزراعة واستصلاح الاراضي، قطاع الثئون الاقتصادية، الادارة المركزية للاقتصاد

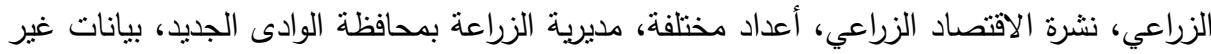


تابع جدول( (): الحد الأدنى والحد الأقصى للمساحة وصافى العائد للفدان والمقننات المائية وإحتياج

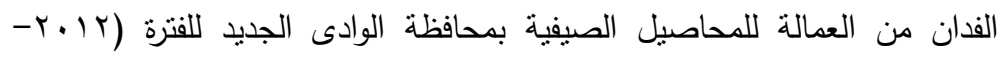

$(r \cdot 10$

\begin{tabular}{|c|c|c|c|c|c|c|c|c|c|c|}
\hline \multicolumn{2}{|c|}{ المائية جنية/مبـ } & \multicolumn{2}{|c|}{ احتياج الفذان من } & \multicolumn{2}{|c|}{ 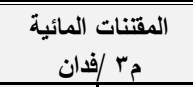 } & \multicolumn{2}{|c|}{ صافى العائد للفدان } & \multicolumn{2}{|c|}{ المساحة (فدان) } & \multirow{2}{*}{ المحصول } \\
\hline أقصى & أدنى & أقصى حل & أدنى & أقصى حد & حنى & أقصى & أدنى & أقصى حـ & أدنى & \\
\hline., $0 \leqslant$ &., 0. & $\Lambda \varepsilon$ & $T \Sigma$ & VTIT & $\varepsilon \wedge \leqslant 0$ & КАT & $r \leqslant r q$ & $\varepsilon \ldots \varepsilon$ & 174 & الارز \\
\hline 1,95 & $1, \times 1$ & or & $\varepsilon r$ & roor & זםדז & $V \varepsilon .0$ & $0 \vee 97$ & 975 & $r \leqslant r$ & 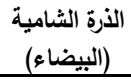 \\
\hline$r, 19$ & 1,91 & or & \&) & TVAT & $r \leqslant r)$ & Arry & TOY & 7910 & r & $\begin{array}{c}\text { الذرة الثشامية) } \\
\text { (الصفراء) }\end{array}$ \\
\hline., $7 \varepsilon$ & $\cdot, \sum 7$ & $\leqslant r$ & ro & rqv & $r \wedge \leqslant r$ & rooo & 15.0 & $|r \Lambda|$ & $r \leq r$ & الذرة الرفيعة \\
\hline $1,1 \varepsilon$ & $1, .0$ & ITV & $11 \leq$ & $\varepsilon$ YO & rTV. & $\varepsilon \wedge \leqslant 0$ & TAYT & 1ATrt & I.KY. & السودانى \\
\hline $1,1 \pi$ & $\cdot, V_{1}$ & IYA & 111 & rवq५ & YAV. & $\{010$ & $r \cdot r$. & $7 \leqslant 7$ & $1 . r$ & السمسم \\
\hline . r. & 政 & 117 & 1.1 & TrTE & rVIT & 914 & 71T & 01 & IT & عباد الثمس \\
\hline $1, \cdot 1$ & $\cdot, \wedge V$ & 71 & 09 & TVAT & ¿qr & TAV. & EYAV & or $\wedge \leqslant 0$ & rraiv & البجازي \\
\hline$\cdot, \mathrm{V}$. & $\cdot, 71$ & IVT & $10 r$ & 0774 & $\varepsilon \cdot v$. & एqVธ & rVos & rr & $r$. & القطن (الزهر) \\
\hline $0, \cdot \varepsilon$ & $\varepsilon, r r$ & 94 & 10 & ra7\& & $Y 170$ & $1 \leq 9 \leq 0$ & 9170 & $v$. & $0 \leqslant$ & الطماطر \\
\hline$r, \leq 7$ & $1,0$. & 19 & $\mathrm{VA}$ & r910 & rTIE & VTr. & ros V & $1 \wedge \varepsilon$ & 01 & فلفل \\
\hline$r, 01$ & $\cdot, \varepsilon V$ & 9. & 19 & rqr & $r \leqslant 10$ & vovo & $11 \mathrm{~A}$. & 19 & 7. & باذنجان \\
\hline$r, r \Lambda$ & $1, r r$ & 91 & הז & ryor & rqYA & 1791 & $r q \leqslant v$ & ro & 17 & كوسة \\
\hline 0,9 . & $r, \cdot r$ & $9 \leqslant$ & 10 & rדז & 5170 & $100 \%$. & rov. & $r \leqslant 1$ & Y19 & بامية \\
\hline $1,7 \varepsilon$ & $1, \varepsilon Y$ & $\Lambda \Lambda$ & $\mathrm{VA}$ & $r V \leqslant r$ & $r .91$ & $\leqslant \leqslant 10$ & rqVY & 197 & $1 \leq 7$ & ملوخية \\
\hline$r, 74$ & $\cdot, V Y$ & 19 & $v 7$ & rVio & 11174 & $99 \leq 0$ & $1 T \leq V$ & r) & 17 & جرجير \\
\hline r,qV & $\cdot, V Y$ & $\Lambda$ & $V \varepsilon$ & YVYA & $194 \pi$ & $\wedge 1 \ldots$ & ITAY & 0 & $\varepsilon$ & فجل \\
\hline$r, \wedge r$ & $1, \wedge$ & 19 & $V 4$ & YATV & 1991 & 1.90 & $r 4 .$. & $r \leq 4$ & vi & شمام \\
\hline r,OV & $r, \leqslant V$ & 94 & $\mathrm{VA}$ & rar & rors & vol. & TrV. & ro & 7 & كنتالوب \\
\hline 1,00 & $1, \cdot \varepsilon$ & $9 \varepsilon$ & $\mathrm{VI}$ & r.110 & TVYI & $0 \times 10$ & rATO & 97 & $\varepsilon V$ & خيار \\
\hline 0,0 r & $1, \cdot 7$ & 19 & $V \varepsilon$ & rYTA & rovt & Art. & rVTr. & $\leqslant 0$ & YY & قتثاء \\
\hline$r, 19$ & $1, \mathrm{r \Lambda}$ & 94 & VV & $r \leq 0 r$ & $r r \leqslant A$ & vooo & $r r \leqslant 0$ & $77 . r$ & $\varepsilon .1 \pi$ & بطيخ لب \\
\hline$\varepsilon, \varepsilon r$ & $r, \sum 9$ & vo & 4 & rAvq & $1199 \mathrm{~V}$ & IrVo. & $\varepsilon Y Y Y$ & rII. & 0 & بطاطس \\
\hline 00,19 & $r 1, v \wedge$ & $r .90$ & $111 \mathrm{~V}$ & 10r.1 & TrATV & 1791rr & הr.Ar & 977.7 & ¿q7人 & الإجمالى \\
\hline
\end{tabular}

المصدر: وزارة الزراعة واستصلاح الاراضي، قطاع الشئون الاقتصادية، الادارة المركزية للاقتصاد

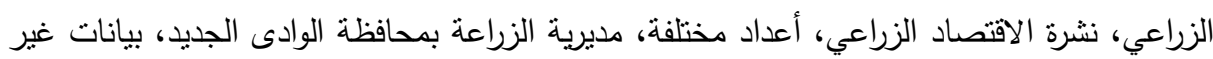
منشورة 
تابع جدول(1): الحد الأدنى والحد الأقصى للمساحة وصافى العائد للفدان والمقننات المائيةوإحتياج الفدان من العمالة للمحاصيل النيلية بمحافظة الوادى الجديد

$$
\text { للفترة (Y. (Y. (Y) }
$$

\begin{tabular}{|c|c|c|c|c|c|c|c|c|c|c|}
\hline \multicolumn{2}{|c|}{ عنئية الوحدة المائية } & \multicolumn{2}{|c|}{ العتياج الفدان من } & \multicolumn{2}{|c|}{ المقتنات المائية } & \multicolumn{2}{|c|}{ صافى العائد للفدان } & \multicolumn{2}{|c|}{ المساحة } & \multirow{2}{*}{ المحصول } \\
\hline أقصى حل & أدنى & أقصى حـ & أدني & أقصي حد & أدنى & أقصى & أدنى & أقصي & أدني حـ & \\
\hline . vo & . & $0 \leq$ & $\varepsilon r$ & raor & rА१V & r907 & $110 \leqslant$ & $\leq \varepsilon .9$ & rVI & الأرة السكرية \\
\hline$\cdot, \vee \vee 9$ & •, TV & 107 & $1 \leqslant V$ & $r \leqslant \wedge \vee V$ & $r Y \leq 0$ & $Y Y \leq T$ & 10.0 & 1915 & 1.9 & لويبا العلف \\
\hline$\cdot, 7$ & $\cdot, 09$ & 100 & $1 \leqslant \Lambda$ & $r \leqslant 09$ & ror. & r.AV & $10 . r, 0$ & 710. & $r \leqslant r o$ & ذرة شامى \\
\hline •, 70 & ז'T, & or & $\varepsilon r$ & rTro & rTol & rioq & $17 \leq 0$ & $7 . \leqslant 1$ & $1 \leqslant 17$ & ذرة الرفيعة \\
\hline$r, \wedge 9$ & I,Ar & 107 & ITV & rq $4 r$ & TYVE & $11 \varepsilon \cdot v$ & $097 V, 0$ & $1 \varepsilon$ & $r$ & طماطم \\
\hline I,rY & $1,1$. & 101 & $1 \leqslant \Lambda$ & TYI & TrOS & rqा. & rove & $\wedge$ & $r$ & باذنجان \\
\hline 1,71 & $1, \leq 0$ & 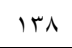 & $1 \times 9$ & rovt & $r \leqslant \vee \wedge$ & T. YO & roqv & $1 \leqslant$ & $\varepsilon$ & فلقل \\
\hline $1,7 V$ & $1,1 \varepsilon$ & $1 \leq 9$ & 1 1r & rion & TH.T & OYYY & & $r \leq$ & $r \varepsilon$ & ملوخية \\
\hline 1,rq & 1,11 & 10 & vr & $r \leqslant 0 T$ & $r \leqslant T_{0}$ & $\varepsilon \vee q$. & rVIT & 0. & $r \varepsilon$ & خيار \\
\hline $1, \lambda 1$ & $\cdot, 91$ & 19 & Vi & TITE & TTK & otV. & rrqv & $r \varepsilon$ & ○ & قتثاء \\
\hline 1,09 & $1, \cdot r$ & 91 & v^ & $r .01$ & TYq & $\leqslant 100$ & rAVT & 111 & זr & شمام \\
\hline $1,0 \mathrm{~V}$ & $1, r V$ & $10 \mathrm{~V}$ & $1 \leqslant 7$ & r907 & rros & $\leq \pi T$ & rQAv & r & 7 & بطيخ بلدى \\
\hline$|7,7|$ & Ir, ro & $1 \leqslant \leqslant$. & $1 \pi .0$ & E.VYA & $r \cdot 9 \leq \wedge$ & 070.1 & TrYOS & $1 \wedge \Lambda .$. & $0 \leqslant Y \wedge$ & الإجمالى \\
\hline
\end{tabular}

المصدر: وزارة الزراعة واستصلاح الاراضي، قطاع النشئون الاقتصادية، الادارة المركزية للاقتصاد الاداد

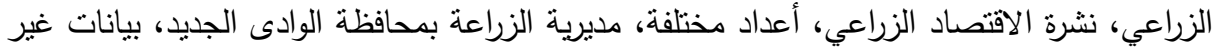


تابع جدول( (): الحد الأدنى والحد الأقصى للسساحة وصافى العائد للفدان والمقننات المائية وإحتياج

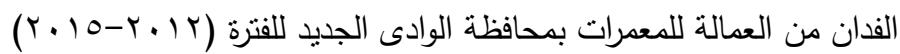

\begin{tabular}{|c|c|c|c|c|c|c|c|c|c|c|}
\hline \multicolumn{2}{|c|}{ المائية جنية/رد الوحدا } & \multicolumn{2}{|c|}{ من العمالة الفدان } & \multicolumn{2}{|c|}{ 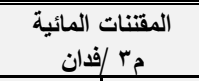 } & \multicolumn{2}{|c|}{ صافى العائد للفدان } & \multicolumn{2}{|c|}{ المساحة المثمرة } & \multirow{2}{*}{ المحصول } \\
\hline أقصى حـ & أدنى & أقصى حد & أدنى & أقصى حـ & أدنى & أقصى حـ & أدنى & أقصى حـ & أدنى & \\
\hline $1, r V$ & $1, \cdot v$ & $\varepsilon r$ & rr & ONAY & 0.1. & $v \leqslant 0 r$ & $0 \leqslant \pi$ & rчq. & TVVT & والبرتقالح \\
\hline $1, \cdot \varepsilon$ & • & $\leqslant V$ & rA & Ormy & TAVT & $0 \leqslant r T$ & TrIT & $\leqslant \leqslant 0$ & $|V|$ & العنب \\
\hline $1,0$. & $1, \varepsilon r$ & $\varepsilon r$ & 4 & $\varepsilon r \wedge q$ & rV৭A & $701 \varepsilon$ & $0 \leqslant \pi r$ & 4410 & $r \leqslant V r$ & المانجو \\
\hline$\cdot, 91$ & $\cdot, 9 \leqslant$ & $\varepsilon r$ & rr & $\{107$ & r4199 & $\varepsilon$ VO & $r \leqslant 0 Y$ & IT & 9 & الموز \\
\hline $1, \ldots$ & •, 9Y & $\sum 7$ & $r q$ & orr & $\varepsilon r \leqslant r$ & OrIT & rqv7 & $7 \varepsilon$ & $\varepsilon \varepsilon$ & تين \\
\hline., 94 & $\cdot, \mathrm{V} \varepsilon$ & rq & rT & $0 \leqslant 1 Y$ & $\sum T V T$ & $\Sigma q \vee r$ & $r \leq 7 r$ & 17 & $1 \varepsilon$ & تين شوكي \\
\hline 1,11 & $1, .9$ & «o & $r v$ & rArV & MOS & sor & ros & ATr & Arq & جوافة \\
\hline $1, K Y$ & $1,1 \leqslant$ & $r$. & $r \varepsilon$ & $\varepsilon v .$. & rVQT & OVTr & ETr & $\varepsilon \pi r$ & $10 \mathrm{~V}$ & رمان \\
\hline$\cdot, \wedge \varepsilon$ & צT, & $\varepsilon r$ & rT & $\{70 \leqslant$ & EITr & r1990 & rove & TKY & r 10 & مشمش \\
\hline $1,1 \mathrm{~V}$ & $\cdot, \wedge \wedge$ & $\varepsilon r$ & $r \varepsilon$ & E07Y & $r 9 \leqslant 1$ & OrIs & $r \leq 0 r$ & $r \varepsilon$ & $r_{1}$ & كمثرى \\
\hline 1,00 & $1, \leqslant 1$ & \&1 & ro & $\$ 10 \mathrm{~V}$ & $r \leqslant 0 r$ & $T \leqslant Y T$ & 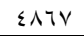 & ITr & $11 \pi$ & تفاح \\
\hline $1,1$. & $1, \ldots$ & 00 & $\varepsilon r$ & OrYI & rqvA & $0 \wedge V \leqslant$ & raT\& & IV & 10 & خوخ \\
\hline$\cdot, \Delta Y$ & $\cdot, \times 4$ & $\leq 0$ & ru & $\varepsilon \Lambda Y \leqslant$ & $r \wedge 90$ & rqvi & rqvr & $\varepsilon$ & $r$ & برقوق \\
\hline $1, .0$ & $1, .1$ & $\varepsilon \Lambda$ & $r 9$ & $07 \leqslant T$ & हाTर & $09 \leqslant 0$ & $\varepsilon 1 \vee 7$ & $M V \varepsilon$ & ro... & زيتون \\
\hline$r, 1$. & 1,01 & $r v$ & rr & 0917 & $\varepsilon$ rod & $1 K 0 \leq \pi$ & $701 \mathrm{~V}$ & $1 \wedge \Sigma \wedge r$ & 17.70 & النخيل \\
\hline $\mid V, V \varepsilon$ & 10,50 & 747 & $01 \leqslant$ & $V \leqslant V \leqslant$. & $7 . r 97$ & ANTะ. & $71 \leqslant$ A & MITVY & YTEVY & الإجمالى \\
\hline
\end{tabular}

المصدر: وزارة الزراعة واستصلاح الاراضي، قطاع الشئون الاقتصادية، الادارة المركزية للاقتصاد

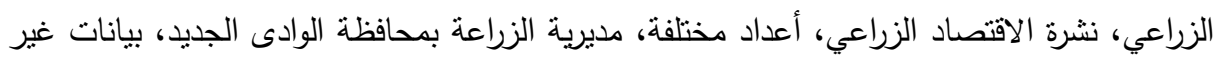

r ب توصيف دالة الهدف لنموذج البرمجة متعددة الأهداف: وهى تاخذ الشكل الرياضى التالىى:

Max $\left\{g_{1}(x), g_{2}(x), \ldots \ldots \ldots, g(x)_{n}\right.$

دالة الهُف الأولى: تعظيم صافى العائد الفدانى:

Max $g_{1}(x)=\sum N_{i} X_{i}$

حيث دالة الهيف الثانية : تعظيم صافى العائد من وحدة مياه الرى:

$\operatorname{Max} \mathrm{g}_{2}(\mathrm{x})=\sum \mathrm{X}_{\mathrm{i}} \mathrm{R} \mathrm{X}_{\mathrm{i}}$

$$
\mathrm{R}=\mathrm{N} / \mathrm{W}
$$


دالة الهُف الثالثة : تدنية الإحتياجات المائية المستخدمة: Min $g_{3}(x)=\sum W_{i} X_{i}$ دالة الهرف الرابعة : تعظيم حجم العمالة الزيراعية المستخدمة: $\operatorname{Max} g_{4}(X)=\sum L_{i} X$

X : المساحة المستهدف زراعتها لكل محصول من محاصيل التركيب المحصولى. N R : صافى عائد الوحدة المائية.

W الإحتياجات المائية للنشاط المحصولى بالالف متر معكب لكل محصول من محاصيل

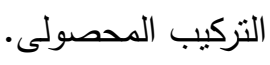

L: إحتباجات الفدان من العمالة الزراعية المستخدمة ( يوم/ رجل/ عمل ) لكل محصول من

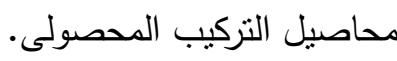
r) قيود البرمجة متعددة الأهداف: اقتصرت الأنشطة الزراعية على القيود الأتية: أ- قيد المساحة المحصولية: ويقصد به عدم زيادة المساحة المحصولية (للحاصلات الثنتوية

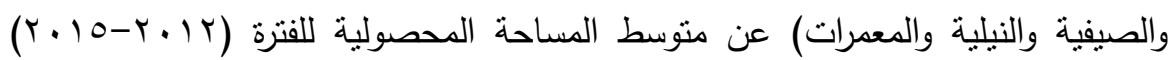

$$
\text { والتي بلغت نحو ع r r r آلف فدان. }
$$

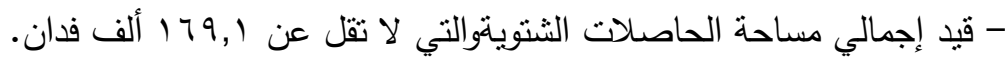

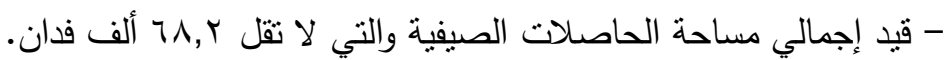
- قبد إجمالي مساحة الحاصلات النيلية والتي لا تقل 1, 1 ألف فدان.

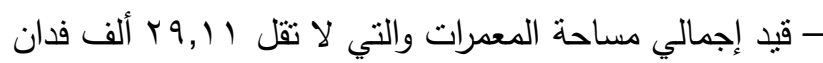

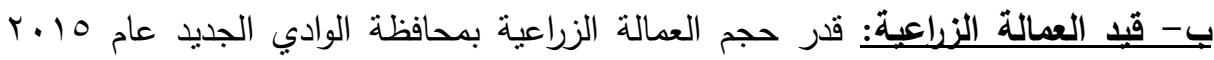

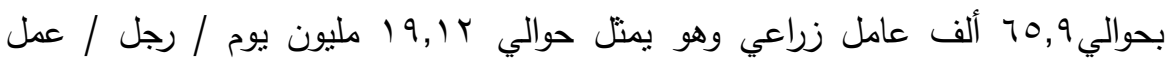
بإعنبار أن أيام العمل نقدر بحوالي .9 ب يوم في السنة بعد إستبعاد الأعباد والأجازات

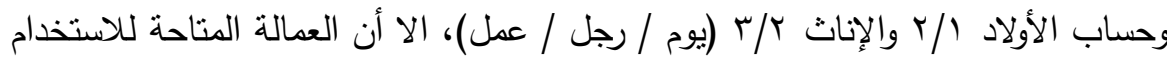


فعلياً في المحافظة قدرت بحوالي ^ץ •, الف عامل حيث يمكن صباغة قيد العمالة الزراعية علي النحو الأتي : $\sum \mathrm{C}_{i} \mathrm{X}_{\mathrm{i}} \leq \mathrm{L}$ إحتياجات المحصول من العمالة الزراعية. $=C_{i}$ الرقعة المزروعة بالمحصول. X = Xi L L العمالة المتاحة.

ج- قبـ الموارد المائية: حددت الموارد المائية المتاحة الجوفية بمحافظة الوادي الجديد من

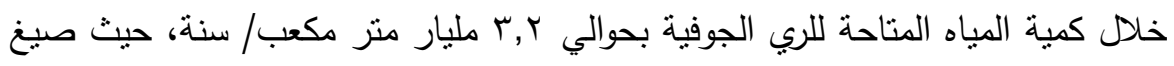
قيد الموارد المائية كالتالي :

$$
\begin{array}{r}
\sum e_{i} X_{i} \leq W \\
\text { إحتياجات المحصول من مياه الرى }=e_{i} \\
\text {. كمية مياه الرقى المتاحة. }=\text { = X }
\end{array}
$$

ويالإضافة إلى القيود السابقة تتضمن البرمجة الاهدئة التف القيود التالية : القيود التنظيمية:وهى قيود نتمثل في الحدود الدنيا والعليا من مساحة المعمرات نظراً لكونها لإهيا

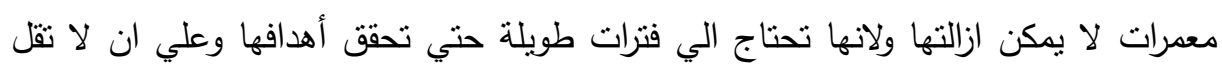

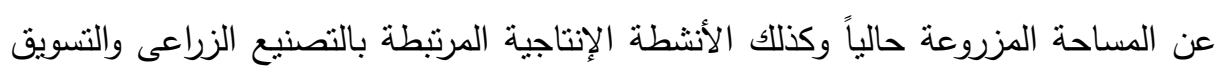
وظروف توفير الأساسية من الموارد الزراعية للاستهلاك المحل. قيود تسويقية: حيث يضاف حد أعلى من المحاصيل التى أوضحت النتائج زيادة مساحتها لزئه

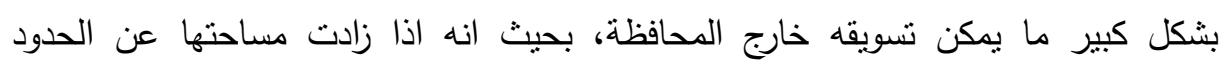
المزروعة حالياً نواجة صعوبات عديدة في تسويقها وهي تتضمن بصفة اساسية الخضروات

$$
\text { الثتوية والصيفية. }
$$

؛) المؤشرات الإقتصادية للتركيب المحصولي الراهن: يوضح الجدول (r) هيكل التركيب المحصولي الراهن والمؤشرات الاقتصادية فى محافظهُ الوادي الجديد، خلال منوسط الفترة

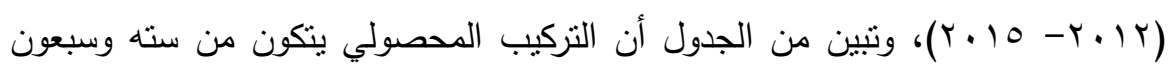

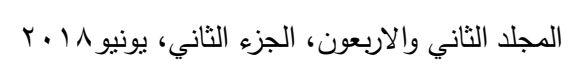




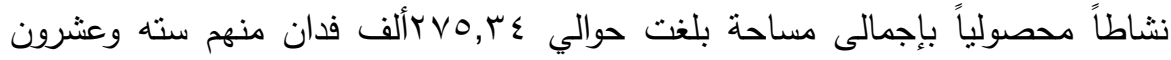

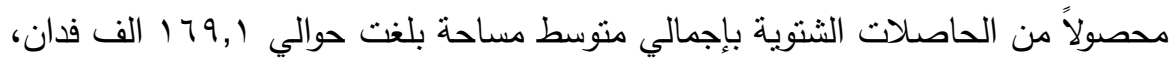

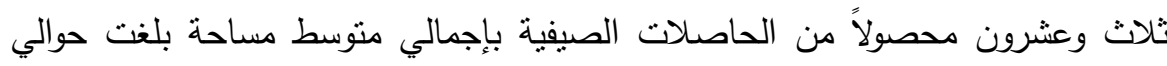
 بلغت حوالي 1,90 الف فدان في المتوسط، في حين يوجد خمس عشر محصولاً من ين

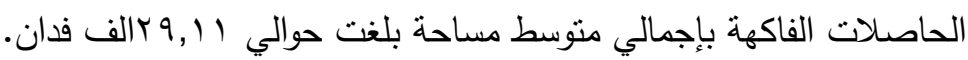

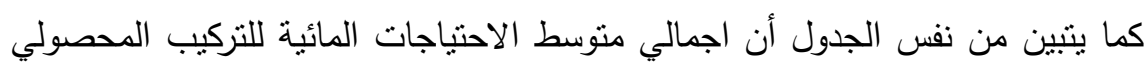

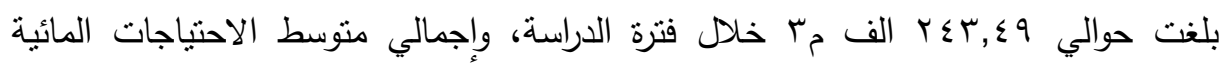

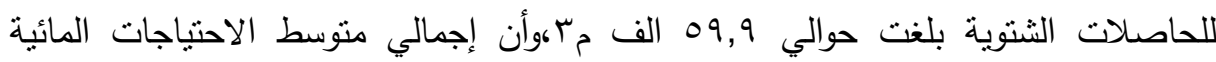
للحاصلات الصيفية بلغت حوالي VV,V الف مجا، وإجمالي متوسط الاحتياجات المائية للحاصلات النيلية بلغت حوالي T,Y T الف مrّ، في حين أن إجمالي منوسط الاحتياجات

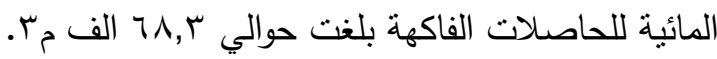


جدول رقم(ץ): متوسط المساحة وصافى العائد وعدد العمال والمقتنات المائية والإحتياجات المائية

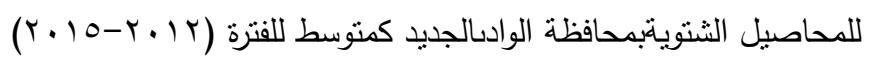

\begin{tabular}{|c|c|c|c|c|c|}
\hline متوسط عائد الوحدة المائية جنية /مج & المقتنات & 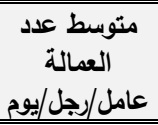 & 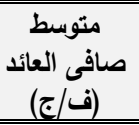 & المساحةت(قدان) & المحصول \\
\hline $1, \varepsilon r$ & $r \leqslant \wedge r,$. & $\varepsilon q$, & rort,. & $11.1 \leq r, \wedge$ & القمت \\
\hline •, AT & IVAr,. & $\varepsilon \vee,$. & $1 \leqslant \pi r,$. & YrMI.,0 & الشعير \\
\hline 1,17 & rrrq,. & $0 \leqslant, \cdot$ & rONV,. & $r O V \cdot, V$ & الفول البلدى \\
\hline$\cdot, \vee \vee 9$ & IAVA, & $97,$. & $1 \leq \vee 7$, & $r q, 0$ & الترمس \\
\hline$\cdot, \lambda \Sigma$ & $r \cdot \wedge l, \cdot$ & $9 r, \cdot$ & $l v \leqslant r,$. & rᄉ५, 0 & الجافة \\
\hline $1, \varepsilon 1$ & r. 7q,. & rr,. & $\varepsilon r r v,$. & 07,0 & السكر \\
\hline$r, .0$ & . ידודי, & $T \varepsilon, \cdot$ & $V \leqslant r_{0}, \cdot$ & $1 \leqslant 100$, & البرسيم \\
\hline$r, \cdot v$ & rrq.,. & $v \varepsilon, \cdot$ & $V r \leq r,$. & 1709, & البصل \\
\hline$\varepsilon, r \leq$ & r $10 \leqslant,$. & $V \vee,$. & ה & $r \leq \cdot, \lambda$ & الثوم \\
\hline 1,11 & rqR ,. & $\wedge \vee,$. & $r \leq 70$, & ru,. & كراوية \\
\hline 1, ro & $r q \leq r,$. & $\Lambda v_{,}$. & ५৭人ч,. & $r v, v$ & كمون \\
\hline$r, q$. & $r V \leqslant 0,$. & $\wedge \vee,$. & $1, v \cdots, \cdot$ & $r q \vee, \Lambda$ & طماطم \\
\hline 1,99 & r10.,. & $9 \cdot, \cdot$ & $\leqslant \curlyvee \wedge \wedge$, & $V, r$ & كوسة \\
\hline$r, 01$ & $r r \leqslant r,$. & $\wedge \wedge, \cdot$ & AY $0, T$ & rı,. & كرنب \\
\hline $1, \lambda V$ & $1100 .,$. & $\wedge \wedge,$. & $r \leqslant 0 r, r$ & $19,$. & باذنجان \\
\hline T & roTs,. & ᄉq,. & $09 \times 1, r$ & $\varepsilon r,$. & فلقل \\
\hline 1,19 & $19 \wedge \mathrm{V}$, & $\wedge \wedge, \cdot$ & rVTo,. & or, $\mathrm{V}$ & سبانتخ \\
\hline$\cdot, r V$ & $1 \wedge \wedge 9$, & ᄉ५,. & $0 . \Sigma, \Lambda$ & $\leq 7, \wedge$ & فجل \\
\hline$r, Y \leq$ & $1147 ., \cdot$ & ᄉ & 纟)Tr,0 & $r \leq, 0$ & لقت \\
\hline $9, \cdot r$ & 19人7,. & ᄉฯ,. & IV9T1,. & $r \varepsilon, r$ & خس \\
\hline $1, r 9$ & IVos,. & ᄉı,. & $r \leq \varepsilon r, 0$ & $V \varepsilon, r$ & بقدونس \\
\hline $1, \leqslant 1$ & IV^५, & $\wedge \uparrow, \cdot$ & rolv,r & rาד,. & جرحير \\
\hline$r, r)$ & rутr,. & $\wedge \uparrow,$. & $q \mid r r, 0$ & $r, v$ & فراولة \\
\hline $1, r r$ & $1 \wedge \varepsilon r,$. & ᄉ५,. & $r \leqslant \leqslant r,$. & $\leq r, \wedge$ & شبت \\
\hline$r, r q$ & $r r \leq 0,$. & ᄉ५,. & $V \vee T, \Lambda$ & 19,0 & خيار \\
\hline$V, 7 Y$ & $r \leq r T,$. & $\mathrm{Vr},$. & $1100 \cdot, \cdot$ & $17 Y 7 \leqslant, 0$ & بطاطس \\
\hline Tr,v. & 09^79,. & $r .01,$. & I $2 \wedge r \vee 1,1$ & $179 . \leq 7,7$ & إجمالى \\
\hline
\end{tabular}

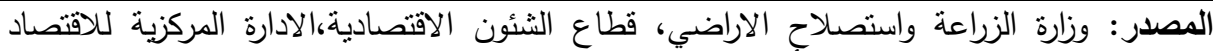

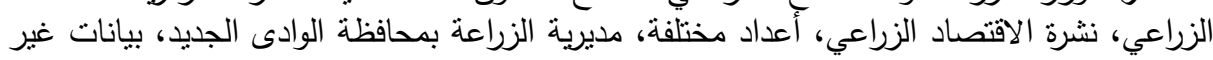
منشورة.

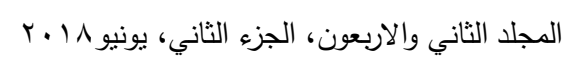


مجلة العلوم البيئية

معهد الدراسات والبحوث البيئية - جامعة عين شمس لهن

تابع جدول(ץ): منوسط المساحة وصافى العائد وعدد العمال والمقننات المائية والإحتياجات المائية

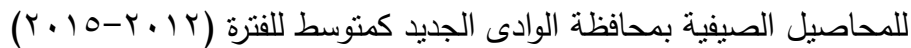

\begin{tabular}{|c|c|c|c|c|c|}
\hline متوسط عائد الوحدة المائية & المقائية & عتوسط عدالة العملة & متوسط صافى العائد (ف/ج) & $\begin{array}{l}\text { المساحة } \\
\text { متوسطان) } \\
\end{array}$ & المحصول \\
\hline$\cdot, \leqslant \Gamma$ & $7 \wedge \ldots, \ldots$ & $V Y, \ldots$ & rq..,... & ro.,r. & الارز \\
\hline $1,9 \vee$ & rття,.. & $\varepsilon \wedge, \cdots$ & $V T \leq 0, \cdots$ & $\leq 91,0$. & الذرة الثامية \\
\hline$r, 1 \wedge$ & rчту,... & $\varepsilon \wedge, \ldots$ & 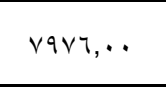 & rヘr৯,vo & $\begin{array}{l}\text { الذرة الثامية } \\
\text { (الصفراء) }\end{array}$ \\
\hline$\cdot, \leqslant 1$ & rVVY,... & rᄉ,.. & $10 \leq 0, \ldots$ & . & الذرة الرفيعة \\
\hline$\cdot, 91$ & rq^.,.. & $\mid r r, .$. & rarr, .. & $\begin{array}{c}1 \leqslant V \cdot V, V \\
0\end{array}$ & 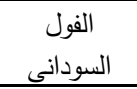 \\
\hline., 07 & 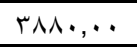 & $1 r r, .$. & Y171,... & MV,VT & السمسم \\
\hline$\cdot, \Lambda$ & $r \cdot v \cdot, \cdots$ & $11 \pi, .$. & $\wedge \leqslant 0, \ldots$ & $r \leqslant, 90$ & عباد الشمس \\
\hline$\cdot, 9 \leq$ & ONOY,... & $T \leq, \ldots$ & $0 \leqslant \vee \neg, .$. & $\varepsilon r \cdot \wedge v, q \wedge$ & البجازي \\
\hline., 09 & oros,... & $170, \ldots$ & MIVq,.. & $r T, Y T$ & القطن (الزهر) \\
\hline$\varepsilon, r \mu$ & r $\backslash \varepsilon \cdot, \ldots$ & $\wedge \mathrm{V}, \ldots$ & $11 \leqslant r q, r_{0}$ & $T r, V T$ & الطماطحم \\
\hline$r, r q$ & ro...,. & ᄉ५, . & OVYT, VO & $110, r \mu$ & فلفل \\
\hline $1, \leqslant 0$ & rAVT,... & $\Lambda \mathrm{v}, \ldots$ & $\sum 101,10$ & $\vee \neg, 0$. & باذنجان \\
\hline 1,97 & r107,... & $\wedge \vee, \ldots$ & T/ᄉ7, Y० & $r Y, Y M$ & كوسة \\
\hline$\varepsilon, \varepsilon$. & roro,... & $\wedge \mathrm{V}, \ldots$ & 11107,10 & $r V \varepsilon, r_{O}$ & بامية \\
\hline $1,0 \leqslant$ & $r \leqslant r V, \ldots$ & $\wedge \vee, \ldots$ & rVr.,o. & 171,90 & ملوخية \\
\hline$r, \wedge T$ & rMV,$\ldots$ & $\Lambda \mathrm{v}, \ldots$ & $\tau \Lambda \cdot V, \ldots$ & $10, \Sigma \Lambda$ & جرجير \\
\hline$r, 11$ & rrVA, . & $\wedge \vee, \ldots$ & $0.19, \ldots$ & $\varepsilon, \vee_{0}$ & فجل \\
\hline$r, Y \leq$ & rvov,... & ᄉ $7, \ldots$ & $7 \backslash \wedge 1, \vee 0$ & $197,0$. & شمام \\
\hline$r, 01$ & 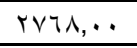 & $\wedge \uparrow, \cdots$ & $79 \leqslant r, \ldots$ & $r \varepsilon, T T$ & كنتالوب \\
\hline 1,07 & 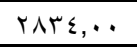 & $\wedge \mathrm{v}, \ldots$ & $\varepsilon \leqslant \mu 1, \vee 0$ & $V \cdot, r$. & خيار \\
\hline $1, V V$ & 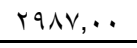 & $\wedge \vee, \ldots$ & orA1, Vo & Mr.vo & قتناء \\
\hline $1, V 4$ & $r q \leq 0, \ldots$ & $\wedge \vee, \ldots$ & $01 \wedge r, .$. & Or $\leqslant \Lambda, r$. & بطيخ لب \\
\hline$r, 09$ & $r \leq r r, \ldots$ & $V Y, \ldots$ & $\wedge \vee r \wedge, 0$. & ors, ro & بطاطس \\
\hline$\varepsilon r, T r$ & VVTOV,.. & $199 \leq, \ldots$ & Iro9rт,.. & TAYTr,VV & إلصيفى \\
\hline
\end{tabular}

المصدر: وزارة الزراعة واستصلاح الاراضي، قطاع الثشئون الاقتصادية،الادارة المركزية للاقتصاد الزراعي، نشرة الاقتصاد الزراعي، أعداد مختلفة، مديرية الزراعة بمحافظة الوادى الجديد، بيانات لإنات الزاتية 
تابع جدول(ץ): منتوسط المساحة وصافى العائد وعدد العمال والمقننات المائية والإحتياجات

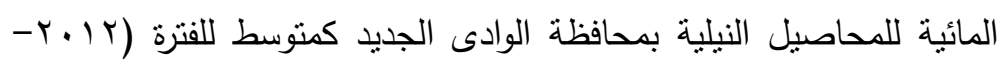

$(r \cdot 10$

\begin{tabular}{|c|c|c|c|c|c|}
\hline متوسط عائد الوحدة المائية جنية /مجr & المقتنات & متوسط عدالة العملة/ عالة & صنافى العائد & متوسط المساحة & المحصول \\
\hline$\cdot, 0 \mathrm{~V}$ & ґА१ч,.. & $\varepsilon \wedge, \cdots$ & rrmi,.. & $190 ., 90$ & الذرة السكرية \\
\hline$\cdot, \mathrm{VV}$ & r110,.. & $10 \leqslant, \ldots$ & $r \leqslant T V, \ldots$ & $O V \Sigma, Y r$ & لوبيا العلف \\
\hline$\cdot, 01$ & $r r \leqslant q, \ldots$ & $10 \leqslant, \ldots$ & $17 \varepsilon r, \ldots$ & $\leqslant O \wedge \vee, q \wedge$ & ذرة شامى \\
\hline$\cdot, 0 \mathrm{~V}$ & rтrA,.. & $\{\wedge, \ldots$ & $\mid \wedge \leq \wedge, \ldots$ & $170 \mathrm{~V}, 0$. & ذرة رفيعة \\
\hline$r, \cdot \wedge$ & rтoт,... & $104, .$. & $11 \times 70, \ldots$ & $9, \leqslant 9$ & طماطح \\
\hline $1, r v$ & 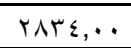 & $10 r, \ldots$ & rAvq,.. & $0, \leqslant 9$ & باذنجان \\
\hline $1, r \varepsilon$ & rq0 ,... & 1 ro,.. & एят०,.. & N, & فلفل \\
\hline$\cdot, 97$ & 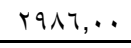 & $1 \leqslant 0, \ldots$ & 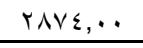 & $r \wedge, \Sigma q$ & ملوخية \\
\hline $1, r \varepsilon$ & หАTУ,.. & $\wedge 1, \ldots$ & rosr,... & $r 0,99$ & خيار \\
\hline., $9 \varepsilon$ & $r q \wedge q, \ldots$ & $\wedge 4, \ldots$ & rVq7,.. & 9,91 & قنثاء \\
\hline $1, r$. & 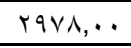 & $\wedge \mathrm{V}, \ldots$ & roTs,... & 70,10 & شمام \\
\hline $1, r \wedge$ & 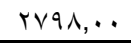 & $10 r, .$. & rᄉтr,... & $1 \leqslant, V_{0}$ & بطيخ بلدى \\
\hline $1 r, 94$ & КУтイА,.. & 1 1т97,... & $\varepsilon r q r v, \ldots$ & & إجمالى النيلي \\
\hline
\end{tabular}

المصدر: وزارة الزراعة واستصلاح الاراضي، قطاع الشئون الاقتصادية، الإدارة المركزية للاقتصاد

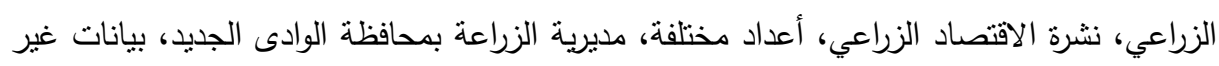
منشور 
تابع جدول(Y): منوسط المساحة وصافى العائد وعدد العمال والمقننات المائية والإحتباجات

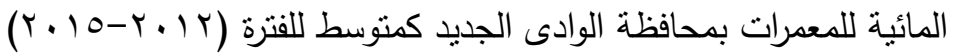

\begin{tabular}{|c|c|c|c|c|c|c|}
\hline المتوسط عائدة الوحة & مالمقائنات & متوسط عدالة العمالة & صنافسالعائد & المستاحة & متوسطة & المحصول \\
\hline $1, \pi|\pi|$ & $01 T_{0}$ & rq & $T V \varepsilon r$ & $r \leq r r$ & OOYA,VO & الموالح والبرتقال \\
\hline$\cdot$, AVฯY & $\varepsilon 97 V$ & $\varepsilon r$ & Eror & roq, ro & $\varepsilon \varepsilon r$ & العنب \\
\hline 1, TYYO & हाए & rq & $07 V \leqslant$ & rTYo,r & ¿19५,9V & المانجو \\
\hline . , 9Y०V & $\leqslant 7.0$ & ऍ & ETTK & $1 \cdot, 0$ & $1 \varepsilon, Y T$ & الموز \\
\hline$\cdot, 91 \cdot 7$ & $\varepsilon 919$ & $\varepsilon \varepsilon$ & $\leqslant 0 \leqslant r$ & or,vo & 90,10 & تين \\
\hline., $90 \times 9$ & $\leq 9 \wedge V$ & $r T$ & EVOr & 10 & 18,90 & تين شوكي \\
\hline $1, .7 \leq 7$ & $r V \leq 0$ & $\sum r$ & raAv & $\Lambda \leq 1,0$ & 997,0 & جوافة \\
\hline $1, \cdot \vee \wedge \wedge \wedge$ & ETIY & rA & \&70Y & $r 4 \varepsilon, 99$ & $V 9 Y, 0$ & رمان \\
\hline •,AYIT & $\varepsilon r \leqslant r$ & rᄉ & $r \leqslant \wedge T$ & $r \cdot \Lambda, r r$ & $\varepsilon \cdot 7,0$ & مشمش \\
\hline $1, \cdot N 1 r$ & $\varepsilon r T \leqslant$ & rq & $\leq 7 \vee 0$ & $r \cdot, r_{0}$ & $111, \varepsilon \wedge$ & كمثرى \\
\hline $1, \leq 7 \leq \wedge$ & $r \wedge \leq 0$ & rA & 07r & Iro,rr & 149,0 & تفاح \\
\hline $1, .94 \varepsilon$ & $\varepsilon 9 \wedge \vee$ & or & osor & 10,90 & ru, Vo & خوخ \\
\hline .,ArOl & EOT1 & $\varepsilon r$ & rVA乏 & $r, r r$ & $\varepsilon, V r$ & برقوق \\
\hline$\cdot, \wedge \vee \vee q$ & $\leq 970$ & $\varepsilon r$ & $\varepsilon r 09$ & rAVT,r & $0 \leq 77, \leqslant 0$ & زيتون \\
\hline $1,7 \cdot \varepsilon$ & $507 \pi$ & $r$ & VTrI & 18.01 & 18.01 & النخيل \\
\hline $17, r V T$ & TאוTו & ONV & VTTVT & rq1. 9 & rorAN,. T & المعمراتى \\
\hline
\end{tabular}

الهصدر: وزارة الزراعة واستصلاح الاراضي، قطاع الثئون الاقتصادية، الادارة المركزية للاقتصاد

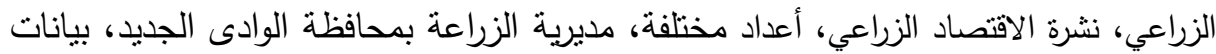

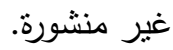

\section{نتائج البرمجة المتعددة الأهداف: قد تم وضع ثنات سيناريوهات كالأتى:}

- السيناريو الأول: وتم فيه استخدام القيود الخاصة بالعروات والمساحة المحصولية والحد

$$
\text { الأدنى والرى والعمالة. }
$$

- السيناريو الثانى: وتم فيه استخدام القيود الخاصة بالعروات والمساحة المحصولية والحد

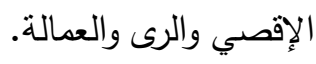


- السيناريو الثالث: وتم فيه إستخدام القيود الخاصة بالعروات والمساحة المحصولية والحد الإدنى والإقصي والرى والعمالة.

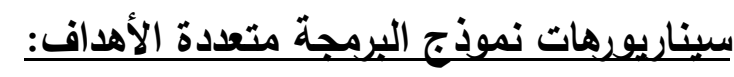

ا. التركيب المحصولى: السيناريو الأول: يتضح من جدول (r) أنه عند مقارنة النركيب المحصولى المقترح بنظيره الراهن، إتضح وجود انخفاض فى إجمالي مساحات المحاصيل

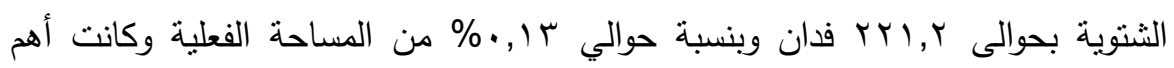

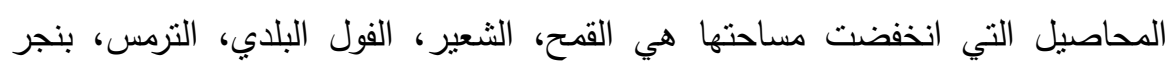

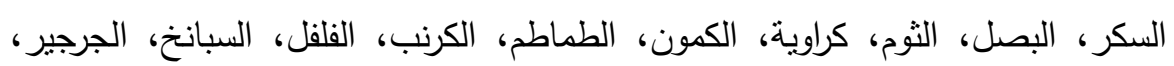

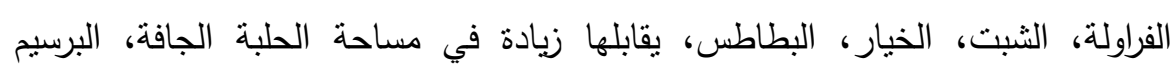
المستديم، الكوسة، الفجل، اللفت، الخس، البقدونس، وزاد مساحات المحاصيل الصيفية

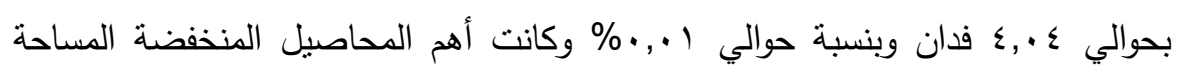

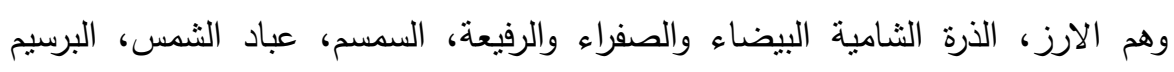

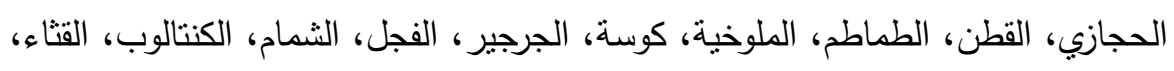
البطيخ، ووجود زيادة في محاصيل البطاطس، الفول السوداني، الفلفل، الباذنجان، البامية،

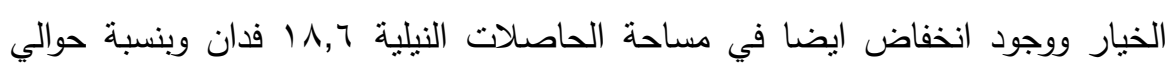
ا r, •• من المساحة الفعلية وكانت أهم المحاصيل ذات المساحات المرتفعة هي اللوبيا

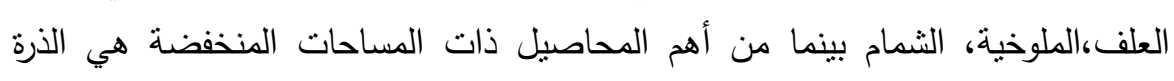

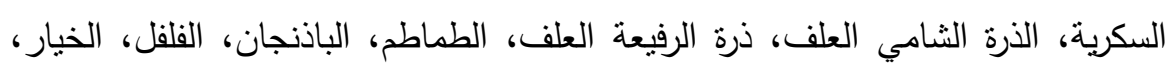

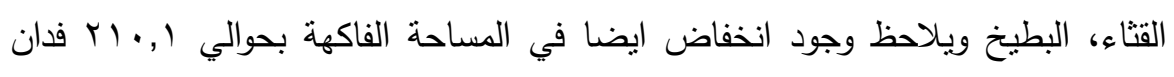
وبنسبة VY, ••\% من المساحة كما اوضحت نتائج نموذج البرمجة الاهداف.وكانت أهم

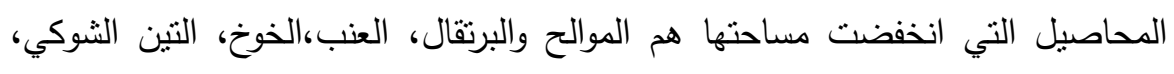

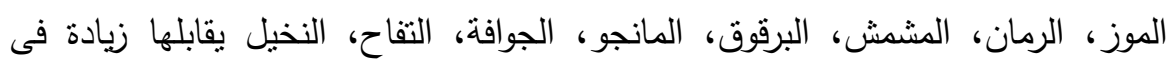
مساحة محصول الكمثري، الزينون. 
السبناريو الثانحي: يوضح من نفس الجدول (ץ) أنة عند مقارنة التركيب المحصولى المقترح من خلا النموذج المقدر للبرمجة الاهداف، بالتركيب المحصولى الراهن وجود زيادة فى لئ

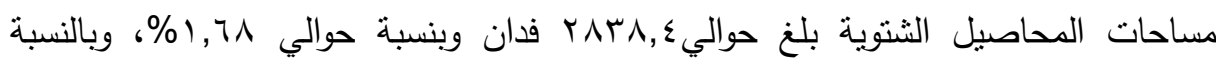

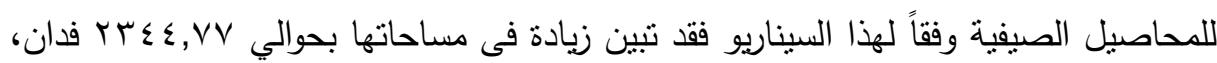

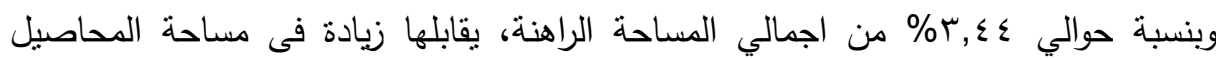

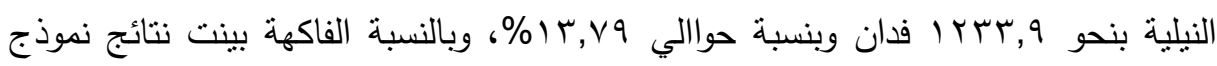

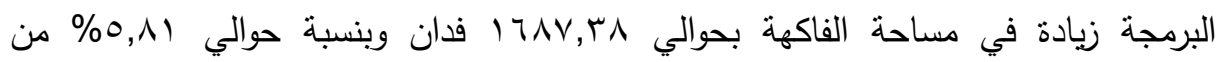
المساحة الراهنة.

السيناريو الثالث: نشير التقديرات الواردة بنفس الجدول (ץ) أنة بمقارنة التركيب المحصولى المقترح وفقاً لنتائج نموذج البرمجة متعددة الأهداف والتركيب المحصولى الراهن وجود

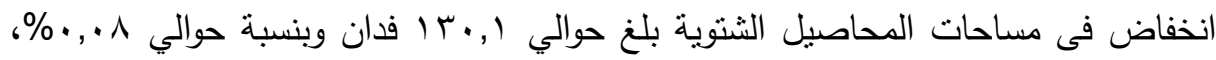
وبالنسبة للمحاصيل الصيفية وفقاً لهذا السيناريو، فقد تبين انخفاض فى مساحاتها بحوالي اله

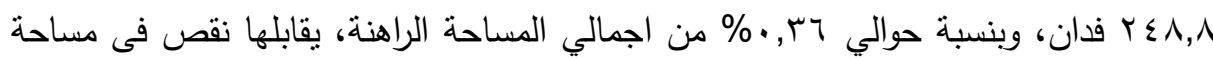

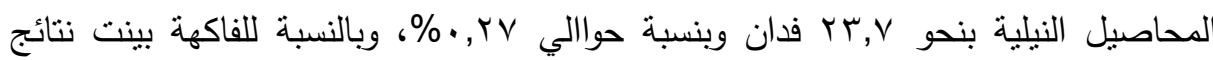

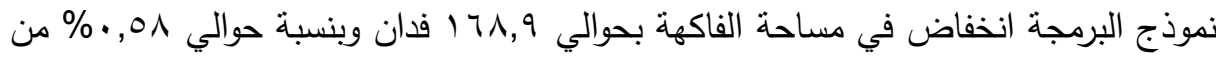

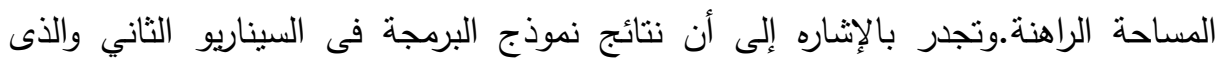

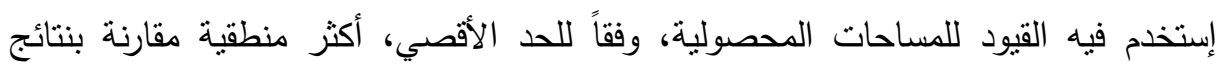
نموذج البرمجة فى السيناريو الأول والثالث، حيث بلغ اجمالى المساحة المزروعة في التركيب

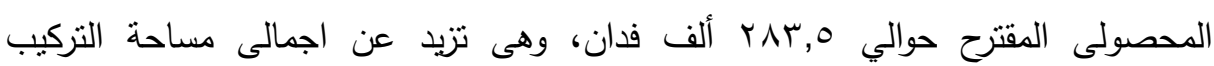

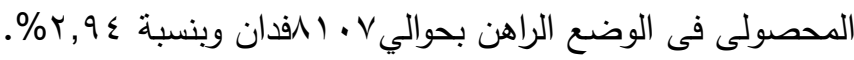


مسعد السعيد رجب وآخرون

جدول(ץ): مقارنة بين التركيب المحصولي الراهن والمقترح بإستخدام البرمجة متعددة الأهداف للحاصلات الشتوية

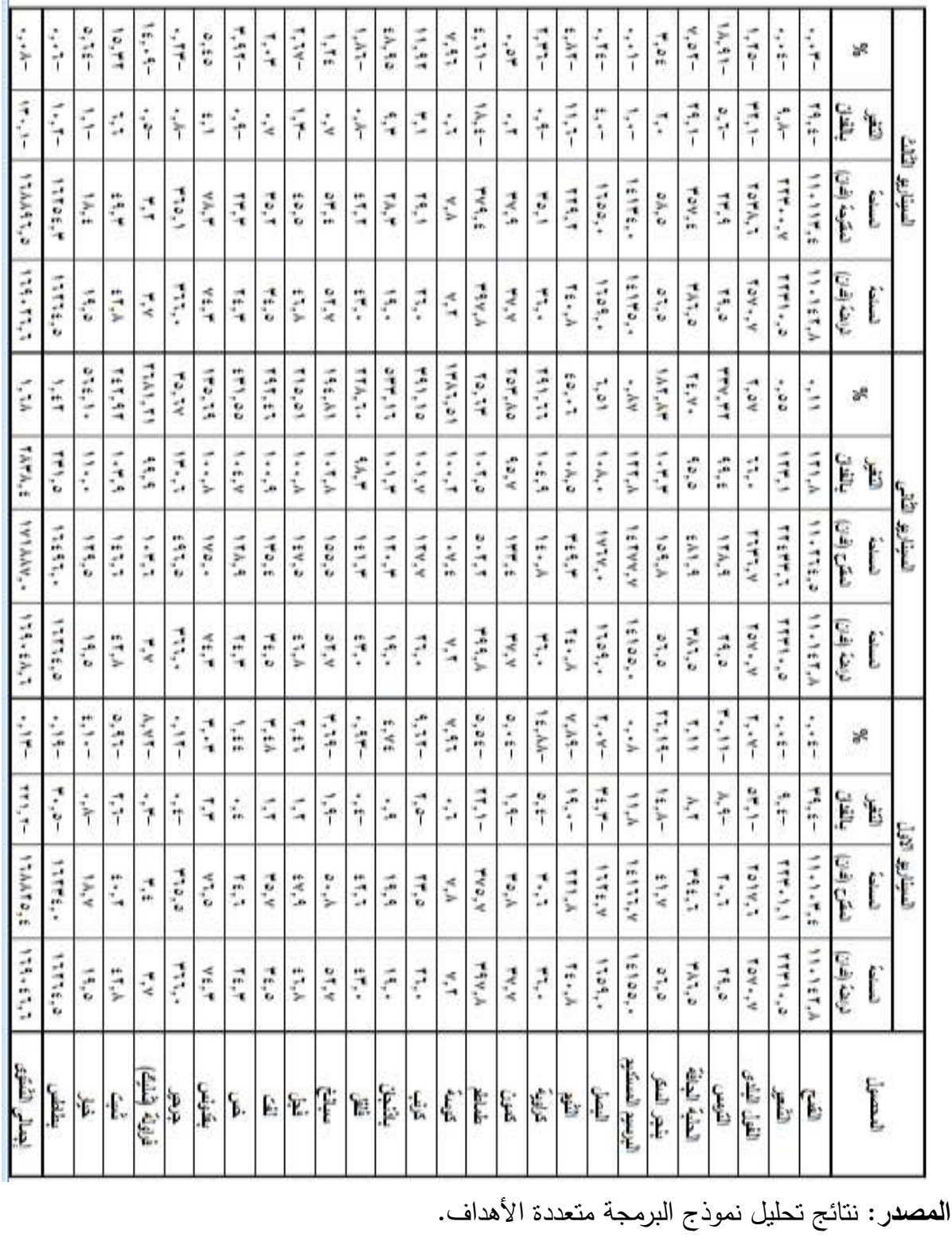

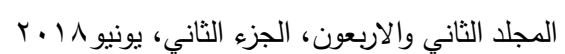


تابع جدول(ץ): مقارنة بين التركيب المحصولي الراهن والمقترح بإستخدام البرمجة متعددة الأهداف للحاصلات الصيفية .

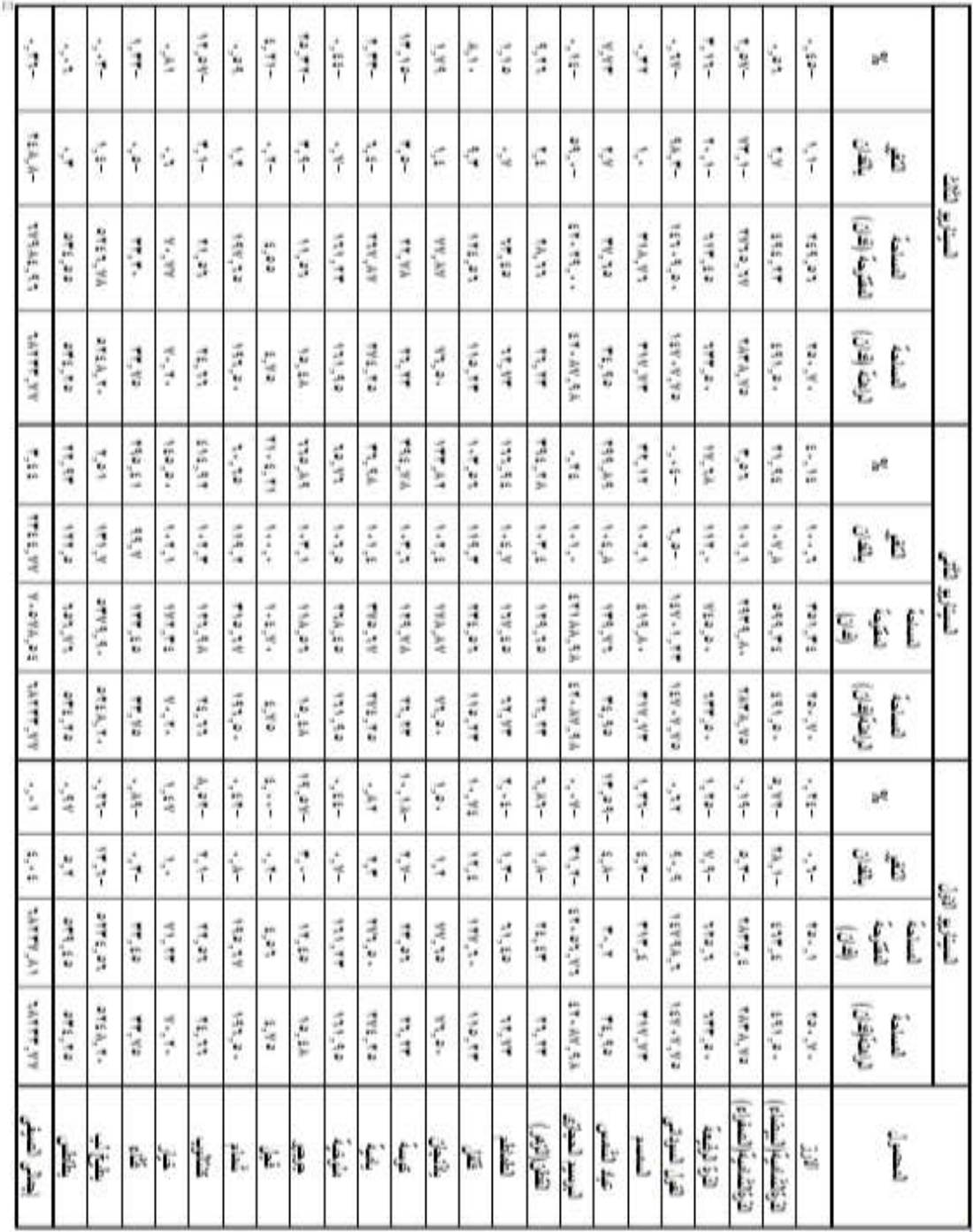

ثار : نتائج تحليل نموذج البرمجة متعددة الأهداف. 
تابع جلول(ץ): مقارنة بين التركيب المحصولي الراهن والمقترح بإستخدام البرمجة متعددة الأهداف للحاصلات النيلية .

\begin{tabular}{|c|c|c|c|c|c|c|c|c|c|c|c|c|c|c|}
\hline 7 & $\xi$ & $\vec{G}$ & $\vec{i}$ & $i$ & 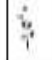 & 7 & $\frac{1}{7}$ & 9 & 3 & 6 & $\dot{7}$ & $\vdots$ & x & \multirow{4}{*}{ E } \\
\hline$i$ & 7 & $\because$ & 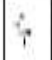 & $\vec{T}$ & $i$ & $\frac{1}{7}$ & $\therefore$ & 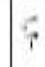 & ? & F & $\vec{t}$ & in & 焉 & \\
\hline 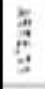 & 6 & 焗 & $\xi$ & \begin{tabular}{l}
4 \\
1 \\
\hdashline
\end{tabular} & $\xi$ & $\vec{t}$ & $\ddot{Z}$ & 7 & 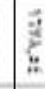 & 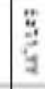 & 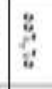 & $\frac{\vec{A}}{\vec{B}}$ & G & \\
\hline 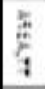 & 5 & $\frac{5}{6}$ & $\%$ & 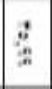 & $\vec{b}$ & $\xi$ & $\because$ & 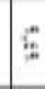 & 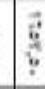 & i: & $\frac{a}{a}$ & 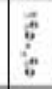 & $\frac{E}{E} E$ & \\
\hline$y$ & $\overrightarrow{3}$ & $\vec{g}$ & $\hat{\vdots}$ & $\vec{b}$ & $\frac{2}{5}$ & 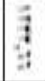 & 5 & $\frac{5}{4}$ & $\because$ & $\overrightarrow{3}$ & $\xi$ & 5 & st & \multirow{4}{*}{$E$} \\
\hline 3 & है & 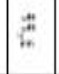 & $\bar{\vdots}$ & $\hat{a}$ & 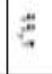 & $\overrightarrow{6}$ & 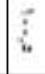 & $\overrightarrow{4}$ & $\xi$ & $\dot{G}$ & $\dot{4}$ & $\underline{\underline{z}}$ & 焉 & \\
\hline كُع & 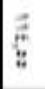 & 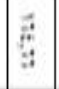 & 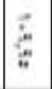 & 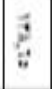 & 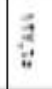 & 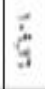 & 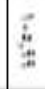 & 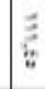 & 新 & F & $\overrightarrow{3}$ & $\vec{b}$ & E & \\
\hline 童 & 5 & $\begin{array}{l}z \\
3\end{array}$ & 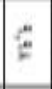 & 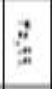 & $\overrightarrow{5}$ & $\frac{\xi}{7}$ & 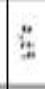 & 5 & $\frac{\vec{a}}{\vec{a}}$ & 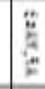 & $\frac{n}{4}$ & 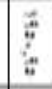 & 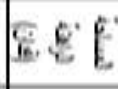 & \\
\hline 4 & 7 & 6 & 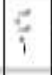 & $\overrightarrow{7}$ & $\therefore$ & $\vec{t}$ & $\frac{\overrightarrow{7}}{7}$ & $\overrightarrow{7}$ & $\frac{i}{1}$ & $\vec{i}$ & $\because$ & $i$ & an & \multirow{4}{*}{1} \\
\hline 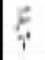 & $i$ & $:$ & $i$ & 7 & $\therefore$ & $\xi$ & it & 5 & $f$ & 5 & $\therefore$ & 4 & $\bar{E}$ & \\
\hline$\frac{3}{4}$ & $\vec{b}$ & 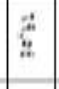 & 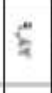 & 8 & $\overrightarrow{\vec{a}}$ & 5 & : & $\xi$ & 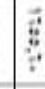 & ह & : & $\frac{\vec{A}}{4}$ & 的点 & \\
\hline 常 & $\overrightarrow{6}$ & $\frac{5}{6}$ & E & 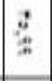 & $\vec{E}$ & $\frac{5}{4}$ & $\vdots$ & 5 & 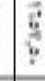 & 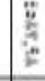 & $\frac{4}{4}$ & 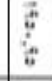 & E & \\
\hline & & & is & & $\mathrm{E}^{\prime}$ & tas & 1 & & & & & $\stackrel{c}{c}$ & & \\
\hline
\end{tabular}

المصدر : نتائج تحليل نموذج البرمجة متعددة الأهداف. 
تابع جدول(r): مقارنة بين التركيب المحصولي الراهن والمقتزح باستخدام البرمجة متعددة الأهداف للفاكهة

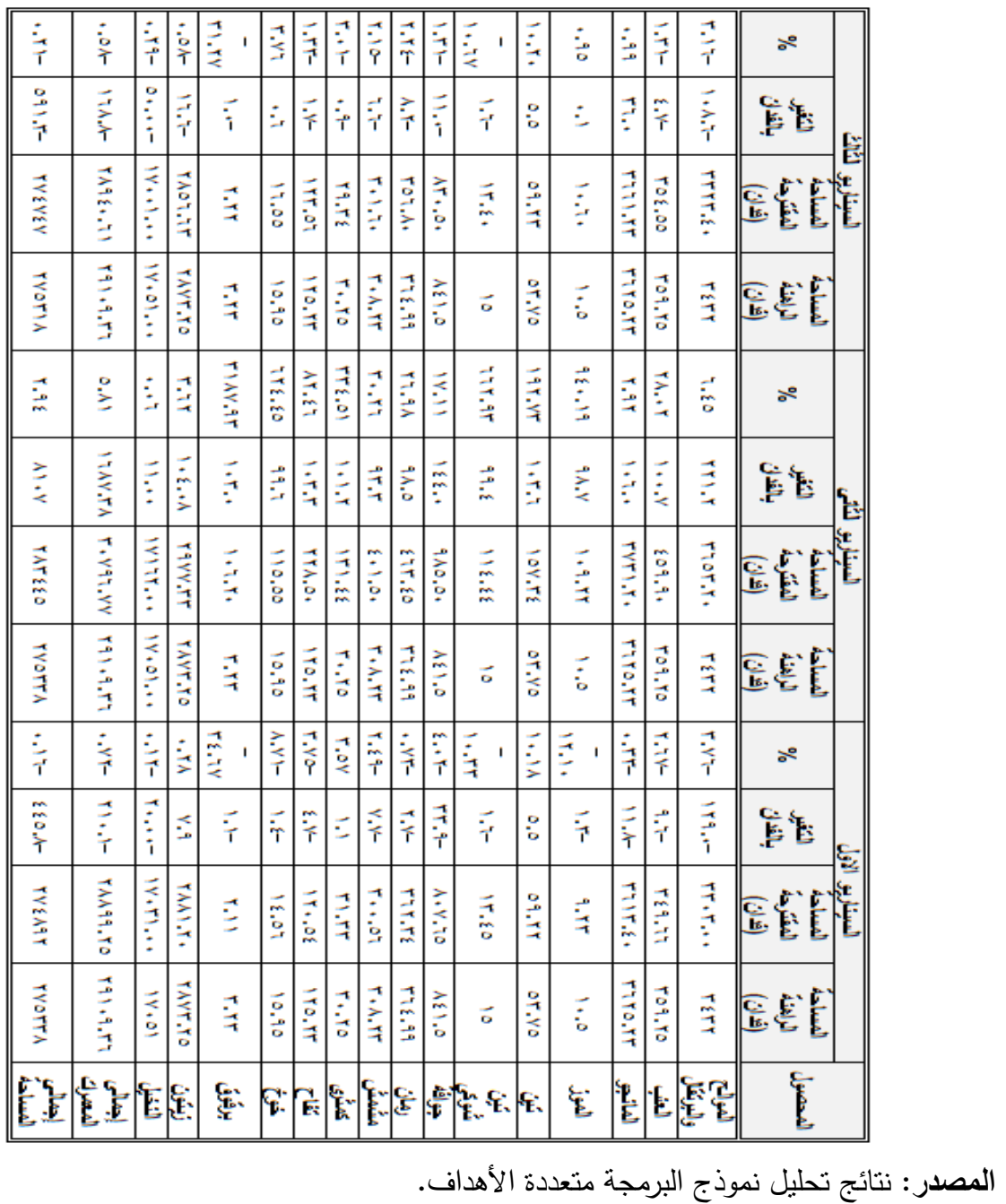




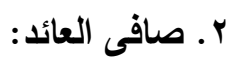

السيناريو الأول: حيث أن النموذج متعدد الأهداف، يهدف الى تعظيم صافى العائد للتركيب

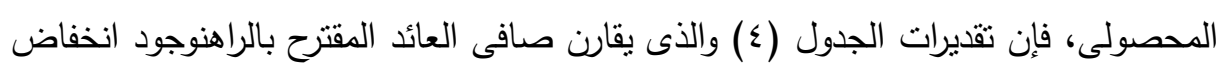

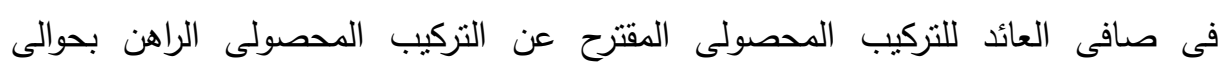

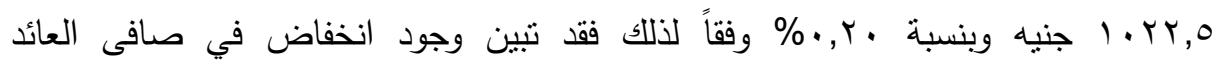

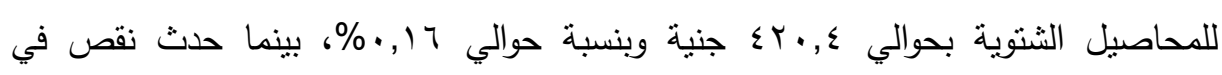

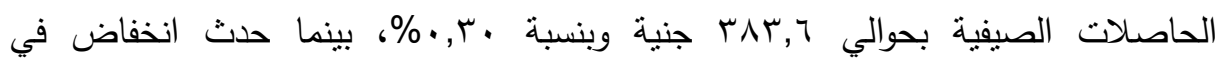

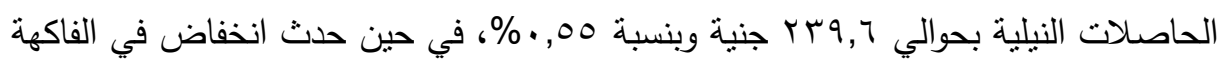

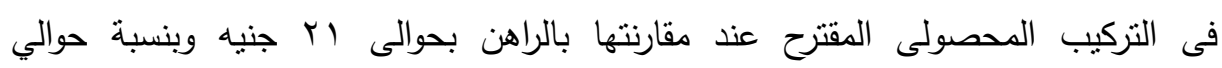
$\% \cdot, \cdot r$

السيناريو الثانى: بتنين من نفس الجدول (ع) وجود زيادة فى صافى العائد للتركيب

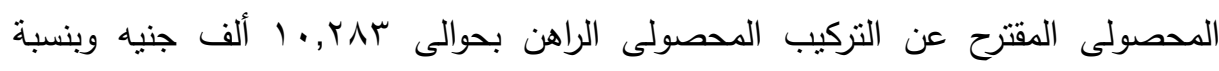

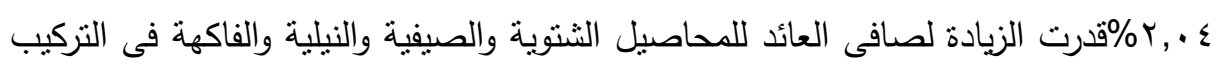

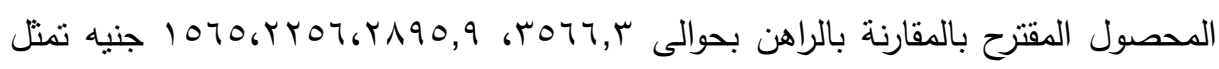

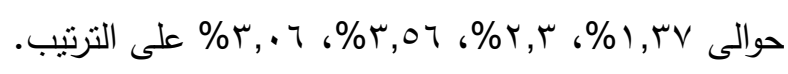

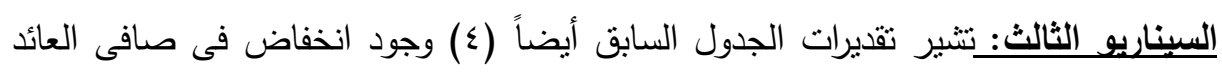

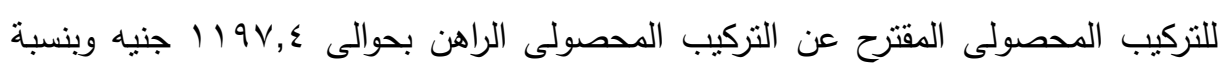
؟r, ••\%، ووفقاً لذلكقدرت الانخفاض لصافى العائد للمحاصيل الشتوية والصيفية والنيلية

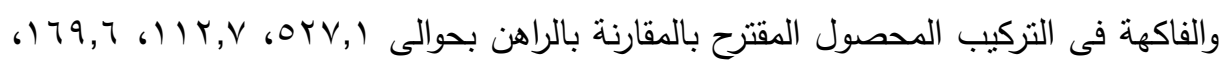

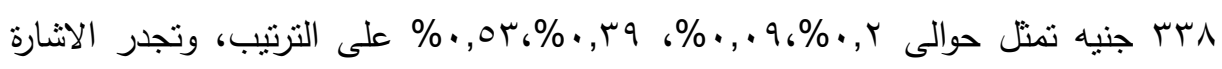

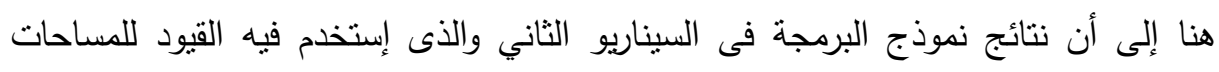

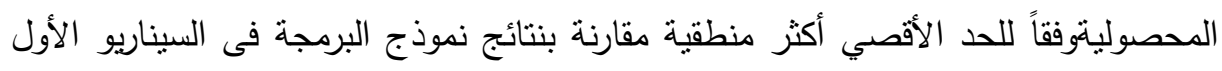

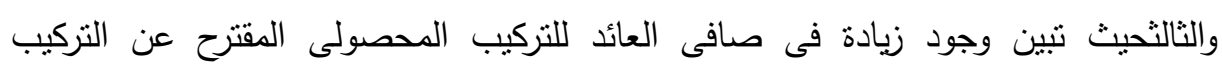

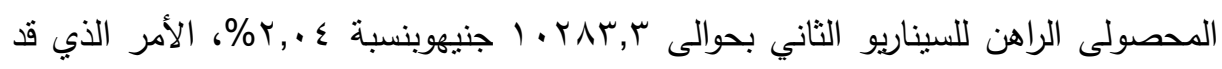

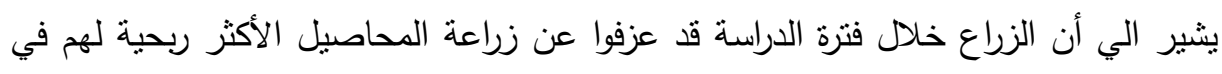

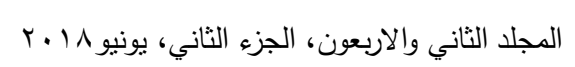


السيناريو الاول والثالث بينما زاد صافي العائد في السيناريو الثاني ويلاحظ ان اجمالي صافي

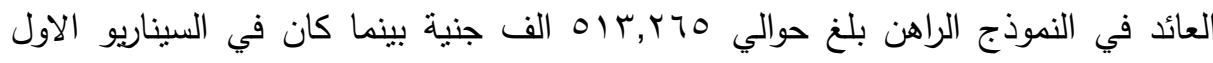
حوالي 909, 1 •0 (0الف للفدان مما يدل علي وجود انخفاض في العائد في هذا السيناريو بنحو

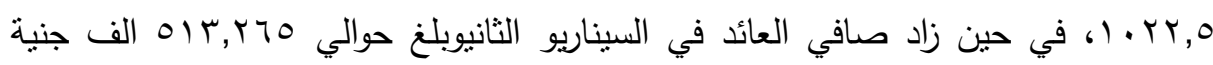

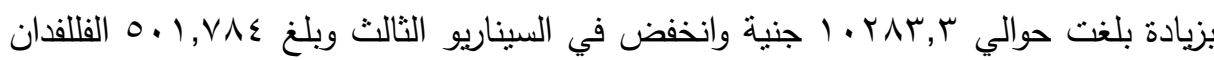

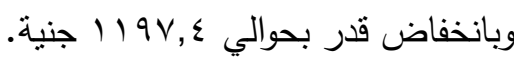


مسعد السعيد رجب وآخرون

جدول(ع): مقارنة بين صافي العائد الراهن والمقترح بإستخدام البرمجة متعددة الأهداف

\begin{tabular}{|c|c|c|c|c|c|c|c|c|c|c|c|c|c|c|c|c|c|c|c|}
\hline$i$ & $\dot{1}$ & 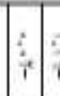 & 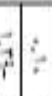 & $\frac{1}{7}$ & 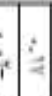 & & & $\vdots$ & 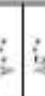 & & & $\frac{4}{7}$ & 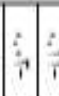 & is & $t$ & & & $\frac{1}{7}$ & $\alpha$ \\
\hline 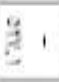 & 要 & 4 & 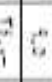 & 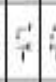 & & & $: 6$ & $\hat{7}$ & $\mathrm{C}$ & & & $\frac{7}{T}$ & i & ? & 5 & & & & $\mathrm{E}: \mathrm{E}: \mathrm{E}$ \\
\hline$\frac{\overrightarrow{\mathrm{E}}}{\overrightarrow{\mathrm{E}}}$ & 青 & 4 & 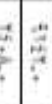 & 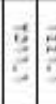 & & $\Rightarrow$ & 3 & 7 & 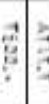 & 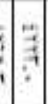 & & 2 & 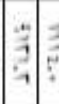 & 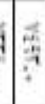 & 4 & & & $\frac{3}{3}$ & \\
\hline 売 & 要 & 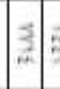 & 龺 & 索: & $\frac{3}{3}$ & $\Rightarrow$ & $\frac{3}{5}$ & 晃 & 烈 & 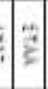 & & 2 & 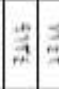 & 4 & 3 & & 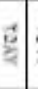 & & $\approx E^{2}$ \\
\hline$\xi$ & $\vdots$ & $\Rightarrow:$ & 7 & 1 & $\Rightarrow$ & 5 & 3 & $\Rightarrow$ & 5 & & & 5 & $\therefore$ & 5 & 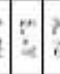 & & & 5 & \\
\hline 3 & 営 & 全 & 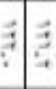 & : & & 素 & 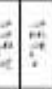 & 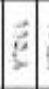 & & & & 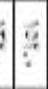 & 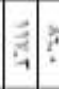 & 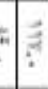 & 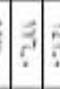 & & & 4 & \\
\hline$\stackrel{\vec{a}}{3}$ & $\begin{array}{l}\overrightarrow{1} \\
\vdots \\
\vdots\end{array}$ & 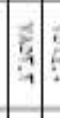 & 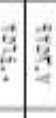 & 2. & & 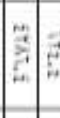 & 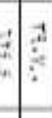 & 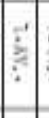 & . & & 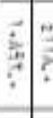 & 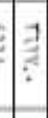 & 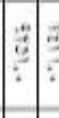 & 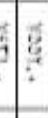 & 4 & & & 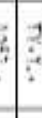 & $E$ \\
\hline 㔛 & 要 & 3 & $\Rightarrow$ & 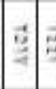 & & 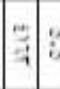 & 3 & . & a) & $=$ & & . & $\Rightarrow$ & 3 & 3 & & 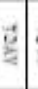 & & \\
\hline$\dot{i}$ & $\dot{\vec{p}}$ & $\vdots$ & 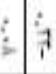 & $\frac{1}{\gamma}$ & $\frac{1}{7}$ & $\div$ & 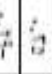 & & & & & $\frac{1}{1}$ & $\frac{1}{7}$ & 4 & $\frac{1}{1}$ & 5 & & 5 & - \\
\hline $\overrightarrow{\vec{i}}$ & $\begin{array}{l}7 \\
\vdots \\
i\end{array}$ & 4 & 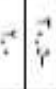 & & & 궁 & $\vec{a}$ & $\mid$ & & & 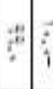 & $i i$ & 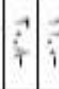 & & : & & & & $E E$ \\
\hline 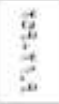 & 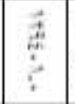 & 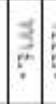 & & & 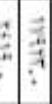 & & ? & & & & & ? & 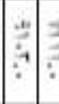 & & & & & & $E^{2}$ \\
\hline 㔛 & 委 & 3 & $\Rightarrow$ & & & 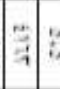 & 3 & & & & & a & 3 & 3 & & & & 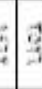 & $\approx E F$ \\
\hline & f & 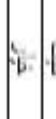 & & & & & & & & & & & & & & & & & \\
\hline
\end{tabular}

المصدر: نتائج تحليل نموذج البرمجة متعددة الأهداف.

المجلد الثاني والاربعون، الجزء الثاني، يونيو 1/ بـ 
مجلة العلوم البيئية

معهد الدراسات والبحوث البيئية - جامعة عين شمس لئة

جدول(§): مقارنة بين صافي العائد الراهن والمقترح بإستخدام البرمجة متعددة الأهداف

للحاصلات الصيفية

\begin{tabular}{|c|c|c|c|c|c|c|c|c|c|c|c|c|c|c|c|c|c|c|c|c|c|}
\hline$\vdots$ & $\%$ & 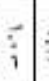 & 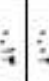 & 4 & & $i$ & 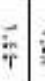 & & & & $\therefore$ & & $\bar{r}$ & $\vec{\Delta}$ & $\overrightarrow{\vec{r}}$ & & $\div$ & & $t$ & $x$ & \\
\hline $\overrightarrow{\bar{F}}$ & $:$ & & $=$ & 7 & & $\overrightarrow{i r}$ & 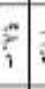 & 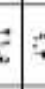 & 5 & 18 & 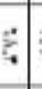 & $i$ & i & 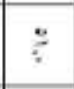 & 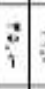 & & & & $i$ & $\mathrm{E}_{\mathrm{B}}: \mathrm{E}$ & E \\
\hline 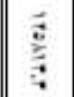 & 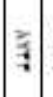 & & 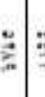 & 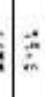 & & $\vdots$ & 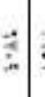 & 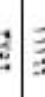 & 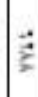 & 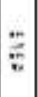 & 3 & 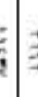 & 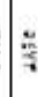 & 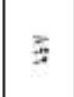 & 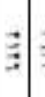 & & & & $\underline{\underline{\prime}}$ & $E_{G}^{E}$ & $\mathrm{C}$ \\
\hline 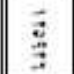 & 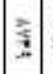 & & & a & & & & 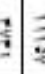 & 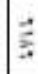 & & 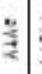 & & $\because$ & है & 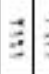 & & & 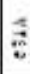 & & $\varepsilon E$ & \\
\hline $\overrightarrow{3}$ & $\vec{a}$ & 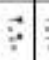 & 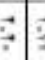 & $\vec{s}$ & 3 & $\vec{s}$ & . & 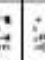 & 5 & 5 & $\vec{\Xi}$ & $:$ & $\overrightarrow{5}$ & .5 & 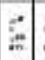 & & 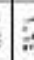 & $\overrightarrow{\mathrm{g}}$ & $\vec{a}$ & $x$ & \\
\hline 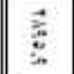 & 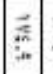 & 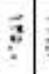 & 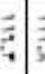 & 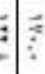 & 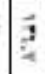 & 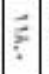 & . & 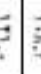 & & 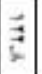 & 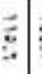 & 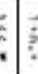 & 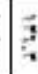 & $\vec{\xi}$ & 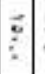 & & & $\xi$ & & E E E & \\
\hline - & 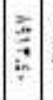 & ב⿱ & & 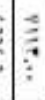 & ? & 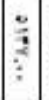 & 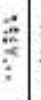 & 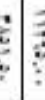 & 苦 & 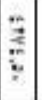 & 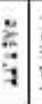 & 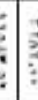 & 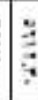 & 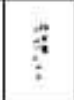 & .3. & & . & 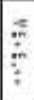 & 节 & ${ }^{2}{ }_{k}^{k}$ & \\
\hline 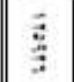 & 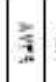 & 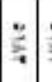 & $:$ & a & है & 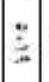 & | & 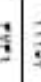 & E & 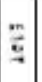 & . & & 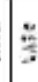 & है & 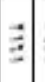 & & & & $\vec{*}$ & $\sum_{E}^{E}$ & \\
\hline$i$ & $\overrightarrow{\dot{7}}$ & $\$$ & 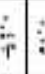 & 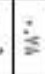 & $\dot{\xi}$ & $\vdots$ & 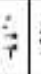 & $=$ & & & 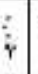 & r & $\%$ & $\vdots$ & $\vdots$ & & & 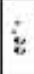 & $\frac{\vec{c}}{\hat{r}}$ & & \\
\hline 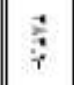 & $\frac{4}{4}$ & & 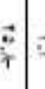 & $:=$ & $\vec{T}$ & $\widehat{r}$ & $\vdots$ & 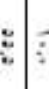 & 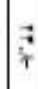 & 7 & & & $\vec{i}$ & $\ddot{i}$ & $\vec{i}$ & & & & $i$ & $\frac{1}{\mathrm{k}}$ & \\
\hline 离 & $\frac{2}{y}$ & & $\stackrel{\vdots}{\Xi}:$ & 6 & 草 & $\frac{1}{\Sigma}$ & 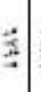 & $=$ & & & 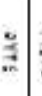 & & $\vdots$ & 를 & $\stackrel{\vec{E}}{.}$ & & & & & 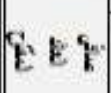 & \\
\hline$\stackrel{\bar{s}}{3}$ & 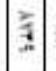 & & : & A & 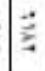 & 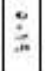 & | & 3 & & 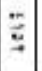 & 31 & & 3 & ?2. & 莫 & & & 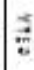 & & 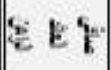 & \\
\hline$\frac{t}{t}$ & & & & & & & & & & & & & & E & & & & & & & \\
\hline
\end{tabular}

المصدر : نتائج تحليل نموذج البرمجة متعددة الأهداف. 
جلول(§): مقارنة بين صافي العائد الراهن والمقترح باستخدام البرمجة متعددة الأهداف للحاصلات النيلية

\begin{tabular}{|c|c|c|c|c|c|c|c|c|c|c|c|c|}
\hline \multicolumn{4}{|c|}{ s.th } & \multicolumn{4}{|c|}{ 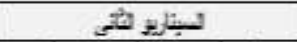 } & \multicolumn{4}{|c|}{ لمبتل } & \multirow[b]{2}{*}{ لسصتئ } \\
\hline$\%$ & بن & صل & ص & $\%$ & بن & $\frac{10}{401}$ & ص & $\%$ & بان & 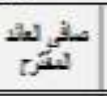 & $\begin{array}{l}30 \\
313 \\
313\end{array}$ & \\
\hline $.89-$ & $y . i-$ & TसाT & זrs? & i.tt & $1 . T_{.}$. & $\pi \pi i$ & (स+T! & $1.71-$ & Tw.i- & $4 \pi . T$ & TrT! & 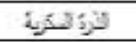 \\
\hline T.2\% - & $31,-$ & $\psi_{i+1}+1$ & Tity & $2, n 7$ & 1Et. & $T .4$ & YETY & 1.14 & $T 2$. & $\gamma_{i 247}$ & тรบิ & tel \\
\hline $.71-$ & $\ldots$ & $13 \pi$ & 17:t & $7 . y$. & $11 \ldots$ & vor & nat & t.iT- & En- & 17.5 & 1725 & (Ale) $13: 5$ \\
\hline$T .24$ & $21 .$. & 1442 & MeÁ & $2.1 \mathrm{t}$ & $1+\lambda_{1}$. & 1991 & MEs & $\ldots n$ & $12,-$ & Whi & MEA & 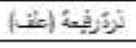 \\
\hline$\ldots+1$ & 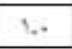 & 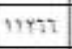 & who & $3 . r_{i}$ & 181.0 & 11612 & 11498 & $\ldots 4$ & $2+1$. & um & $11+19$ & bu \\
\hline$\ldots+1$ & a. & THUY & TAV4 & T.T. & $1+\lambda .$. & $i \ldots v$ & Tave & $\ldots 2$ & T.1. & ran & rivif & بأنجان \\
\hline. $.2 \mathrm{~A}$ & $\pi r_{*}$. & там & T470 & r.3. & $1 \pi \pi$. & $i=\mu$ & एक & t..2i- & u... & Tras & This & J \\
\hline$\ldots T 4-$ & $y_{.}+$ & YATY & tAYY & E. 5 a & 124. & $r .1 Y$ & qavi & $\ldots+1$ & 4. & FMT & $\tau_{\text {ini }}$ & عكوفية \\
\hline$\ldots T$ & $\cdots$ & rois & Tait & T.Y. & $\pi \%$. & $n x_{i}$ & rast & $1.1-$ & $T+,-$ & $r 2 . i$ & Tait & جاجز \\
\hline r.tr- & $4 \ldots-$ & $\mathrm{rv} \cdot \mathrm{I}$ & $7 \times 47$ & E.rt & $15 \%$ & т49 & nati & $-.+4-$ & $x-$ & ras & $\mathrm{Fv4t}$ & 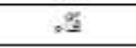 \\
\hline$\ldots \pi$ & A. & Tosi & Toliti & $T .4 \lambda$ & 1हT. & $\pi \cdot \pi$ & T21i & $1, \ldots+$ & $\pi,-$ & Terv & resi & 24 \\
\hline 1.2Y- & $00,-$ & $T A . y$ & Thit & $T .41$ & $124 .-$ & 4.18 & Tatt & $\therefore, A-$ & T1.. & Tat & raty & S \\
\hline$+T^{2}-$ & $\overline{11 \pi, 1}$ & ervar & ETAT & $T .27$ & 1075.. & 200.4 & irary &., 03 & $-\overline{1}+4.1$ & inצY & iran & 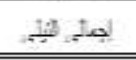 \\
\hline
\end{tabular}


جدول(§): مقارنة بين صافي العائد الراهن والمقترح بإستخدام البرمجة متعددة الأهداف للفاكهة.

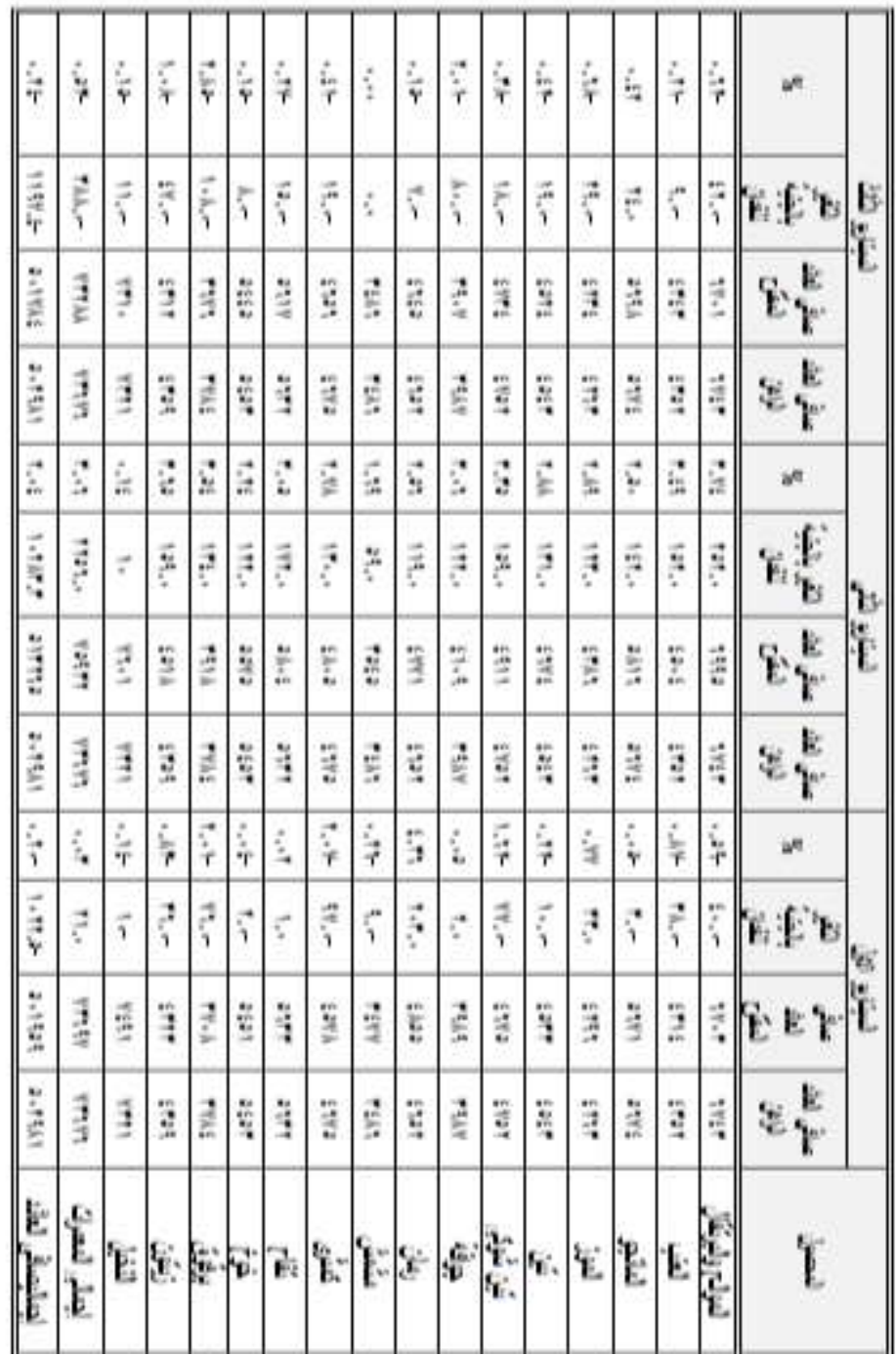

المصدر : نتائج تحليل نموذج البرمجة متعددة الأهداف. 
r. عائد وحدة المياه:

السيناريو الأول: يتضح من الجدول (0) والخاص بالهدف الثالث بنموذج البرمجة متعددة

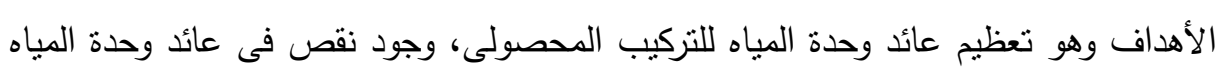

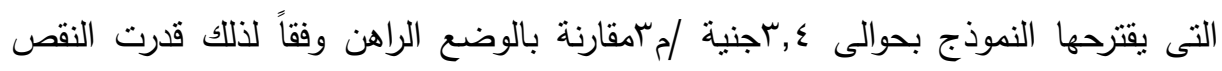

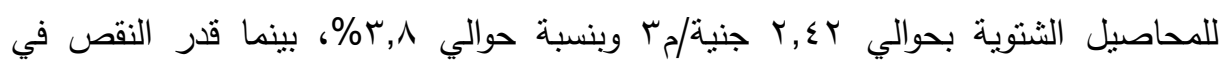

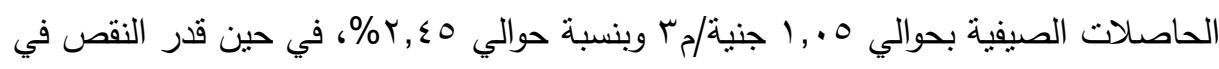

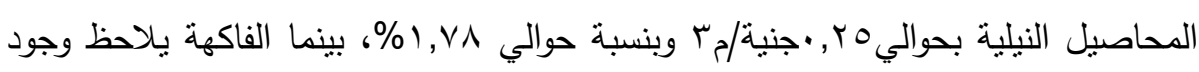
نفص فى صافى العائد للتركيب المحصولى المقترح عن التركيب المحصولى الراهن

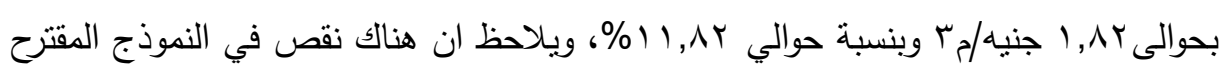

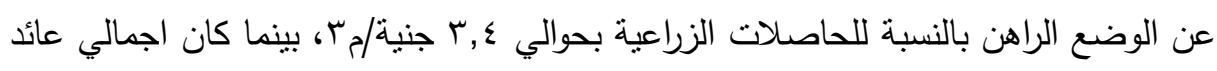

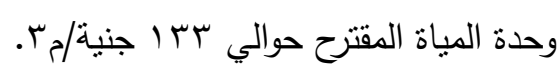
السيناريو الثانى: تبين من الجدول (ه) وجود زيادة فى عائد وحدة المياه التى يقترحها النموذج بحوالى YV,V

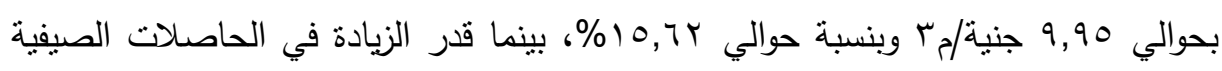

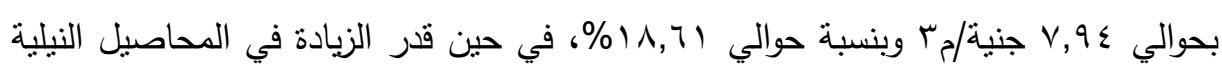

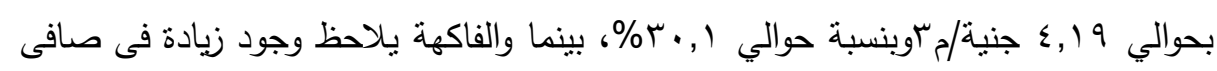

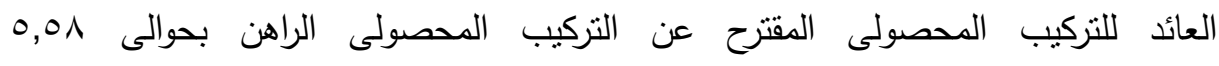

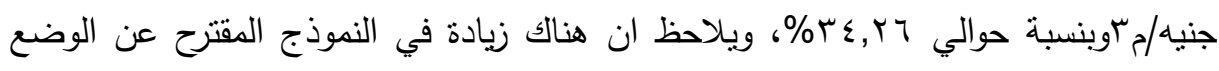

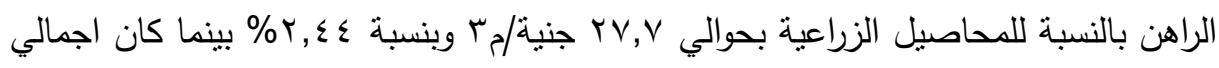

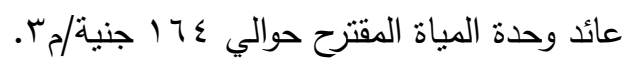

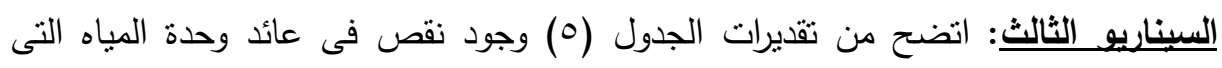

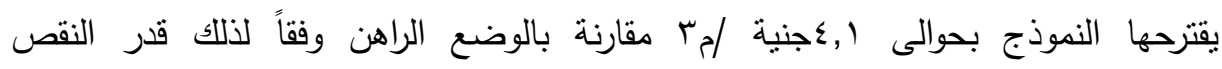

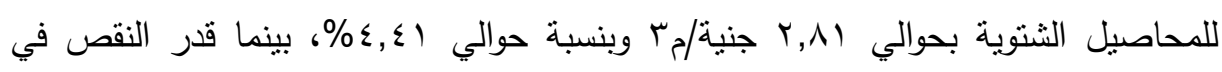

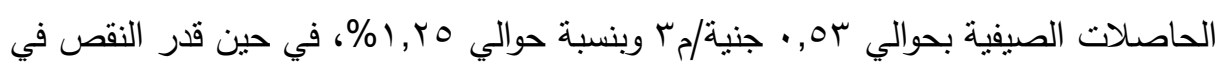

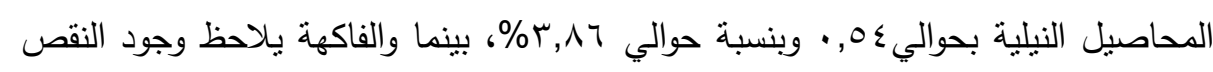

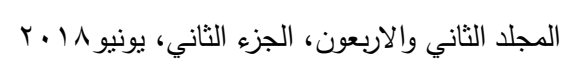


فى صافى العائد للتركيب المحصولى المقترح عن التركيب المحصولى الراهن بحوالى بr,.

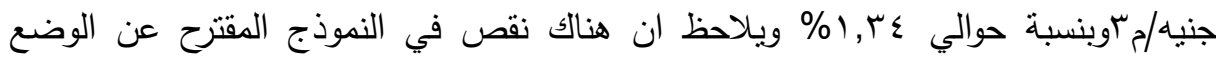

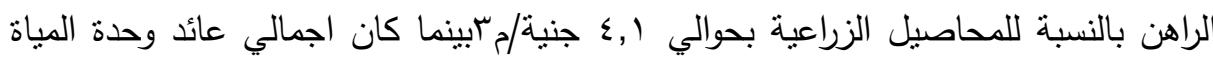

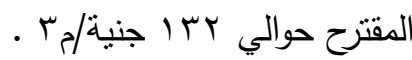

وتوضح نتائج تقدير عائد وحدة المياه أن السيناريو الثاني هو الافضل لوجود زيادة في عائد وحدة المياه في التراكيب المحصولية المقترحة بمقارنتها بعائد وحدة المياه في التراكيب المحصولية السائدة حالياً. 
مسعد السعيد رجب وآخرون

جدول(ه): مقارنة بين عائد وحدة المياه الراهنة والمقترحة باستخدام البرمجة متعددة الأهداف

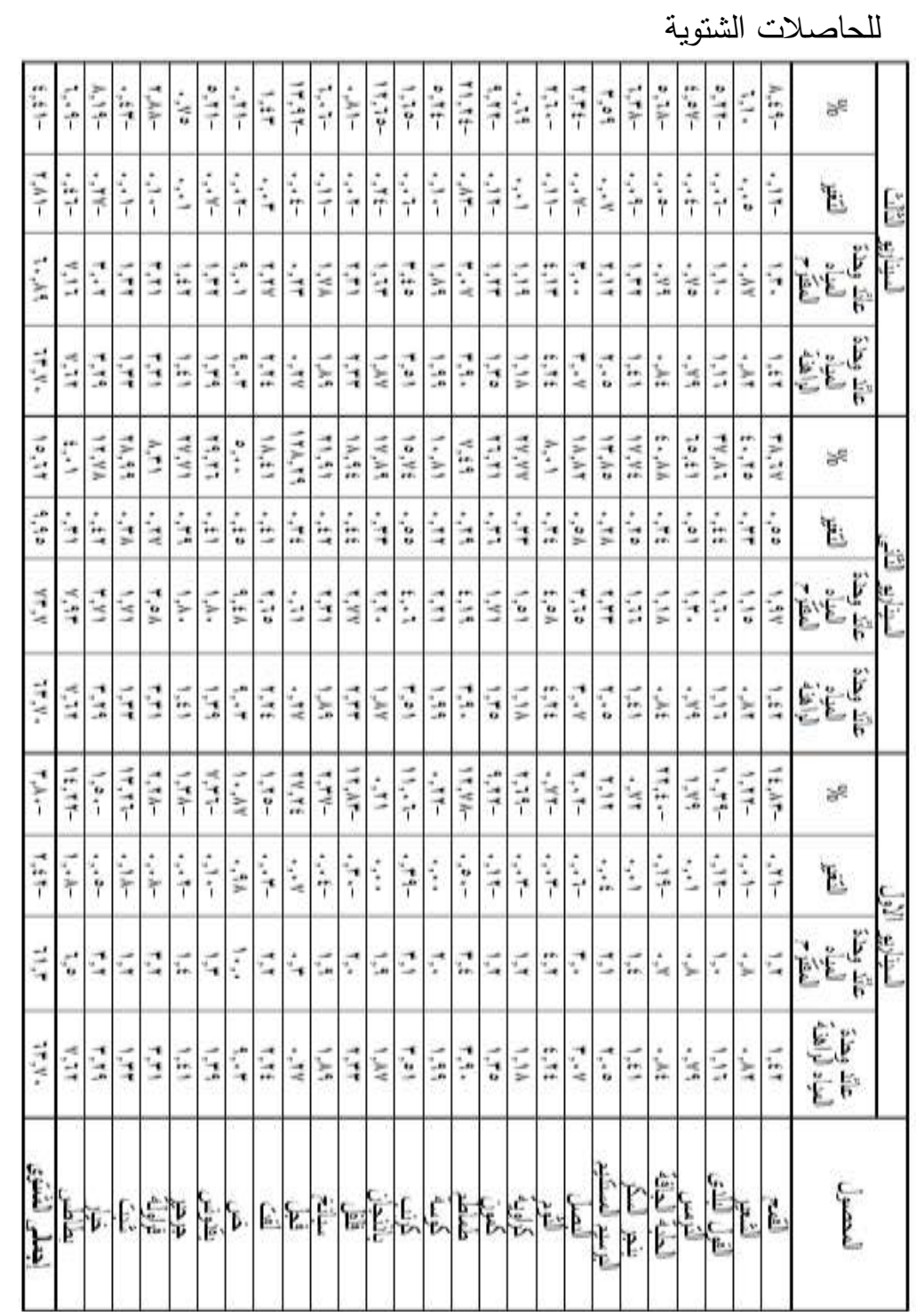

المصدر : نتائج تحليل نموذج البرمجة متعددة الأهداف.

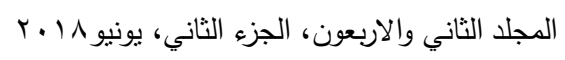


مجلة العلوم البيئية

معهد الدراسات والبحوث البيئية - جامعة عين شمس لبهن

تابع جدول(ه): مقارنة بين عائد وحدة المياه الراهنة بإستخدام البرمجة متعددة الأهداف للحاصلات الصيفية.

0
0

المصدر : نتائج تحليل نموذج البرمجة متعددة الأهداف. 
تابع جدول(ه): مقارنة بين عائد وحدة المياه الراهنة والمقترحة بإستخدام البرمجة متعددة الأهداف للحاصلات النيلية.

\begin{tabular}{|c|c|c|c|c|c|c|c|c|c|c|c|c|c|c|}
\hline$\hat{i}$ & $\because 1$ & $\underline{i}$ & $\begin{array}{l}3 \\
\vdots \\
\vdots \\
\vdots\end{array}$ & 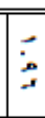 & $\hat{y}$ & $\begin{array}{l}\overrightarrow{1} \\
\hat{i}\end{array}$ & $\vdots$ & $\vec{i}$ & j) & $\mid \begin{array}{l}n \\
\vdots \\
2\end{array}$ & $\stackrel{2}{1}$ & $\vdots$ & $\therefore$ & \\
\hline 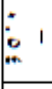 & $\vdots 1$ & $\vdots 1$ & 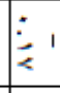 & $\vdots$ & $\vdots$ & $\vdots 1$ & $\vdots$ & $\vdots$ & $\vdots 1$ & $\vdots 1$ & $\vdots$ & $\vdots$ & E & Ev \\
\hline $\begin{array}{c}1 \\
1 \\
0\end{array}$ & $\dot{i}$ & $\zeta$ & $\dot{s}$ & 3 & $\vdots$ & 3 & $\frac{1}{y}$ & $\vdots$ & $\vdots$ & $\vdots$ & $\vdots$ & $\vdots$ & 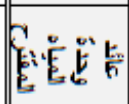 & E \\
\hline $\begin{array}{l}1 \\
3 \\
3\end{array}$ & $\dot{1}$ & $\dot{3}$ & $\vdots$ & $\dot{1}$ & $\vdots$ & $\dot{1}$ & $\dot{1}$ & $\vdots$ & $\vdots$ & $\vdots$ & $\dot{z}$ & $\vdots$ & $\frac{5}{5}$ & \\
\hline$\vdots$ & $\begin{array}{l}\hat{1} \\
\vdots\end{array}$ & $\begin{array}{l}1 \\
3 \\
z\end{array}$ & 3 & $\begin{array}{l}3 \\
\vdots \\
0\end{array}$ & $\ddot{3}$ & $\frac{1}{3}$ & $\hat{?}$ & 3 & 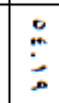 & 童 & \begin{tabular}{l}
0 \\
\hdashline \\
\hdashline
\end{tabular} & 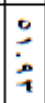 & $\therefore$ & \\
\hline 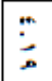 & 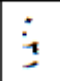 & $\vdots$ & $\vdots$ & $\vdots$ & $\vdots$ & $\vdots$ & $\vdots$ & $\vdots$ & $\vdots$ & 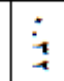 & $\vdots$ & $\vdots$ & 复 & 点. \\
\hline$\frac{3}{3}$ & 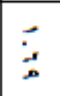 & 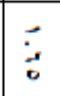 & $\dot{3}$ & $\because$ & $\dot{3}$ & $\dot{3}$ & گ & 3 & $\vdots$ & $\vdots$ & $\dot{s}$ & $\vdots$ & Fin & E \\
\hline i & $\dot{1}$ & $\dot{2}$ & $\therefore$ & $\underline{x}$ & $\vdots$ & $\dot{1}$ & $\dot{3}$ & $\vdots$ & $\vdots$ & $\vdots$ & $\dot{s}$ & $\vdots$ & 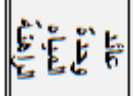 & \\
\hline 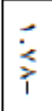 & $\begin{array}{l}z \\
\vdots \\
i\end{array}$ & آن & $\begin{array}{l}\vdots \\
\vdots\end{array}$ & $\vdots$ & 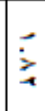 & 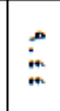 & $\vec{i}$ & $:$ & $\begin{array}{l}\circ \\
1\end{array}$ & iَ & $\dot{y}$ & 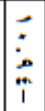 & $\therefore$ & \\
\hline$\vdots$ & $\dot{\vdots}$ & $\dot{i}$ & $\vdots$ & $\vdots$ & $\vdots$ & $\vdots$ & $\vdots$ & $\vdots$ & $\vdots$ & $\vdots$ & $\vdots$ & $\vdots$ & 堛 & 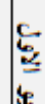 \\
\hline$\frac{1}{3}$ & $\vdots$ & $\vdots$ & i & 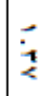 & $\vdots$ & z & 1 & $\vdots$ & $\vdots$ & $\vdots$ & $\vdots$ & $\vdots$ & 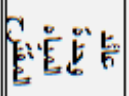 & \\
\hline $\begin{array}{l}1 \\
i \\
i\end{array}$ & $\dot{3}$ & $\dot{3}$ & $\vdots$ & $\dot{x}$ & $\vdots$ & $\dot{1}$ & $\dot{3}$ & $\vdots$ & $\vdots$ & $\vdots$ & $\dot{z}$ & $\vdots$ & $\frac{5}{5}$ & \\
\hline 怎 & $\begin{array}{l}C_{5} \\
. \\
\text { W. } \\
\text { ". }\end{array}$ & $\tilde{E}^{2}$ & Es & E. & E. & F & E. & ह & 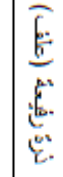 & 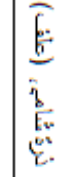 & $\frac{E}{E}$ & E. & & \\
\hline
\end{tabular}

المصدر : نتائج تحليل نموذج البرمجة متعددة الأهداف.

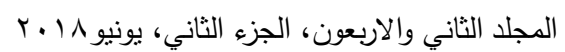


تابع جدول(ه): مقارنة بين عائد وحدة المياه الراهنة والمقترحتبإستخدام البرمجة متعددة الأهداف للفاكهة

\begin{tabular}{|c|c|c|c|c|c|c|c|c|c|c|c|c|c|c|c|c|}
\hline$\vdots$ & iَ & $\vec{i}$ & $\mid \begin{array}{l}\overrightarrow{0} \\
\vec{i}\end{array}$ & $\dot{\vdots}$ & $\overrightarrow{3}$ & 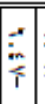 & דיר & $\bar{Z}$ & & $\mid$ & & $=$ & & & 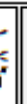 & ¿ \\
\hline î & $\dot{i}$ & $\vdots$ & $\vdots$ & $\vdots$ & $\vdots$ & $\vdots$ & $\vdots$ & $\vdots$ & & $\vdots$ & 4 & $\vdots$ & & & 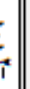 & E \\
\hline 季 & 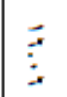 & $\frac{1}{6}$ & $\vdots$ & 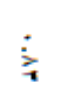 & $\dot{1}$ & 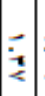 & $\dot{z}$ & 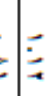 & & $\vdots$ & $:$ & $\therefore$ & & & 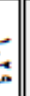 & E焉点占 \\
\hline z & 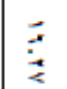 & $\underline{z}$ & $\dot{\vdots}$ & $\dot{\vdots}$ & $\vdots$ & $=$ & $\dot{z}=$ & 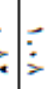 & 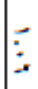 & $\vdots$ & 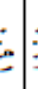 & 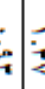 & & 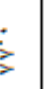 & ch. & 点焉苫占 \\
\hline 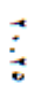 & 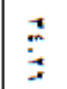 & $\vec{\vdots}$ & $\begin{array}{ll}0 \\
\vdots \\
\vdots\end{array}$ & $\ddot{\vdots}$ & 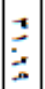 & $\begin{array}{l}3 \\
\vdots \\
>\end{array}$ & 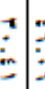 & $:$ & 3 & \begin{tabular}{l}
0 \\
0 \\
$⿱ 亠 䒑$ \\
\hdashline
\end{tabular} & 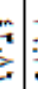 & 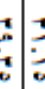 & & 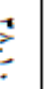 & 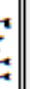 & $\therefore$ \\
\hline$\underset{⿱}{*}$ & $\therefore$ & $i$ & $\because$ & $\dot{z}$ & $\vdots$ & $:$ & : & $\therefore$ & 5 & $\vdots$ & $\because$ & 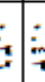 & & 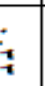 & 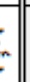 & E \\
\hline בَت & $\frac{1}{3}$ & $\overrightarrow{3}$ & $\dot{3}$ & 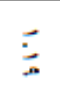 & 恶 & 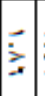 & $=$ & ć. & 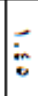 & 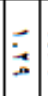 & 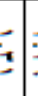 & 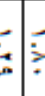 & & 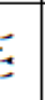 & 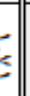 & EัẼ \\
\hline 重 & 孚 & בُ & $\vdots$ & $\vdots$ & $\vdots$ & $=$ & 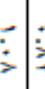 & 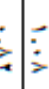 & 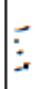 & $\vdots$ & $=$ & 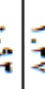 & & 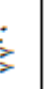 & c. & 焉焉泀占 \\
\hline $\begin{array}{l}\vec{b} \\
\vec{i}\end{array}$ & $\begin{array}{l}1 \\
1 \\
1 \\
1\end{array}$ & $\vdots$ & 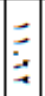 & $\begin{array}{l}\xi_{1} \\
\vdots \\
\vdots\end{array}$ & 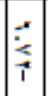 & 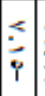 & 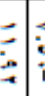 & $\begin{array}{l}\vdots \\
\vdots \\
\vdots\end{array}$ & & $\dot{\bar{q}}$ & $?$ & 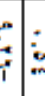 & $\dot{\vec{z}}$ & ' & 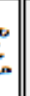 & $\therefore$ \\
\hline$\dot{i}$ & $\stackrel{i}{i}$ & $\vdots$ & $\vdots$ & $\vdots$ & $\vdots$ & $\mid \begin{array}{l} \\
\vdots \\
\end{array}$ & $\vdots$ & $\vdots$ & 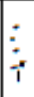 & $\vdots$ & $>$ & $\vdots$ & & í & 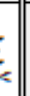 & 'E: \\
\hline 季 & $0=$ & -8 & $\vdots$ & 玄 & $\vdots$ & $\dot{y}$ & $\dot{a}=$ & 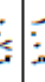 & & $\vdots$ & & 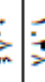 & & 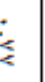 & . & 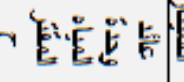 \\
\hline$\frac{1}{8}$ & 莩 & 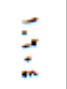 & $\vdots$ & $\dot{\vdots}$ & $\vdots$ & $=$ & $\begin{array}{l}> \\
>\end{array}$ & 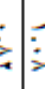 & & $\vdots$ & & 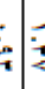 & & & 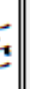 & 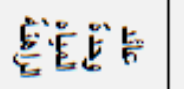 \\
\hline & & E & & 象: & & $\frac{1}{8}$ & & & & & & & & & & $\bar{\xi}$ \\
\hline
\end{tabular}

المصدر : نتائج تحليل نموذج البرمجة متعددة الأهداف. 
؛ ـ المقتنات المائية:

السيناريو الاول: فقد أثنارات التقديرات الي وجود زيادة في الإحتياجات المائية للنموذج المقترح قدرت بحوالي 797,0 مجاعن مثنلتها في الوضع الراهن حيث بلغت الاحتياجات

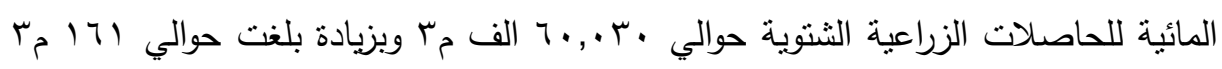
وبنسبة حوالي VY Y • ٪ ع عن الوضع الراهن، بينمابلغت الاحتباجات المائية للحاصلات الزراعية

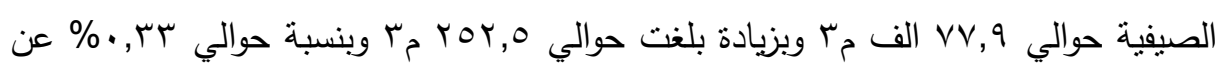

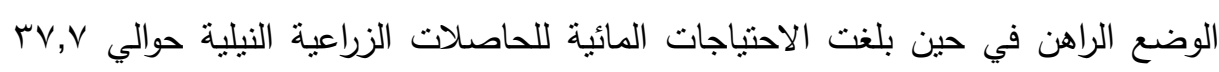

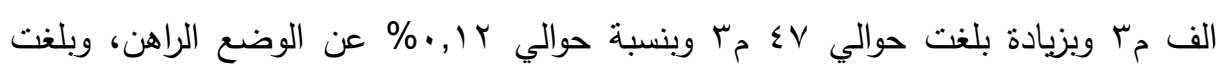

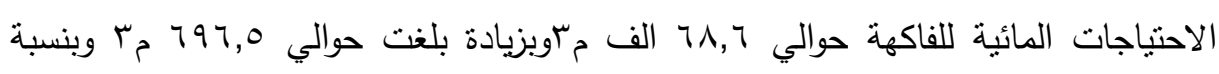

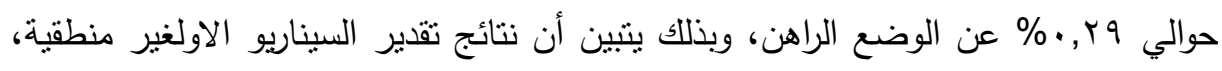

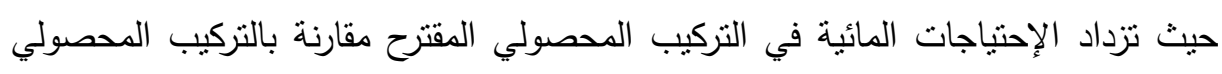

الراهن كما موضح بالجدول (7).

السيناريو الثاني:وأثنارات التقديرات الموضح بالجدول) بالجدول (†) الي وجود زيادة في الإحتياجات

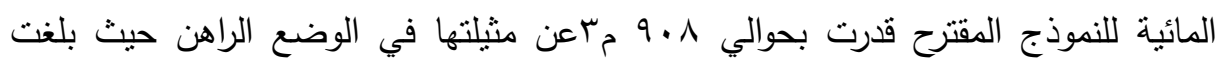

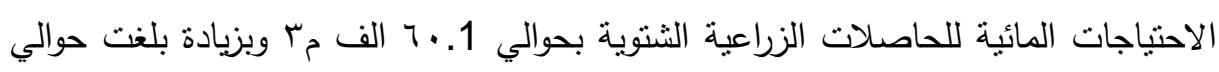
222 مr وبنسبة حوالي Vr, •• عن الوضع الراهن، بينمابلغت الاحتياجات المائية

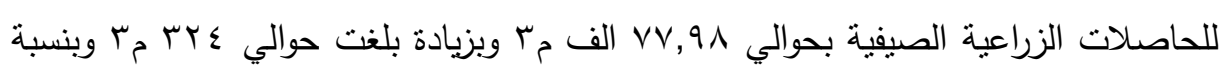
حوالي rع, ••\% عن الوضع الراهن في حين بلغت الاحتياجات المائية للحاصلات الزراعية

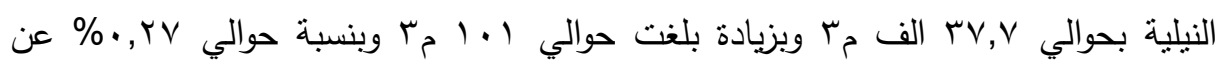

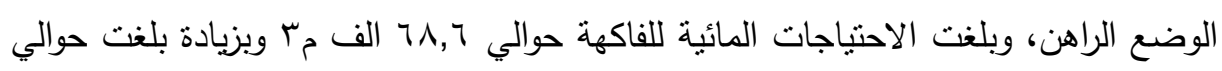

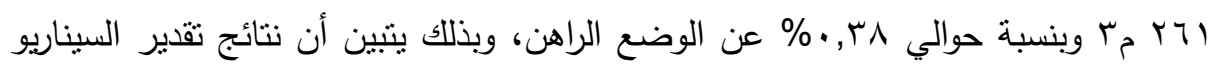

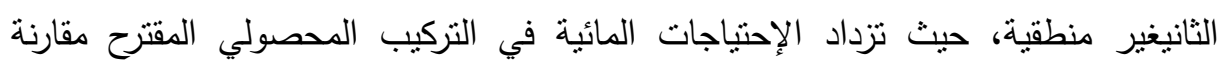

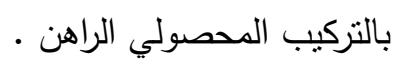


السيناريو الثالث: فقد أنشارات التقديرات الي وجود انخفاض في الإحتياجات المائية للنموذج المقترح قدرت بحوالي rors مrاعن مثيلتها في الوضع الراهن، وبلغت الاحتياجات المائية

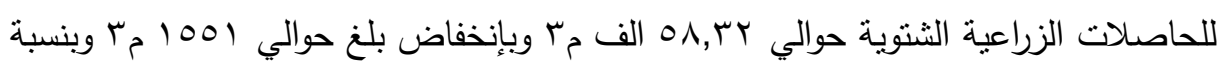

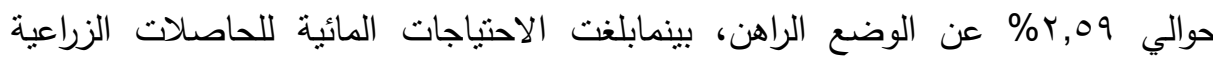

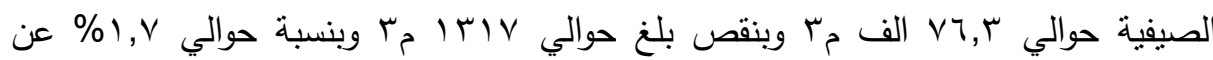

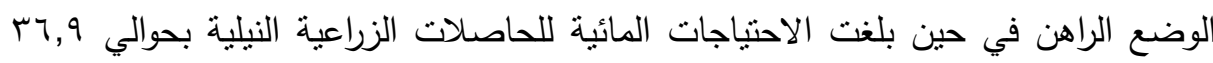

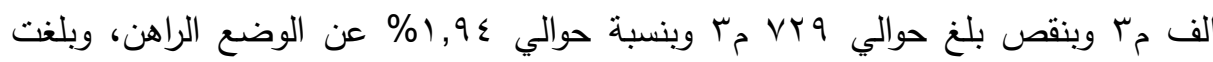

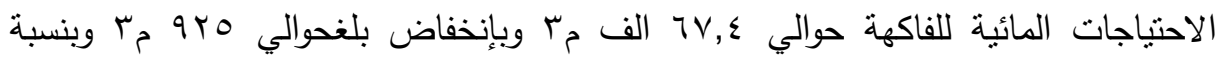

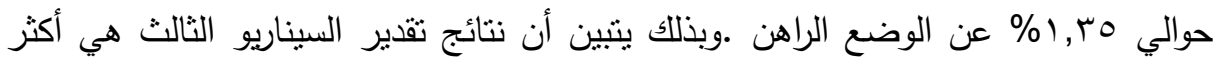
منطقية حيث تتخفض الإحتياجات المائية في التزكيب المحصولي المقترح مقارنة بالتركيب المحصولي الراهن كما موضح بالجدول (†). 
مسعد السعيد رجب وآخرون

جدول(†): مقارنة بين المقننات المائية الراهنة والمقترحة باستخدام البرمجة متعددة الأهداف للحاصلات الثنتوية

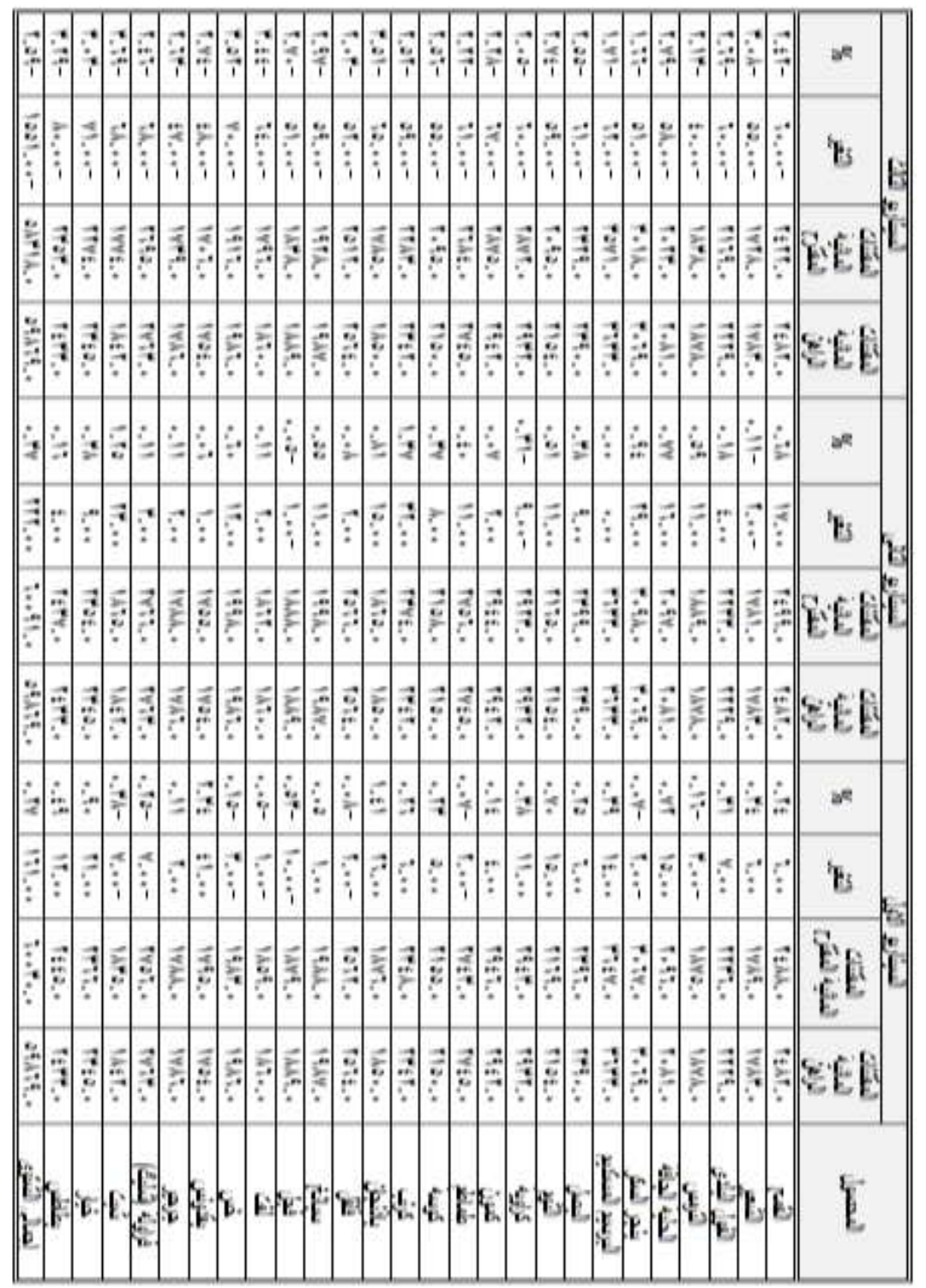

المصدر : نتائج تحليل نموذج البرمجة متعددة الأهداف

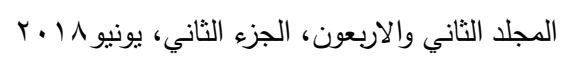


تابع جدول(؟): مقارنة بين المقتنات المائية الراهنة والمقترحة باستخدام البرمجة متعددة الأهداف للحاصلات الصيفية.

\begin{tabular}{|c|c|c|c|c|c|c|c|c|c|c|c|c|c|c|c|c|c|c|c|c|c|}
\hline$\hat{i}$ & 3 & & 5 & $i$ & 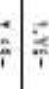 & 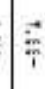 & $\vec{y}$ & 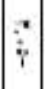 & $\overrightarrow{7}$ & 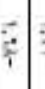 & 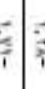 & $\overrightarrow{3}$ & 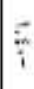 & $\frac{1}{\gamma}$ & 3 & it & 7 & & & 5 & 2 \\
\hline 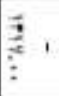 & 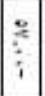 & 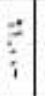 & & & 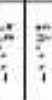 & 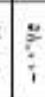 & 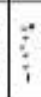 & 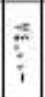 & 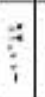 & 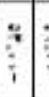 & 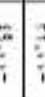 & 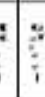 & 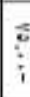 & & $\because$ & $\tilde{z}$ & & & & 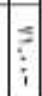 & E \\
\hline 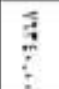 & 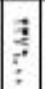 & 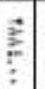 & 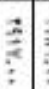 & & 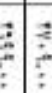 & 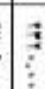 & $\frac{3}{5}$ & 3 & 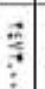 & 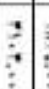 & & 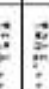 & 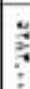 & 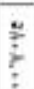 & 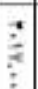 & 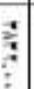 & 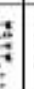 & & & 8 & EE \\
\hline 茪 & 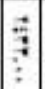 & 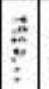 & 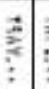 & 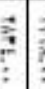 & ? & ? & $\frac{1}{5}$ & 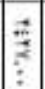 & 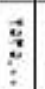 & 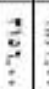 & 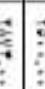 & 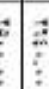 & 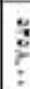 & Еँ & 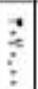 & 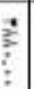 & 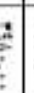 & 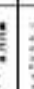 & & 2 & \\
\hline$\therefore$ & $\xi$ & $\vdots$ & $\forall$ & 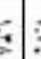 & $\vdots 5$ & 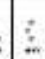 & 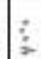 & 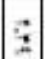 & $\vdots$ & 4 & 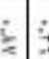 & 5 & $\vdots$ & $\because$ & 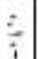 & 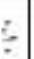 & $i$ & & & $=$ & $\Rightarrow$ \\
\hline$\cdot \frac{7}{3}$ & $=$ & 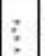 & 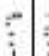 & 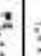 & ? & 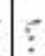 & $?$ & $\%$ & 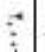 & 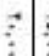 & 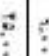 & 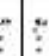 & 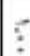 & 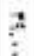 & 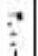 & 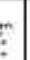 & & & & 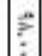 & "F: \\
\hline 童 & $\mid$ & 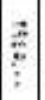 & 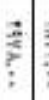 & 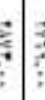 & 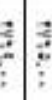 & & $\frac{1}{3}$ & 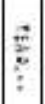 & 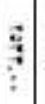 & 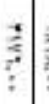 & 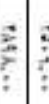 & 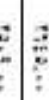 & 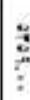 & $\cong$ & 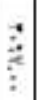 & 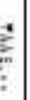 & & 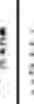 & & 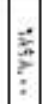 & $\begin{array}{c}E \\
E \\
E\end{array}$ \\
\hline 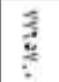 & $\frac{\vec{a}}{3}$ & 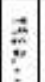 & 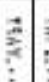 & 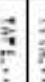 & 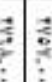 & $\frac{1}{3}$ & $\frac{3}{3}$ & 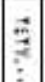 & 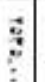 & 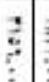 & 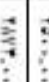 & 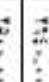 & 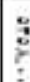 & $\frac{0}{6}$ & 3 & 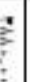 & 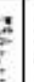 & 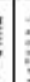 & & & \\
\hline 4 & $\vdots$ & 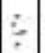 & $\vdots$ & 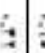 & 8 & 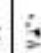 & 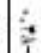 & 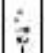 & 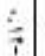 & $\vdots$ & $\div$ & 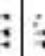 & 4 & 5 & $\vdots$ & $i$ & 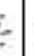 & & & 5 & $\therefore$ \\
\hline $\overrightarrow{\mathrm{s}}$ & $\varepsilon^{\circ}$ & $\therefore$ & ? & $=$ & $=$ & 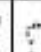 & 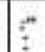 & $\because$ & 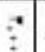 & $=$ & $\because$ & $=1$ & 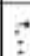 & $=$ & 7 & 8 & & & & 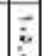 & \\
\hline 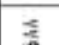 & $\approx 1$ & & $=1$ & 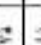 & 2 & 3 & 18 & 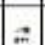 & $\approx 1$ & $\exists$ & 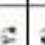 & 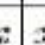 & $y$ & $\cong$ & $z$ & & 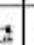 & & & & \\
\hline : & 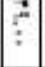 & $?$ & ?. & & 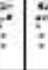 & 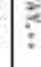 & 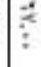 & 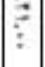 & 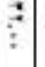 & 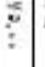 & & 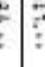 & 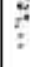 & & & & & & & & $E E$ \\
\hline 童 & $\vec{a}$ & $\frac{1}{2}$ & 虽. & 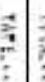 & 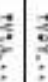 & $\frac{1}{3}$ & $\frac{1}{5}$ & $\vec{z}$ & $\vec{g}$ & 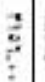 & 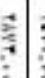 & 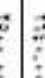 & 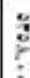 & & 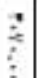 & & & & & & $E$ \\
\hline$\frac{E}{E}$ & & & & & & & & & & & & & & & & & & & & & 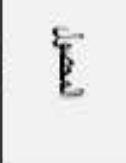 \\
\hline
\end{tabular}


تابع جدول(7): مقارنة بين المقننات المائية الراهنة والمقترحتبإستخدام البرمجة متعددة الأهداف للحاصلات النيلية

\begin{tabular}{|c|c|c|c|c|c|c|c|c|c|c|c|c|c|c|c|}
\hline 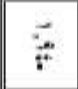 & $\vec{*}$ & $\overrightarrow{\ddot{r}}$ & $\vec{v}$ & 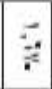 & $\vec{y}$ & $\because$ & $\vec{p}$ & 7 & & $\dot{\gamma}$ & $\vec{v}$ & 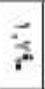 & $\bar{y}$ & $8^{2}$ & \\
\hline 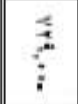 & 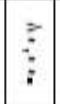 & 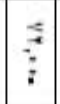 & 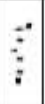 & $\ddot{z}$ & 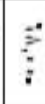 & 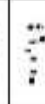 & 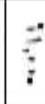 & 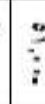 & & & 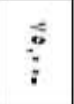 & 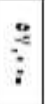 & $\vec{z}$ & E: & {[} \\
\hline 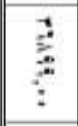 & 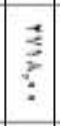 & $\begin{array}{c}3 \\
\vdots \\
\vdots \\
\vdots\end{array}$ & 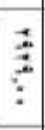 & 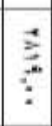 & 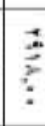 & 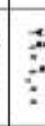 & 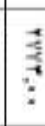 & 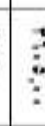 & & 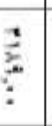 & 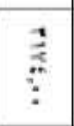 & 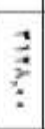 & 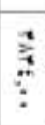 & & E \\
\hline $\begin{array}{l}3 \\
\frac{3}{3} \\
\frac{1}{3} \\
:\end{array}$ & 告 & 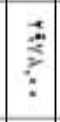 & 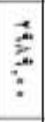 & 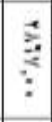 & 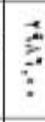 & 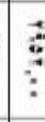 & 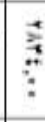 & 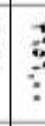 & & 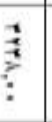 & $\stackrel{7}{3}$ & $\begin{array}{l}3 \\
\vdots \\
\vdots \\
\vdots\end{array}$ & 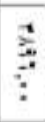 & & \\
\hline$\dot{\vec{z}}$ & 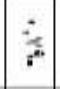 & $\therefore$ & $\therefore$ & 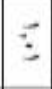 & $\therefore$ & $\dot{~}$ & $\hat{\Sigma}$ & $\therefore$ & & $\dot{\vec{p}}$ & $\dot{0}$ & $\therefore$ & $\dot{\vec{r}}$ & & \\
\hline 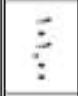 & $\vec{a}$ & $\bar{\vdots}$ & 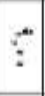 & 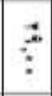 & $\vec{s}$ & $\because$ & 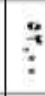 & 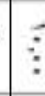 & & $\because$ & $\because$ & $\begin{array}{c}a \\
\vdots \\
\vdots\end{array}$ & $\vdots$ & & 9. \\
\hline t: & 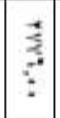 & ? & 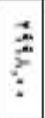 & $\vdots$ & 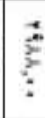 & 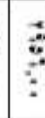 & : & 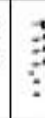 & & 3 & $\stackrel{Z}{a}$ & 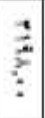 & $\underline{z}$ & & $\frac{c}{k}$ \\
\hline 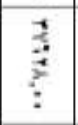 & 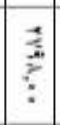 & 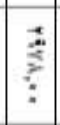 & 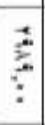 & 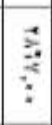 & 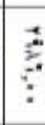 & 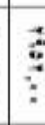 & 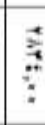 & 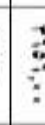 & & 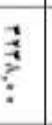 & $\stackrel{3}{3}$ & 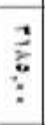 & 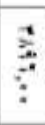 & & \\
\hline$\vdots$ & $\vdots$ & 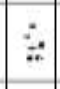 & $\vdots$ & 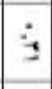 & 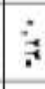 & $\dot{i}$ & 8 & 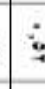 & & $\vdots$ & 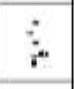 & $\therefore$ & $\vdots$ & 促 & \\
\hline 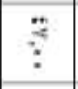 & 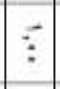 & 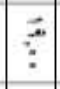 & $\vec{\vdots}$ & 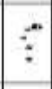 & 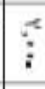 & $\dddot{\vdots}$ & $\vec{u}$ & 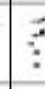 & & 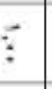 & 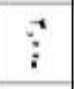 & $\begin{array}{l}1 \\
\vdots \\
\vdots\end{array}$ & $\vec{a}$ & $\underline{E}$ & \\
\hline $\begin{array}{l}3 \\
\vdots \\
\vdots\end{array}$ & 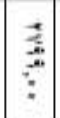 & 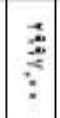 & 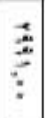 & $\vec{\vdots}$ & 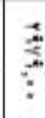 & 3 & 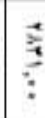 & 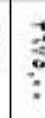 & & 1 & $\stackrel{7}{3}$ & 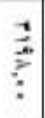 & 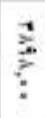 & & \\
\hline 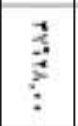 & : & $\mid \begin{array}{c}\frac{1}{3} \\
\frac{3}{2} \\
:\end{array}$ & 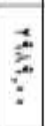 & 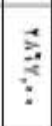 & 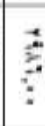 & 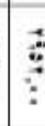 & 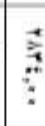 & 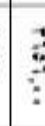 & & 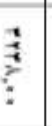 & $\frac{1}{2}$ & $\begin{array}{l}3 \\
\vdots \\
\vdots \\
\vdots\end{array}$ & 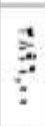 & E & \\
\hline 4. & 㲋 & $k$ & 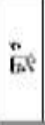 & & 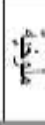 & & & & & & $E^{c}$ & & & & \\
\hline
\end{tabular}

المصدر : نتائج تحليل نموذج البرمجة متعددة الأهداف . 
تابع جدول(؟): مقارنة بين المقننات المائية الراهنة والمقترحة باستخدام البرمجة متعددة الأهداف للفاكهة.

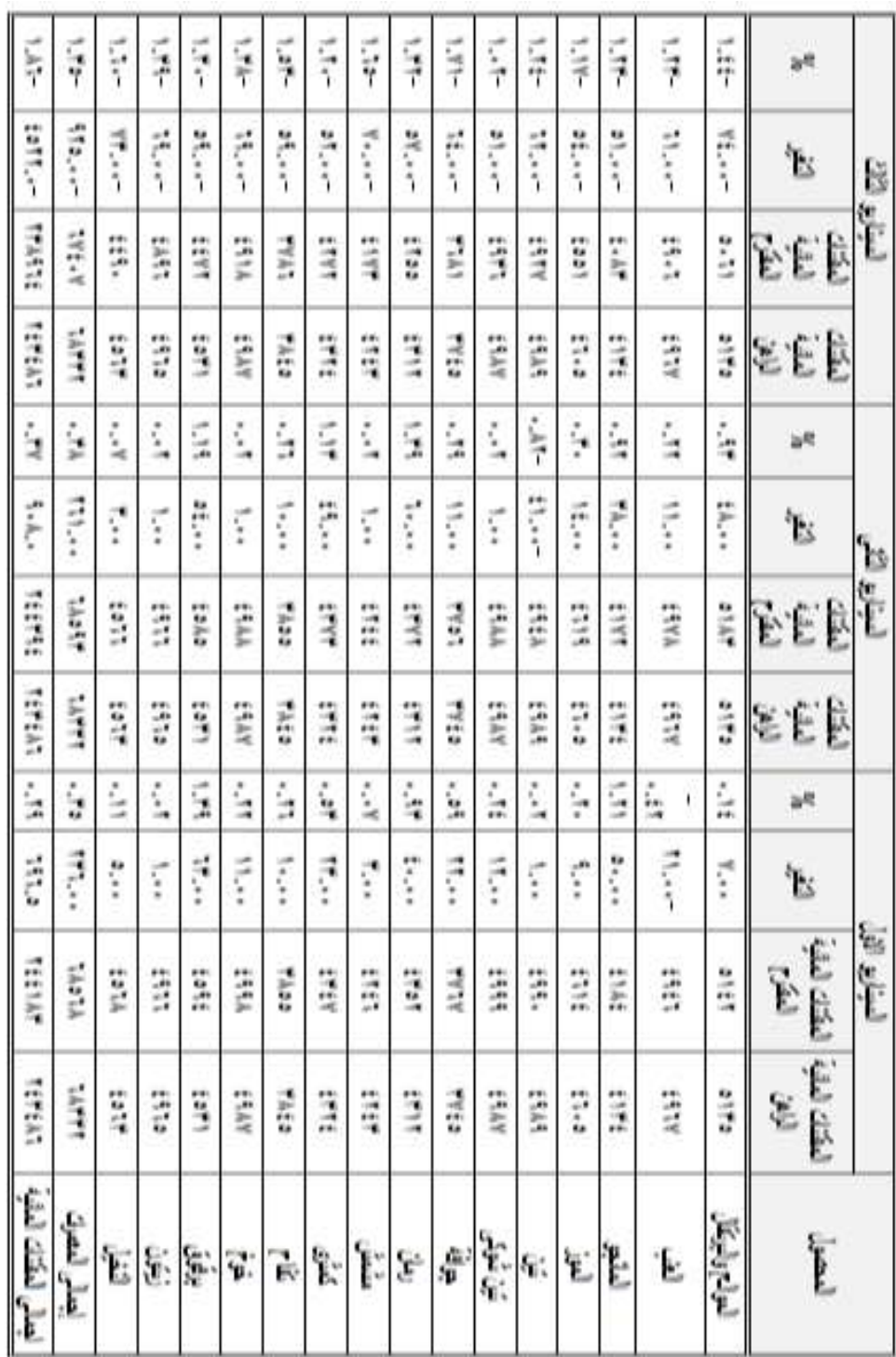

المصدر: نتائج تحليل نموذج البرمجة متعددة الأهداف. 
هـ الإحتياجات من العمالة: أوضحت نتائج الثقديرات والخاص بالهدف الخامس بنموذج البرمجة متعددة الإهدافبدراسة الإحتياجات من العمالة في السيناريوهات الثنالثةوجود نتابهاً

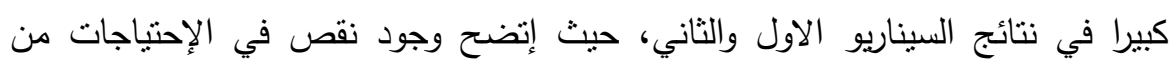

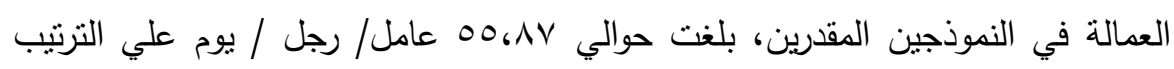

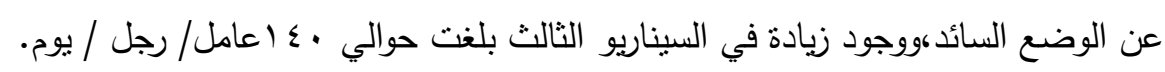
اللسبناريو الاول: يشير جدول (7) إلى وجود انخفاض فى هذه الإحتياجات للنموذج المقترح تقدر بحوالى NV يوم عمل عن الوضع الراهن حيث بلغ الاحتياجات من العمالة للحاصلات الاصني

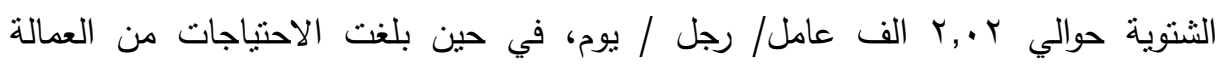

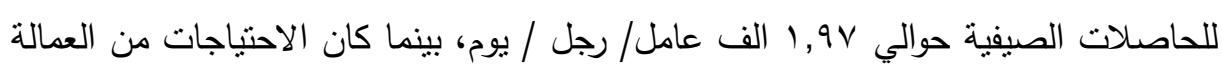

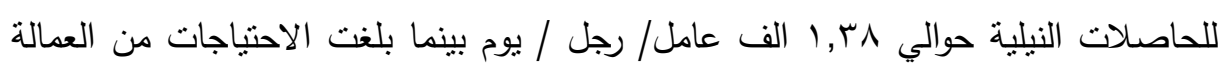

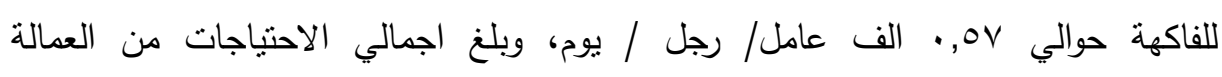

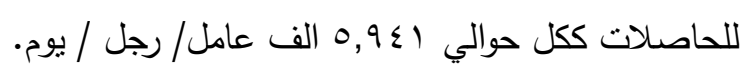
السيناريو الثانى: يبين الجدول (7) وجود انخفاض فى هذه الإحتياجات من العماله للنموذج المقترح تقدر بحوالى 00 يوم عمل عن الوضع الراهن حيث بلغ الاحتباجات من العمالة

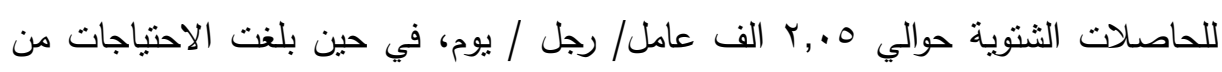

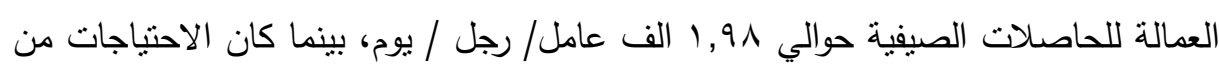

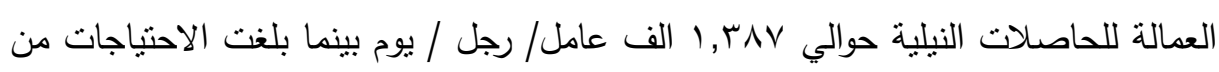

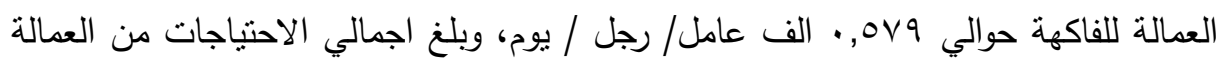

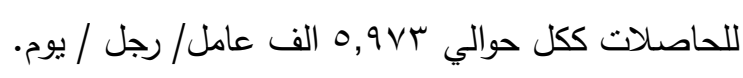

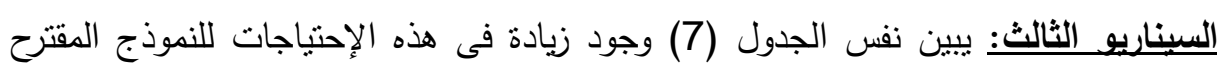
قدرت بحوالى 7011 يوم عمل عن الوضع الراهن حيث بلغ الاحتياجات من العمالة

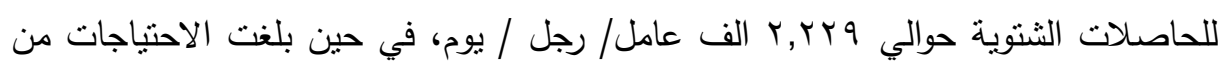

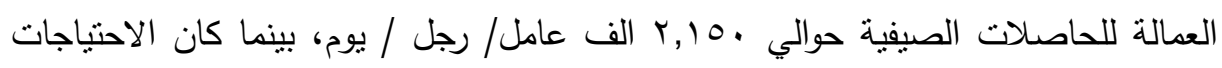

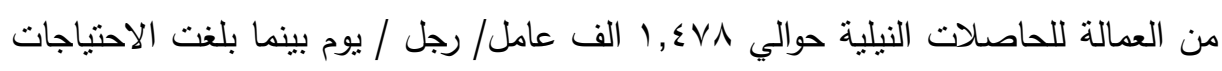

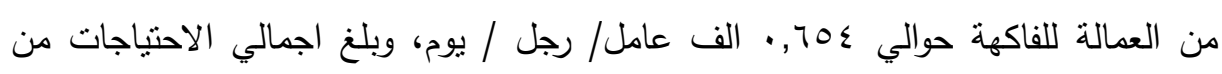

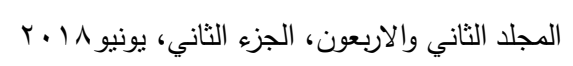


العمالة للحاصلات ككل حوالي 7,011 الف عامل/ رجل / يوم، ومن نتائج نماذج البرمجة

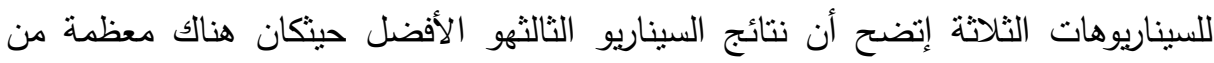
الإحتياجات من العمالة فى التركيب المحصولنالمقترح مقارنهُ بالتركيب المحصولى الراهن. جدول(V): مقارنة بين الاحتياجات من العمالة الراهنة والمقترحة باستخدام البرمجة متعددة الأهداف للحاصلات الثنتية

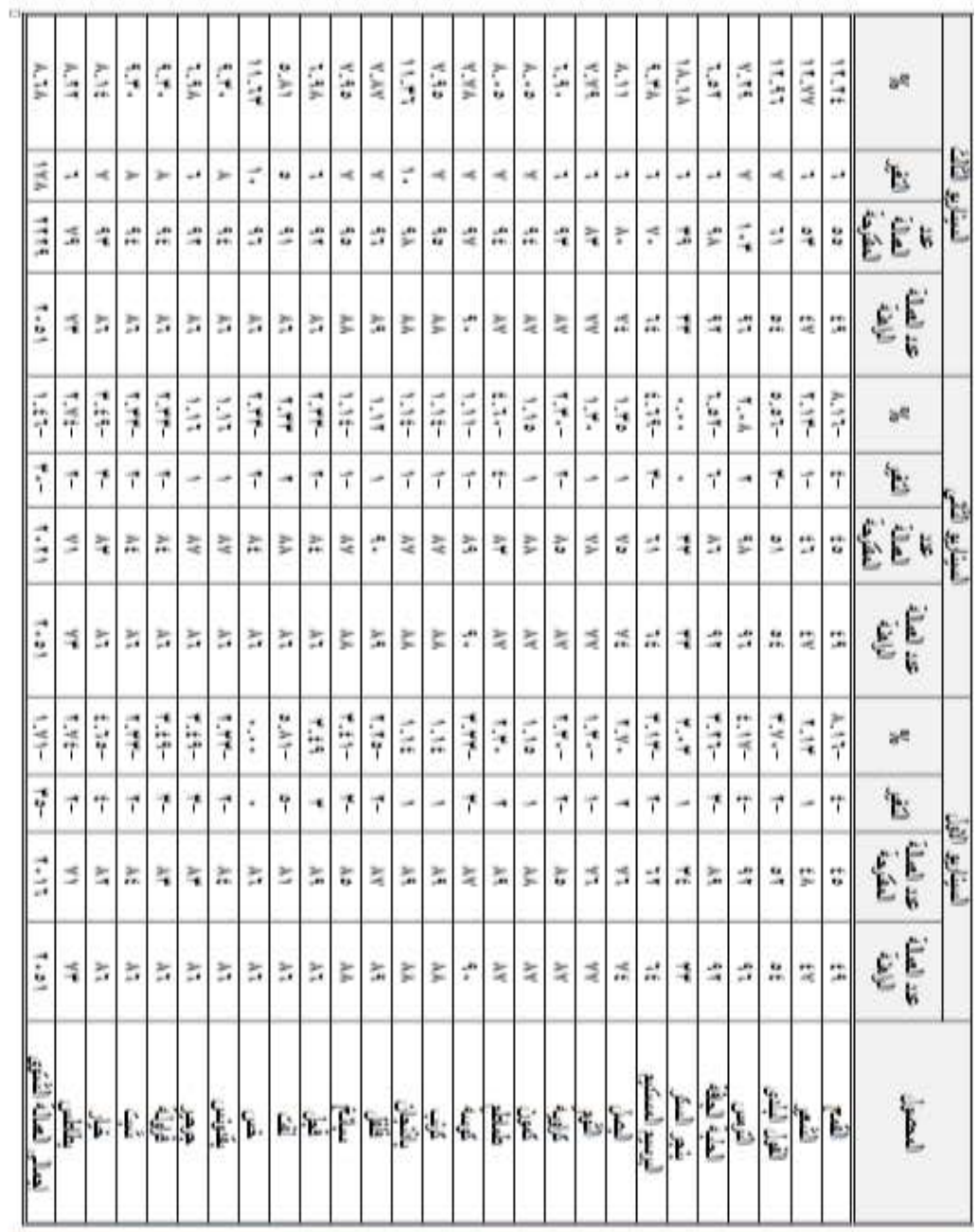


تابع جدول(V): مقارنة بين الاحتياجات من العمالة الراهنة والمقترحة باستخدام البرمجة متعددة الأهداف للحاصلات الصيفية .

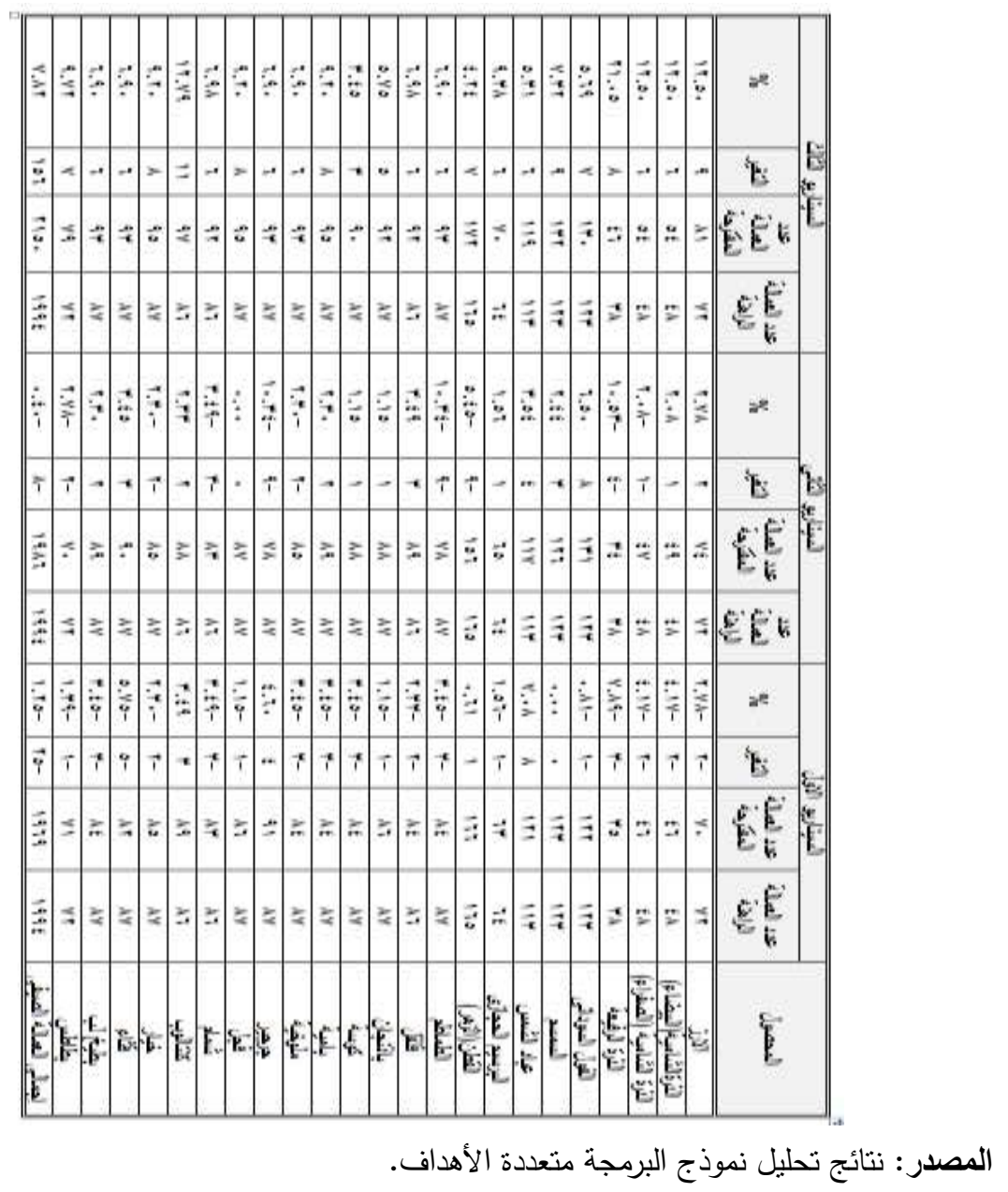

المجلد الثاني والاربعون، الجزء الثاني، يونيو 1 ا ـ r 
تابع جدول(V): مقارنة بينالاحتياجات من العمالة الراهنة والمقترحة بإستخدام البرمجة متعددة الأهداف للحاصلات النيلية

\begin{tabular}{|c|c|c|c|c|c|c|c|c|c|c|c|c|c|c|}
\hline ¿ & $\ddot{3}$ & $\because$ & $\underset{*}{*}$ & 5 & $\ddot{\square}$ & $\dot{\alpha}$ & 5 & $\because$ & 3 & $\ddot{E}$ & 8 & $\overrightarrow{\vec{z}}$ & we & \\
\hline$\dddot{z}$ & $=$ & $\cdots$ & - & $<$ & $=$ & - & \% & $=$ & $\cdots$ & $1 \div$ & $<$ & $\Rightarrow$ & E & \\
\hline$\ddot{z}$ & $\Xi$ & $\approx$ & $\approx$ & 5 & 4 & 5 & 7 & (ج) & $\because$ & 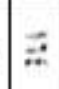 & E & $\therefore$ & $E E$ & 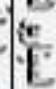 \\
\hline$\Xi$ & $\because$ & $\geqslant$ & $\geqslant$ & $\geq$ & 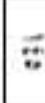 & 5 & 5 & $\Xi$ & $=$ & $\overrightarrow{5}$ & 音 & $=$ & $E \frac{E}{k}$ & \\
\hline$\frac{3}{7}$ & $\div$ & $\vec{i}$ & $\overrightarrow{7}$ & 3 & 萑 & $\frac{\dot{t}}{7}$ & $\div$ & $\because$ & $\frac{\pi}{\bar{T}}$ & $\dot{a}$ & $\because$ & 7 & $\approx$ & \\
\hline$r$ & $T$ & $T$ & $T$ & - & 7 & $T$ & - & $\cdots$ & $\vec{T}$ & - & $\rightarrow$ & 7 & t & \\
\hline 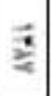 & $\underline{z}$ & 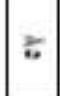 & * & 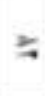 & 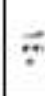 & 5 & 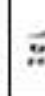 & 5 & $\because$ & $\overline{8}$ & $\Xi$ & $\therefore$ & $\frac{E}{E}$ & $\frac{1}{10}$ \\
\hline 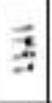 & 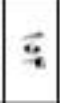 & $\gtrless$ & $\geqslant$ & $y$ & 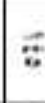 & 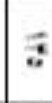 & 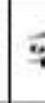 & $\overline{0}$ & $z$ & 5 & 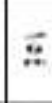 & $\approx$ & $E \frac{E}{k}$ & \\
\hline$\dot{i}$ & $\because$ & $\vec{\forall}$ & $\vec{i}$ & 7 & 8 & $\vec{i}$ & $\frac{5}{4}$ & 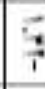 & $\vec{i}$ & $\therefore$ & $\frac{1}{4}$ & $\overrightarrow{\vec{T}}$ & $a^{e}$ & \\
\hline $\bar{T}$ & - & $\rightarrow$ & - & $T$ & 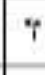 & 7 & T & $T$ & $T$ & - & $T$ & 7 & 'E: & \\
\hline 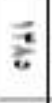 & 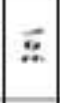 & $\geqslant$ & $y$ & $?$ & $\%$ & 3 & $\%$ & 8 & $\ddot{z}$ & $\overline{8}$ & 5 & $\because$ & $E \frac{E}{E}$ & \\
\hline 3 & $\because$ & $\geqslant$ & $\geqslant$ & $z$ & $\overline{5}$ & 5 & 5 & $\square$ & $=$ & $\underline{\underline{z}}$ & $\vec{z}$ & $=$ & $E \frac{E}{E}$ & \\
\hline $\begin{array}{l}E \\
E \\
E\end{array}$ & & & $\bar{E}$ & E. & 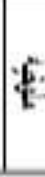 & $\mathrm{E}$ & $E$ & $\mathrm{E}$ & $\frac{6}{E}$ & $\frac{E}{6}$ & $\frac{E}{4}$ & E & E & \\
\hline
\end{tabular}

المصدر: نتائج تحليل نموذج البرمجة متعددة الأهداف. 
تابع جدول(V): مقارنة بين الاحتباجات من العمالة الراهنة والمقترحة باستخدام البرمجة متعددة الأهداف للفاكهة.

\begin{tabular}{|c|c|c|c|c|c|c|c|c|c|c|c|c|c|c|c|c|c|c|}
\hline 8 & 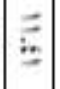 & $=$ & $\overrightarrow{4}$ & 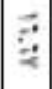 & $\div$ & 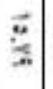 & 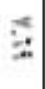 & $\underline{3}$ & 2 & $\stackrel{3}{\square}$ & 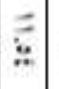 & है & 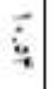 & 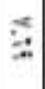 & $\%$ & 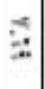 & $\Rightarrow 2$ & \\
\hline $\bar{Y}$ & $\neq 1$ & $<$ & - & $<$ & $\cdots$ & $\cdot$ & $\cdot$ & $\Rightarrow$ & $-\cdots$ & - &. & $\cdot$ & $*$ & $\cdot$ & $\cdots$ & $\cdot$ & ' & ${ }_{s e}^{\mathrm{E}}$ \\
\hline 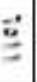 & $\ddot{s}$ & $\because$ & 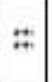 & $\because$ & $\because$ & $\approx$ & $\because$ & $=$ & 3 & 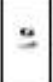 & $=$ & $z$ & $\because$ & $\Rightarrow$ & $\approx$ & 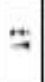 & EE & \\
\hline \pm & $\frac{g}{k}$ & 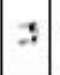 & $\because$ & $\because$ & $\because$ & 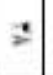 & $\leq$ & $\Rightarrow$ & $\Rightarrow$ & $\Rightarrow$ & $\geq$ & $=$ & \pm & $\therefore$ & $\because$ & 2 & $E \mathrm{E} k$ & \\
\hline $\bar{t}$ & 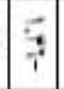 & $\because$ & $i$ & 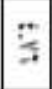 & $\bar{i}$ & $\because$ & 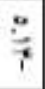 & $\because$ & 8 & $\because$ & 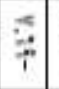 & 4 & $i$ & $\ddot{7}$ & $\overrightarrow{7}$ & $\frac{1}{7}$ & $=2$ & \\
\hline 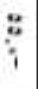 & $T$ & $\rightarrow$ & $T$ & $\rightarrow$ & $T$ & -1 & $T$ & - & $\uparrow$ & $\cdots$ & $T$ & $T$ & $T$ & $T$ & $T$ & $\vec{T}$ & ' & is \\
\hline 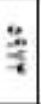 & $\Xi$ & $\Rightarrow$ & 2 & $\therefore$ & $\because$ & 2 & 2 & 2 & Z & $\because$ & $F$ & $\Rightarrow$ & 2 & 2 & $\because$ & 2 & $E_{E}^{E}$ & E \\
\hline 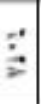 & 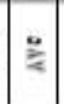 & 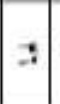 & $\because$ & $\because$ & $\because$ & $\geqslant$ & \pm & $\geqslant$ & $F$ & $\Rightarrow$ & 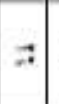 & $::$ & $\geqslant$ & 2 & $\because$ & 2 & $\varepsilon_{k}^{E}$ & \\
\hline 7 & $\overline{7}$ & $\ddot{0}$ & $\ddot{7}$ & $\vec{y}$ & $\because$ & 3 & $\vec{s}$ & $\vec{i}$ & $\frac{6}{7}$ & $\vec{t}$ & 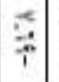 & $\overrightarrow{4}$ & $\vdots$ & $\overrightarrow{7}$ & $\frac{9}{4}$ & $\overrightarrow{\mathrm{S}}$ & 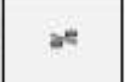 & \\
\hline 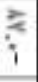 & $\bar{F}$ & $T$ & 7 & -1 & - & $T$ & - & $T$ & $\vec{\imath}$ & $T$ & $T$ & $T$ & $\cdot$ & 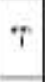 & $\vec{T}$ & - & $\mathrm{E}$ & 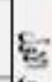 \\
\hline בֶ: & $\Xi$ & $\therefore$ & $\because$ & $\because$ & $\because$ & 2 & $\because$ & 2 & 2 & $=$ & $\approx$ & $\because$ & $\geqslant$ & $\therefore$ & $=$ & $*$ & EE & E \\
\hline $\overrightarrow{2}$ & $\stackrel{2}{*}$ & 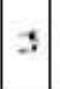 & $\because$ & $\Rightarrow$ & $\because$ & \pm & $\therefore$ & $=$ & $\vec{F}$ & $\Rightarrow$ & $\Rightarrow$ & $=$ & $\Rightarrow$ & $\therefore$ & $\because$ & \pm & $E E^{\circ}$ & \\
\hline & 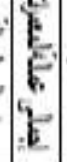 & & F: & ii. & $\overrightarrow{\mathrm{v}}$ & $\mathrm{EN}$ & 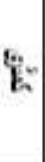 & & & 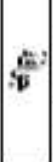 & 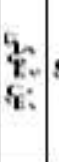 & & & 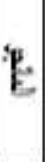 & $E$ & $\frac{E}{2}$ & E & \\
\hline
\end{tabular}

المصدر: نتائج تحليل نموذج البرمجة متعددة الأهداف. 
مجلة العلوم البيئية

معهز الدراسات والبحوث البيئية - جامعة عين شمس لهن

جدول(^): ملخص لنتائج البرمجة متعددة الأهداف للحاصلات الثتوية والصيفية والنيلية

\begin{tabular}{|c|c|c|c|c|c|c|c|c|c|c|c|c|}
\hline \multicolumn{4}{|c|}{$22, \div$} & \multicolumn{4}{|c|}{ (2) } & \multicolumn{4}{|c|}{ 2013 } & \multirow{2}{*}{ 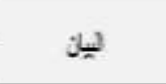 } \\
\hline$\%$ & in & لمائر & ja). & $\%$ & 象 & (العرج) & (2) & $\%$ & 国 & (3) & ats & \\
\hline$\cdot, n-$ & $251,7-$ & Tyever & Tyatth & $9,7:$ & A1.\% & thitito & Trotth & , , 1:- & $: 40, \mathrm{~h}-$ & Ty: & Tratth & إبلحي لفسلدا \\
\hline$\cdot, \mathrm{rt}-$ & $114 \%, 4-$ & s.1vat & $2 .+4,4$ & $7,-4$ & wester & גידויו & $=.74$, & , , + & $1 . \pi, 2-$ & 2.1409 & $2.74,4$ & 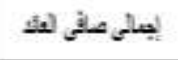 \\
\hline,$+ \ldots$ & f, $1-$ & ter & 178 & $\tau, \tau$, & $\tau x, y$ & 174 & $17 \%$ & $7,27-$ & $\tau, t^{-}$ & $1 \pi$ & 17 & لبملي غثل زهذ: لسياء \\
\hline $1, \mathrm{hi}-$ & เ21T, ,- & T*a47t & $T+T_{t}=\mathrm{s}$ & $+\pi$ & q.h, & $T: t * z_{t}$ & TEFtat: &,$- r^{4}$ & $\$ 4 \%, 8$ & Tiz & Tefent & 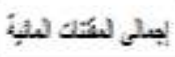 \\
\hline$A, \cdot 1$ & she, & :211 & $\because+1 /$ & -31- & $32,-$ & $25 v^{\circ}$ & $2+1 \mathrm{~A}$ & $1,54-$ & AV,,- & $24 \div$ & itth & لجشلم الملة \\
\hline
\end{tabular}

المصدر: جداول بالدراسة من (ץ) الي (V)

توصيات من نتائج تحليل النماذج المقترحة: ضرورة تعديل التركيب المحصولى الرهن

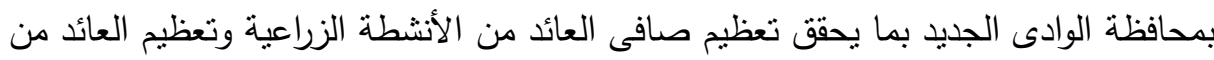
وحدة مياه الرى وترشيد استهلاك المياه وتندى إستخدتها وتعظيم استخدام عنصر العمل وذلك فى ظل القيود والمحددات الإنتاجية المتعلقة بكل نشاط للوصول إلى التركيب المحصولى الأكثر كفاءة فى تحقيق دالة الهدف وذللك فى ظل الموارد المتاحة بمحافظة الوادى الجديد والتى تتضمن زراعة أهم الحاصلات الزراعية التى تحتاجها المحافظة بالإضافة إلى الوفاء فله باحتياجات الإستهلاكى والقدرات التسويقية .

\section{المرام:}

الجهاز المركزي للتعبئه العامة والاحصاء "نشرة الموارد المائيه"، أعداد متفرقه

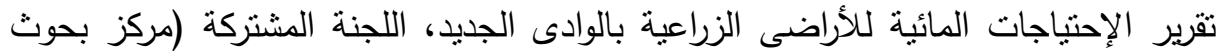

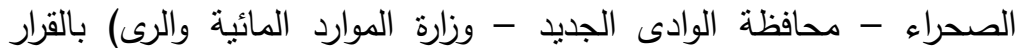

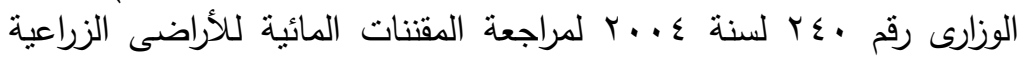

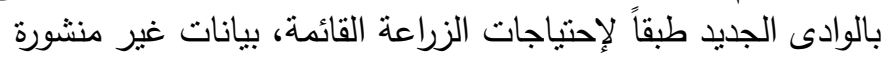

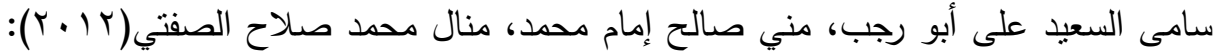

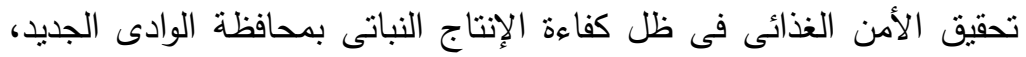

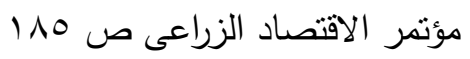




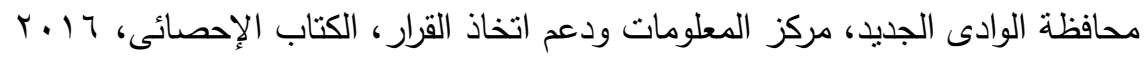

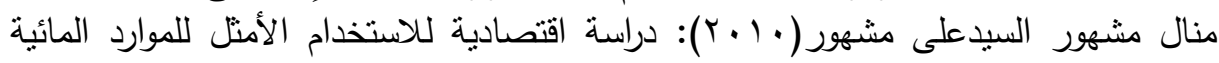

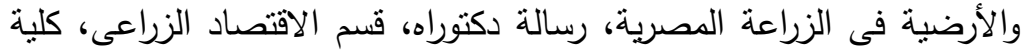

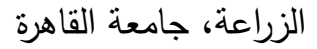

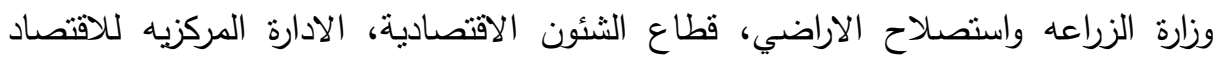

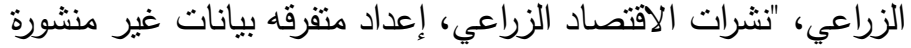

Ann Martine(1968):."Economics\&Agriculture",Rouledgan Kegan Poul, London, p157.

Anderson David.R, Thomas A. Willams and Dennis j. Sweeney (1976): An Introductuon to Management Science, Quantitative Approaches to Decision Making Copyrightm, By West Puplishing Co, p179.

Dorfman Robert, Paul Anthony Samuelson and Robert M. Solow(1987): Linear Programming and Economic Analysis MCGraw-Hill Book Company, INC, p 235.

Lee, S.M.and Olson, D.L,(2004): Goal Programming Formulations Fora Comparative Analysis Of Scalar Normsand Ordinalvs.Ratioata,CanadianOperational Research Society, ProQuest, Aug, p33. 


\title{
AN ECONOMIC STUDY OF THE IMPACT OF WATERUSERESOURCES UNDER AVAILABLE ENVIRONMENTAL CONDITIONS IN THE NEW VALLEY GOVERNORATE
}

\author{
Rajab, M. E. ${ }^{(1)}$; Hashem, Seham, A. A. ${ }^{(2)}$; Ali, S. E. ${ }^{(3)}$ \\ and Sobhy, E. M. ${ }^{(4)}$
}

1) Departmentof Agricultural Economic, Faculty of Agriculture, Ain Shams University 2) Department of Agricultural Sciences, Institute of Environmental Studies and Research, Ain Shams University 3) Department of Economic Studies, Desert Research Center 4) Department of Economic Studie, Desert Research Center.

\begin{abstract}
The study aimed at finding the best alternatives for agriculturalCropping pattern in the New Valley Governorate, taking into consideration the achievement of the development objectives in terms of maximizing economic efficiency by using the resources available in the New Valley governorate, the most important of which are agricultural lands, irrigation water and agricultural labor under theconstraints and Determinants available in the New Valley.

Cropping pattern is the most important objective of agricultural policies.Cropping pattern is generally the different crops and cultivated areas of a particular season, at a given periodof time, whether long or short. The best Cropping pattern is the one that achieves compatibility between more than Aiming to reach the most efficientcrop structurein view of achieving the objective functions, which may aim to maximize the net return of agricultural activities, rationalize water consumption by maximizing the return on the water unit and minimizing the quantity used, and maximizing the use of the work element. A range of constraints and productivity determinants.
\end{abstract}

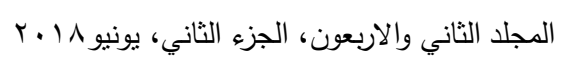


The use of multi-objective programming has been used. Three models have been estimated to achieve the agricultural structure that achieves the objectives of maximizing the net return of agricultural activities, maximizing the return of the irrigation water unit, rationalizing water consumption, minimizing use and maximizing the use of the labor component.

Keywords: Cropping pattern, water resources, New Valley Governorate, multi-objective programming. 